Wolfgang Scherf

\title{
Schlüsselzuweisungen und Kreisumlage
}




\section{Wolfgang Scherf}

\section{Schlüsselzuweisungen und Kreisumlage}

Die Finanzierung der Landkreise basiert im wesentlichen auf den Finanzzuweisungen der Länder und der Kreisumlage. Damit stellt sich die Frage, wie die Schlüsselzuweisungen und die Kreisumlage als Instrumente des kommunalen Finanzausgleichs so miteinander verknüpft werden können, daß im kreisangehörigen Raum eine den jeweiligen Aufgaben entsprechende Finanzausstattung zustande kommt. Dieses Problem wird am Beispiel des kommunalen Finanzausgleichs von Rheinland-Pfalz diskutiert. Der Verfasser zeigt insbesondere, daß die Verteilung der Schlüsselzuweisungen bei sachgerechtem Einsatz der Kreisumlage nicht zu einer Übernivellierung zwischen den rheinlandpfälzischen Landkreisen führt.

Wolfgang Scherf wurde 1956 in Trier geboren. 1975-80 Studium der Volkswirtschaftslehre an der Universität Freiburg i. Br. 1981-86 wissenschaftlicher Mitarbeiter, 1987-93 Hochschulassistent am Institut für Finanzwissenschaft der Universität Freiburg, Lehrstuhl Professor Alois Oberhauser. Promotion 1986, Habilitation 1993. Seit 1996 Professor für Volkswirtschaftslehre, insbesondere Finanzwissenschaft, an der Universität Gießen. 
Schlüsselzuweisungen und Kreisumlage 


\section{FINANZWISSENSCHAFTLICHE SCHRIFTEN}

Herausgegeben von den Professoren

Albers, Krause-Junk, Littmann, Oberhauser, Pohmer, Schmidt

Band 90

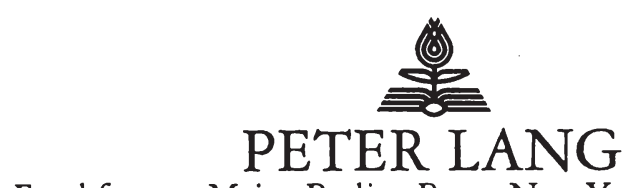

Frankfurt am Main · Berlin · Bern - New York · Paris - Wien 


\section{Wolfgang Scherf}

\section{Schlüsselzuweisungen und Kreisumlage}

Die Problematik der Finanzierung der Landkreise am Beispiel des kommunalen Finanzausgleichs von Rheinland-Pfalz

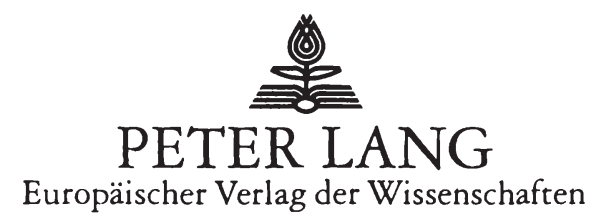


Die Deutsche Bibliothek - CIP-Einheitsaufnahme

Scherf, Wolfgang:

Schlüsselzuweisungen und Kreisumlage : die Problematik der Finanzierung der Landkreise am Beispiel des kommunalen Finanzausgleichs von Rheinland-Pfalz / Wolfgang Scherf. Frankfurt am Main ; Berlin ; Bern ; New York ; Paris ; Wien : Lang, 1998

(Finanzwissenschaftliche Schriften ; Bd. 90)

ISBN 3-631-33798-1

Open Access: The online version of this publication is published on www.peterlang.com and www.econstor.eu under the international Creative Commons License CC-BY 4.0. Learn more on how you can use and share this work: http://creativecommons. org/licenses/by/4.0.

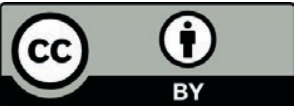

This book is available Open Access thanks to the kind support of ZBW - Leibniz-Informationszentrum Wirtschaft.

Gedruckt auf alterungsbeständigem, säurefreiem Papier.

\author{
ISSN 0170-8252 \\ ISBN 3-631-33798-1 \\ ISBN9 78-3-631-75194-7 (eBook) \\ (C) Peter Lang $\mathrm{GmbH}$ \\ Europäischer Verlag der Wissenschaften \\ Frankfurt am Main 1998 \\ Alle Rechte vorbehalten.
}

Das Werk einschließlich aller seiner Teile ist urheberrechtlich geschützt. Jede Verwertung außerhalb der engen Grenzen des Urheberrechtsgesetzes ist ohne Zustimmung des Verlages unzulässig und strafbar. Das gilt insbesondere für Vervielfältigungen, Übersetzungen, Mikroverfilmungen und die Einspeicherung und Verarbeitung in elektronischen Systemen.

Printed in Germany 124567 


\section{Inhaltsverzeichnis}

A. Einführung 9

1. Die Finanzierung der Landkreise 9

2. Problemstellung und Aufbau der Arbeit 10

B. Der kommunale Finanzausgleich in Rheinland-Pfalz

1. Begründung und Gestaltung des horizontalen Finanzausgleichs

2. Finanzielle Grundlagen des kommunalen Finanzausgleichs in Rheinland-Pfalz

3. Berücksichtigung der Aufgabenteilung im Kreisbereich 19

4. Das System der kommunalen Finanzzuweisungen 21

a. Funktion und Arten der Schlüsselzuweisungen 22

b. Berechnung und Verteilung der Schlüsselzuweisungen $B 2$

5. Die Funktion der Kreisumlage im Finanzausgleich

C. Interdependenzen zwischen Schlüsselzuweisungen und Kreisumlage im Finanzausgleich

1. Die Abhängigkeit der Kreisumlage von den Schlüsselzuweisungen

a. Schlüsselzuweisungen und Kreisumlage auf der Ebene der Gesamtkreise

b. Schlüsselzuweisungen und Kreisumlage im Ver hältnis zwischen Zentralkreis und Gemeinden

c. Schlüsselzuweisungen und Kreisumlage auf der Ebene der kreisangehörigen Gemeinden

2. Entwicklung eines Modells zur Analyse der Ausgleichseffekte 
3. Vergleich zwischen Gesamtkreisen und kreisfreien Städten

4. Vergleich zwischen Gesamtkreisen mit unterschiedlicher Finanzkraft

5. Verteilungsschlüssel 69/31 und Finanzkraft kreisangehöriger Gemeinden

6. Unterschiede in der Aufgabenverteilung zwischen Zentralkreis und Gemeinden

D. Auseinandersetzung mit der Kritik am kommunalen Finanzausgleich in Rheinland-Pfalz

1. Zur Lösbarkeit der Ausgleichsaufgabe in einem Schritt

2. Die Kreisumlage als Instrument des kreisinternen

Finanzausgleichs

a. „Feinsteuerung" versus aufgabenorientierte Finanzkraftregulierung

b. Berücksichtigung der Schlüsselzuweisungen im kreisinternen Finanzausgleich

3. "Übernivellierung" bei den Zentralkreisen durch Schlüsselzuweisungen?

a. Übernivellierungseffekte auf der Ebene der Zentralkreise?

b. Probleme einer Gegensteuerung mittels der Kreisumlage

4. Die Problematik des Verteilungsschlüssels 69/31

a. Mögliche Einwände gegenüber dem Verteilungsschlüssel 69/31

b. Zur Begründung des Verteilungsschlüssels 69/31

5. Das Problem der „Grenzbelastung“ im Finanzausgleich 


\section{Tabellen}

Tabelle 1: Vergleich zwischen Gesamtkreis und kreisfreier Stadt

Tabelle 2: Vergleich zwischen Gesamtkreisen mit unterschiedlicher Finanzkraft

Tabelle 3: Verteilungsschlüssel und Finanzkraft kreisangehöriger Gemeinden

Tabelle 4: Unterschiede in der Aufgabenverteilung zwischen Zentralkreis und Gemeinden

Tabelle 5: „Übernivellierung“ bei den Zentralkreisen durch Schlüsselzuweisungen?

Tabelle 6: Benachteiligung finanzschwacher Gemeinden in finanzstarken Gesamtkreisen?

Tabelle 7: Das Problem der Grenzbelastung bei wachsender Steuerkraft 
Wolfgang Scherf - 978-3-631-75194-7

Downloaded from PubFactory at 01/11/2019 07:16:26AM

via free access 


\section{A. Einführung}

\section{Die Finanzierung der Landkreise}

Die Kreise sind konstitutiver Teil des föderativen Staatsaufbaus der Bundesrepublik Deutschland. Als Leistungsträger auf der kommunalen Ebene verfügen sie über das Recht auf Selbstverwaltung. Eine Besonderheit besteht darin, daß die Kreise einerseits Gemeindeverbände und andererseits unmittelbar demokratisch legitimierte Gebietskörperschaften sind. Ersteres begründet einen Anspruch auf frei verfügbare eigene Einnahmen, letzteres rechtfertigt eine Refinanzierung bei den kreisangehörigen Gemeinden über die Kreisumlage1. Die kommunale Finanzautonomie ist allerdings auf der Kreisebene relativ begrenzt, denn die Landkreise verfügen nicht über ins Gewicht fallende eigene Steuereinnahmen 2 . Ihre Haupteinnahmequelle neben der Kreisumlage bilden vielmehr die Finanzzuweisungen der Länder. Insofern kann man sagen, daß sich die Finanzkraft der Kreise erst im kommunalen Finanzausgleich konstituiert.

Entscheidend geprägt wird die finanzielle Situation der Kreise damit durch die Gestaltung der Finanzzuweisungen, insbesondere der Schlüsselzuweisungen. Infolgedessen stellt sich das Problem, wie die Schlüsselzuweisungen und die Kreisumlage als Instrumente des kommunalen Finanzausgleichs so miteinander verknüpft werden können, daß im kreisangehörigen Raum eine sachgerechte, den jeweiligen Aufgaben entsprechende Finanzausstattung der Kreise und ihrer Gemeinden zustande kommt. Dieses Zusam-

1 Vgl. A. v. Mutius, Verfassungsrechtliche Aspekte einer Reform des Kreisfinanzsystems, in: Der Landkreistag, 1985, S. 133.

2 Die vergleichsweise geringe Einnahmenautonomie der Kreise hat immer wieder zu Forderungen nach einer direkten Beteiligung am Steueraufkommen geführt. Vgl. A. Günther, Verbesserung der Kreisfinanzen, in: F. Wagener (Hrsg.), Kreisfinanzen, Göttingen 1982, S. 114 ff; E. Recker, Mehr Finanzautonomie für die Kreise, in: Der Landkreistag, 1985, S. 129 ff. 
menspiel von Schlüsselzuweisungen und Kreisumlage steht im Vordergrund der folgenden Analyse der Finanzierung der Landkreise in Rheinland-Pfalz.

Anlaß für die Auseinandersetzung mit diesem in der Finanzwissenschaft relativ wenig diskutierten Problem des kommunalen Finanzausgleichs war ein Rechtstreit zwischen dem Landkreis Germersheim und dem Land Rheinland-Pfalz über die Höhe der dem Landkreis zustehenden Schlüsselzuweisungen. Die vorliegende Arbeit stellt die leicht überarbeitete und erweiterte Fassung eines finanzwissenschaftlichen Gutachtens dar, das der Verfasser in diesem Zusammenhang dem Land Rheinland-Pfalz erstattet hat 1 . Unabhängig von den Besonderheiten des rheinland-pfälzischen Finanzausgleichs verdienen die Überlegungen jedoch allgemeines Interesse, da die Finanzierung der Landkreise in allen Bundesländern, wenn auch in unterschiedlicher Weise, über die beiden Instrumente Schlüsselzuweisungen und Kreisumlage erfolgt.

\section{Problemstellung und Aufbau der Arbeit}

Im kommunalen Finanzausgleich von Rheinland-Pfalz werden die Schlüsselzuweisungen, die dem kreisangehörigen Raum insgesamt zufließen, im Verhältnis 69 zu 31 auf die Landkreise auf der einen und die kreisangehörigen Gemeinden auf der anderen Seite verteilt. Dieses Verfahren hat Kritik hervorgerufen. Nach Finanz-

1 Hintergrund des Gutachtens war ein vor dem Verfassungsgerichtshof Rheinland-Pfalz anhängiges Normenkontrollverfahren (Az VGH N 2/97) gegen $\S 10$ Abs. 3 und $\S 11$ Abs. 2 des Landesgesetzes über den Finanzausgleich (FAG). $\S 10$ Abs. 3 bezieht sich auf den Ansatz der Bedarfsmeßzahl, § 11 Abs. 2 auf die Ermittlung der Finanzkraftmeßzahl der kommunalen Gebietskörperschaften. Dem Verfahren lag ein Vorlagebeschluß des 7 . Senats des Oberverwaltungsgerichts Koblenz (Az 7 A 12002/93.OVG) zugrunde, der die genannten Bestimmungen des FAG für verfassungswidrig hielt. Der Verfassungsgerichtshof Rheinland-Pfalz entschied dagegen am 30. Januar 1998, daß $\S 10$ Abs. 3 und $\S 11$ Abs. 2 des FAG mit der Landesverfassung vereinbar sind. 
ausgleich könne es zu einer Umkehrung der Finanzkraftrangfolge zwischen den rheinland-pfälzischen Landkreisen kommen. Der Versuch einer Korrektur dieser „Übernivellierung“ oder „Überkompensation" mit Hilfe der Kreisumlage behebe die Übernivellierung nicht, sondern führe zu vielfältigen weiteren Verzerrungen, vor allem zwischen den kreisangehörigen Gemeinden1.

Diese Arbeit dient in erster Linie der Überprüfung der These, die Verteilung der Schlüsselzuweisungen gemäß $\S 10$ Abs. 3 und $\S 11$ Abs. 2 des rheinland-pfälzischen Finanzausgleichsgesetzes (FAG) bewirke eine Ungleichbehandlung der am Finanzausgleich beteiligten kommunalen Gebietskörperschaften, insbesondere eine verfassungswidrige Übernivellierung zwischen den Landkreisen (Zentralkreisen). Gegenstand der Untersuchung ist mithin die Stellung der Landkreise (Zentralkreise) im kommunalen Finanzausgleich des Landes Rheinland-Pfalz.

Innerhalb dieses Rahmens sollen vor allem folgende Fragen beantwortet werden:

(1) Ist es aus finanzwissenschaftlicher Sicht sinnvoll, zwischen Gesamtkreis, Zentralkreis und kreisangehörigen Gemeinden zu unterscheiden, wobei der Gesamtkreis als Entsprechung zu den kreisfreien Städten anzusehen wäre?

(2) Welche Besonderheiten kennzeichnen verglichen mit anderen Bundesländern den rheinland-pfälzischen kommunalen Finanzausgleich in Bezug auf das Verhältnis, in dem die Zentralkreise, die diesen zugeordneten Gemeinden und die Gesamtkreise zueinander stehen?

1 Vgl. zur Kritik am rheinland-pfälzischen Finanzausgleich G. Färber, Schlüsselzuweisungen an die Landkreise im kommunalen Finanzausgleich von Rheinland Pfalz, Gutachten, Hannover 1994. 
(3) Ist die 1977 erfolgte Umstellung vom Drei-Säulen-Modell auf das heutige System aus finanzwissenschaftlicher Sicht angemessen? Was ist von der Auffassung zu halten, das rheinland-pfälzische Konzept leide an einem inneren Widerspruch, der unvertretbare Ergebnisse unvermeidlich mache?

(4) Erfordert das rheinland-pfälzische Konzept des Finanzausgleichs einen Rückgriff auf die Kreisumlage als ein systemkonform aktives Element des fiskalischen Finanzausgleichs zwischen Zentralkreisen und kreisangehörigen Gemeinden? Ist ein solcher Einsatz der Kreisumlage empfehlenswert oder doch zumindest akzeptabel?

(5) Kann das Verbot einer Übernivellierung in Bezug auf die Zentralkreise überhaupt sinnvoll angewandt werden, wenn man berücksichtigt, daß sich die Finanzkraft der Zentralkreise erst im Finanzausgleich konstituiert? Wie ist in diesem Zusammenhang die Verwendung eines landesdurchschnittlichen und damit festgeschriebenen Kreisumlagesatzes bei einer Nivellierungsprüfung zu bewerten?

(6) Steht der Verteilungsschlüssel 69/31 einem sachgerechten Finanzausgleich entgegen,

(a) weil die durch diesen Maßstab bewirkten Verzerrungen zu groß sind, um durch die Kreisumlage korrigiert zu werden,

(b) weil eine zur Ausbalancierung erforderliche Anhebung der Kreisumlage den Gemeinden nicht zugemutet werden kann,

(c) weil der Einsatz der Kreisumlage als Instrument des fiskalischen Finanzausgleichs zur Ungleichbehandlung der kreiszugehörigen oder der anderen Gesamtkreisen angehörigen Gemeinden führt, 
(d) weil der Einsatz der Kreisumlage an anderer Stelle im System des Finanzausgleichs verfassungsrechtlich problematische Nebenwirkungen auslöst,

(e) oder weil die Steuerung des fiskalischen Finanzausgleichs durch die Kreisumlage darauf hinausläuft, die Gemeinden der "Willkür" des Kreistages auszuliefern?

Die Aufgabe der vorliegenden Arbeit besteht also in der Überprüfung der Frage, ob $\S 10$ Abs. 3 und $\S 11$ Abs. 2 FAG einen aus finanzwissenschaftlicher Sicht insgesamt angemessenen kommunalen Finanzausgleich zulassen. Eine Analyse dieses Problems muß vor dem Hintergrund der Gesamtkonstruktion des kommunalen Finanzausgleichs erfolgen. Daher werden die im vorliegenden Zusammenhang wesentlichen Elemente und Besonderheiten des rheinland-pfälzischen Systems zunächst beschrieben (Kapitel B). Danach geht es um die Verteilungswirkungen des Schlüsselzuweisungsverfahrens, die den Kern der Auseinandersetzung bilden. Die wechselseitigen Beziehungen zwischen Schlüsselzuweisungen und Kreisumlage werden anhand verschiedener Modellrechnungen diskutiert (Kapitel $C$ ). Davon ausgehend erfolgt eine Auseinandersetzung mit den wesentlichen Einwänden gegenüber dem rheinland-pfälzischen Finanzausgleich (Kapitel D). Eine Zusammenfassung der wichtigsten Ergebnisse schließt die Untersuchung ab (Kapitel E). 
Wolfgang Scherf - 978-3-631-75194-7

Downloaded from PubFactory at 01/11/2019 07:16:26AM

via free access 


\section{B. Der kommunale Finanzausgleich in Rheinland-Pfalz}

Für das Verständnis der in dieser Arbeit zu diskutierenden Probleme ist eine kurze Darstellung des kommunalen Finanzausgleichs in Rheinland-Pfalz nützlich1. In Kenntnis der Funktionsweise des Ausgleichssystems lassen sich die später im einzelnen zu analysierenden Zusammenhänge zwischen Schlüsselzuweisungen und Kreisumlage besser einordnen und bewerten.

\section{Begründung und Gestaltung des horizontalen Finanz- ausgleichs}

Die Notwendigkeit eines horizontalen Finanzausgleichs gründet sich darauf, daß die unterschiedlichen Gebietskörperschaften einer gleichen staatlichen Ebene sich nach Größe, natürlichen Gegebenheiten, Bevölkerungs-, Siedlungs- und Wirtschaftsstruktur und infolgedessen auch in ihrer Finanzkraft und ihrem Finanzbedarf unterscheiden ${ }^{2}$. Alle Gebietskörperschaften, auch die leistungsschwächeren, müssen aber finanziell in die Lage versetzt werden, die innen zugeordneten öffentlichen Pflichtaufgaben angemessen wahrzunehmen. Die Ursachen der Wohlstandsunterschiede lassen sich zwar im Rahmen einer finanziellen Ausgleichsregelung nicht beheben, aber ihre wirtschaftlichen und sozialen Auswirkungen können gemildert und erträglich gestaltet werden. Ein solcher Ausgleich erfüllt zugleich eine sozialstaatliche Funktion und entspricht dem staatswirtschaftlichen Erfordernis, allen Gebietskörperschaften einen ausreichenden finanziellen Bewegungsspielraum auch für ihre freiwilligen Aufgaben zu sichern.

1 Vgl. insbesondere A. Nell / R. Steenbock, Der kommunale Finanzausgleich in Rheinland-Pfalz, FAG RhPf / 8.94, 212. Nachlieferung Praxis der Gemeindeverwaltung.

2 Vgl. zum folgenden $\mathrm{H}$. Fischer-Menshausen, Finanzausgleich II: Grundzüge des Finanzausgleichsrechts, in: Handwörterbuch der Wirtschaftswissenschaft (HdWM), Band 2, Stuttgart u. a. 1980, S. $654 \mathrm{ff}$. 
An einen aus finanzwissenschaftlicher Sicht rationalen Finanzausgleich sind gewisse Erfolgs- und Rahmenbedingungen geknüpft:

(1) Bei gleicher Aufgabendringlichkeit sind die Deckungsbedürfnisse der beteiligten Gebietskörperschaften prinzipiell gleichwertig.

(2) Die Finanzausstattung jeder Gebietskörperschaft soll wenigstens ihrem politisch festgelegten Mindestfinanzbedarf entsprechen.

(3) Soweit der horizontale Ausgleich auf einem Steuerkraftvergleich basiert, setzt er ein einheitliches Steuerrecht und Steuersystem voraus. Unterschiedliche steuerliche Anspannungsgrade, $z$. B. aufgrund örtlicher Hebesatzdifferenzen, sind in der Ausgleichsrechnung zu vereinheitlichen.

(4) Die Ausgleichsregelung soll die finanzielle Selbstverantwortung der Gebietskörperschaften nicht beeinträchtigen und ist daher so zu gestalten, daß die Freiheit der Mittelerhebung und -verwendung gewahrt bleibt und eigene Anstrengungen die Höhe der Ausgleichszahlungen nicht unmittelbar beeinflussen. Dies spricht gegen eine die Selbstverantwortung der Beteiligten schwächende Nivellierung der Finanzkraftrelationen.

(5) Die Ausgleichsregelung soll darüber hinaus keine negativen Rückwirkungen auf die gesamtstaatliche Wirtschafts- und Finanzpolitik haben. Dies gilt beispielsweise für stabilitätspolitische oder sozial- und verteilungspolitische Ziele, deren Verfolgung nicht primär Sache des Finanzausgleichs ist.

(6) Der horizontale Finanzausgleich steht auch im Dienst der regionalen Struktur- und Raumordnungspolitik. Da er auf die Ursachen der Wohlstandsgefälle nicht unmittelbar einwirken 
kann, ist er durch investitionspolitische Maßnahmen zu ergänzen und zu unterstützen.

(7) Völlige Ausgleichsgerechtigkeit ist unerreichbar. Der Versuch, möglichst alle Ungleichheiten zu berücksichtigen, führt nur zu komplizierten Verfahren, deren Nutzen infolge ihrer Intransparenz zweifelhaft ist.

Die Aufgabe des horizontalen Finanzausgleichs kann methodisch durch zwei unterschiedliche Verfahren erfüllt werden. Das horizontale Verfahren sieht vor, daß der Ausgleich durch Mittelumschichtung innerhalb der den Unterverbänden zustehenden Finanzmasse durchgeführt wird. Diese Vorgehensweise charakterisiert beispielsweise den Länderfinanzausgleich im engeren Sinne (ohne Ergänzungszuweisungen). Im vertikalen Verfahren mit horizontalem Effekt erfolgt der Ausgleich dagegen durch Finanzzuweisungen des Oberverbandes, in erster Linie durch die allgemeinen Finanzzuweisungen. Sie sind so zu differenzieren, daß den finanzschwächeren Verbänden höhere Pro-Kopf-Beträge zugewiesen und damit horizontale Ausgleichswirkungen ausgelöst werden.

Die Gründe für einen horizontalen Finanzausgleich unterscheiden sich von denen für einen vertikalen Einnahmenausgleich. Die vertikale Zuordnung der Aufgaben, Ausgaben und Einnahmen ist eine primär allokationspolitische Entscheidung, bei der es um die Zweckmäßigkeit einer zentralen oder dezentralen Aufgabenerfüllung geht. Dem horizontalen Finanzausgleich kommt dagegen die Funktion zu, die Finanzausstattung von Gebietskörperschaften der gleichen Ebene so zu regulieren, daß die nach vertikaler Verteilung noch verbleibenden Unterschiede abgebaut werden. Das Ziel des horizontalen Finanzausgleichs ist daher relativ einfach und klar: Im Vordergrund steht die distributive Absicht einer Verringerung regionaler, auf den Finanzbedarf bezogener Finanzkraftdifferenzen. 


\section{Finanzielle Grundlagen des kommunalen Finanz- ausgleichs in Rheinland-Pfalz}

Nach Art. 106 Abs. 7 GG steht den Gemeinden und Gemeindeverbänden ein nach Maßgabe landesgesetzlicher Vorschriften bestimmter Prozentsatz vom Länderanteil am Gesamtaufkommen der Gemeinschaftsteuern zu (Einkommensteuer, Körperschaftsteuer und Mehrwertsteuer). Das Land Rheinland-Pfalz geht mit einer zusätzlichen Beteiligung an den Einnahmen aus Kraftfahrzeugsteuer, Vermögensteuer (bis 31.12.1996), Länderfinanzausgleich und Bundesergänzungszuweisungen über die grundgesetzlichen Verpflichtungen hinaus.

Die genannten Einnahmen des Landes bilden die Verbundmasse. Gemeinden und Gemeindeverbände werden mit $20,25 \%$ an dieser Verbundmasse beteiligt (1.1.1992 bis 31.12.1995: 19,75\%). Der kommunale Anteil an der Verbundmasse bildet den ersten Teil der Finanzausgleichsmasse. Seit dem 1.1.1997 kommen $35,2 \%$ der ab 1.1.1996 entstandenen Erbschaft- und Schenkungsteuer sowie die Grunderwerbsteuer (abzüglich des Anteils der Landkreise und kreisfreien Städte) hinzu. Den restlichen Teil der Finanzausgleichsmasse bildet das Aufkommen aus der Finanzausgleichsumlage und der Umlage Fonds „Deutsche Einheit".

Aus der Finanzausgleichsmasse werden die allgemeinen Finanzzuweisungen und die zweckgebundenen Zuweisungen an Gemeinden, Verbandsgemeinden und Landkreise gezahlt. Zu den allgemeinen Finanzzuweisungen rechnen die Schlüsselzuweisungen, deren Gesamtbetrag als Schlüsselmasse bezeichnet wird. Die Schlüsselzuweisungen dienen vor allem der Stärkung der kommunalen Finanzkraft sowie dem Abbau von Finanzkraftunterschieden und bilden daher das Kernstück des kommunalen Finanzausgleichs. Sie umfassen Schlüsselzuweisungen A zum Vorwegausgleich unterdurchschnittlicher Steuerkraft, Schlüsselzu- 
weisungen B1 nach der Einwohnerzahl, Schlüsselzuweisungen B2 nach dem Finanzbedarf und der Finanzkraft sowie Investitionsschlüsselzuweisungen.

Die Schlüsselmasse entscheidet letztlich über das Ausmaß der durch den Finanzausgleich bewirkten Aufstockung der kommunalen Finanzkraft und der damit verbundenen Veränderung der relativen Finanzkraftpositionen der kommunalen Gebietskörperschaften. Die Verteilungseffekte ergeben sich daraus, daß bei einer Erhöhung der Schlüsselmasse der Grundbetrag steigt und alle Körperschaften gleiche Beträge in DM pro Einwohner zusätzlich erhalten. Infolgedessen werden die relativen Abstände zwischen finanzschwachen und finanzstarken Gebietskörperschaften verringert.

Das Land hat über die Gestaltung des Zuweisungssystems erheblichen Einfluß auf die Finanzlage der untergeordneten Gebietskörperschaften. Die Senkung des Verbundsatzes von 20,25\% auf $19,75 \%$ im Jahr 1992 deutet darauf hin, daß in Rheinland-Pfalz wie auch in anderen Bundesländern - ein Teil des Konsolidierungsdrucks bei den öffentlichen Haushalten auf die kommunalen Gebietskörperschaften abgewälzt wurde. Konjunkturpolitisch ist dies angesichts der ausgeprägten Neigung der Gemeinden und Gemeindeverbände zu einem prozyklischen Ausgabeverhalten von Nachteil. Andererseits weisen die kommunalen Haushalte im Vergleich zu Bund und Ländern noch den geringsten Verschuldungsgrad auf, so daß fiskalisch gesehen bei den Gemeinden eine Mehrbelastung vertretbar erscheint.

\section{Berücksichtigung der Aufgabenteilung im Kreisbereich}

Eine wichtige Besonderheit des rheinland-pfälzischen Finanzausgleichs besteht darin, daß die Schlüsselmasse nicht auf die verschiedenen Gebietskörperschaftsgruppen aufgeteilt wird. Viel- 
mehr errechnen sich die Schlüsselzuweisungen an Gemeinden, Kreise und kreisfreie Städte in einem einheitlichen und geschlossenen System. Eine weitere Besonderheit ist die konsequente Anwendung des „Einwohner = Einwohner"-Prinzips, d. h. der Finanzbedarf der Gemeinden wird pro Einwohner zunächst als gleich hoch angesehen. Funktionen, die nur bestimmte kommunale Gebietskörperschaften haben, werden durch „Leistungsansätze" berücksichtigt.

Die Umsetzung des „Einwohner = Einwohner"-Prinzips und die Einbeziehung aller Gemeinden und Gemeindeverbände in ein einheitliches Verteilungssystem erfordert eine Berücksichtigung der funktionellen Gliederung im Kreisbereich (Ortsgemeinde, Verbandsgemeinde, Landkreis). Eine kreisfreie Stadt hat alle Funktionen einer Ortsgemeinde, einer Verbandsgemeinde und eines Landkreises. Infolgedessen ist es angebracht, die drei Funktionsebenen im Kreisbereich zusammenfassend als "Gesamtkreis" zu bezeichnen, um eine Entsprechung zur kreisfreien Stadt zu erhalten. Gesamtkreis und kreisfreie Stadt bilden eine erste wichtige Ebene, auf der ein sinnvoller Vergleich der Wirkungen von Finanzausgleichssystemen möglich ist.

Innerhalb eines Gesamtkreises werden die öffentlichen Aufgaben teilweise von den kreisangehörigen Gemeinden (Orts- und Verbandsgemeinden sowie verbandsfreie Gemeinden und große kreisangehörige Städte) und teilweise von den Landkreisen erfüllt. Daher bietet es sich an, zwischen diesen Gebietskörperschaftsgruppen zu differenzieren. Da der Begriff "Landkreis" auch im Sinne von "Gesamtkreis" verwendet wird, soll die zentrale Funktionsebene des Gesamtkreises im folgenden als "Zentralkreis" bezeichnet werden. Bei der Beurteilung des Finanzausgleichs muß man sehen, daß Zentralkreise untereinander nur eingeschränkt 
vergleichbar sind, da der Zentralisierungsgrad der Aufgabenerfüllung zwischen den Gesamtkreisen variiert.

Die funktionelle Gliederung im Kreisbereich findet ihren Niederschlag in der Gestaltung des Zuweisungssystems. Schlüsselzuweisungen $A$ erhalten nur Ortsgemeinden, verbandsfreie Gemeinden, große kreisangehörige und kreisfreie Städte. Schlüsselzuweisungen $B$ gehen an kreisfreie und große kreisangehörige Städte, verbandsfreie Gemeinden, Verbandsgemeinden und Landkreise. Da die Schlüsselzuweisungen B an Gemeinden und Zentralkreise fließen, müssen die Ausgangsdaten für die Berechnung (Finanzkraft, Einwohnerzahl) aufgeteilt werden. Dies geschieht gemäß $\S 10$ Abs. 3 und $\S 11$ Abs. 2 FAG im Verhältnis von $69 \%$ für den Zentralkreis zu $31 \%$ für die verbandsfreien Gemeinden und Städte sowie Verbandsgemeinden.

\section{Das System der kommunalen Finanzzuweisungen}

Die Finanzzuweisungen sind neben den Steuern die wichtigste Einnahmeart der kommunalen Gebietskörperschaften. Die verschiedenen Zuweisungsarten werden nach dem Kriterium der Zweckbindung eingeteilt in allgemeine Finanzzuweisungen, über die die Gemeinden frei verfügen können, und in spezielle Finanzzuweisungen, die mit Zweckbindungen gewährt werden. Die allgemeinen Finanzzuweisungen können den Steuereinnahmen annähernd gleichgesetzt werden. Sie unterscheiden sich von den Realsteuern dadurch, daß die Gemeinden auf ihre Höhe keinen Einfluß nehmen können. Die speziellen Finanzzuweisungen lassen sich nach der Art der dotierten Aufgaben in Zuweisungen für Selbstverwaltungsaufgaben, für Gemeinschaftsaufgaben und für Auftragsangelegenheiten aufgliedern. Ihre relative Bedeutung divergiert in den einzelnen Bundesländern aufgrund der unterschiedlichen Aufgabenverteilung zwischen Ländern und Gemein- 
den erheblich. In Rheinland-Pfalz stieg der Anteil der Zweckzuweisungen an den gesamten Finanzzuweisungen von $35,2 \% \mathrm{im}$ Jahr 1990 auf 38,9 \% im Jahr 1995.

\section{a. Funktion und Arten der Schlüsselzuweisungen}

Der größte Teil der allgemeinen Finanzzuweisungen entfällt in allen Ländern auf die allgemeinen Schlüsselzuweisungen; in Rheinland-Pfalz sind es ca. $80 \%$. Die Schlüsselzuweisungen haben eine doppelte Aufgabe: Sie sollen die kommunale Finanzmasse insgesamt verstärken (fiskalische Funktion) und einen Abbau von Finanzkraftunterschieden zwischen den Gemeinden unter Berücksichtigung des Finanzbedarfs herbeiführen (Ausgleichsfunktion). Auf der kommunalen Ebene reichen die Steuereinnahmen, die speziellen Entgelte sowie die sonstigen Einnahmen insgesamt nicht aus, um alle Aufgaben zu finanzieren. Die fiskalische Funktion der Schlüsselzuweisungen liegt also darin, die den Gemeinden insgesamt zur Verfügung stehende Finanzmasse auf ein ausreichendes Niveau anzuheben. Dies geschieht faktisch, indem die Gemeinden an den Steuereinnahmen des jeweiligen Landes beteiligt werden (Steuerverbund).

Die Ausgleichsfunktion der Schlüsselzuweisungen kann darin gesehen werden, daß die Verteilung der den kommunalen Gebietskörperschaften insgesamt zufließenden Schlüsselmasse so zu gestalten ist, daß sich bei allen Gemeinden ein möglichst ausgeglichenes Verhältnis zwischen dem Ausgabenbedarf und den Einnahmemöglichkeiten einstellt. Die Frage, bis zu welchem Grade die Finanzbedarfs- und Finanzkraftunterschiede ausgeglichen werden sollen, läßt sich wegen des politischen Charakters dieser Entscheidung keineswegs eindeutig beantworten, und die diesbezüglichen Auffassungen gehen weit auseinander. Eine völlige Angleichung ist aber nicht erstrebenswert, denn die Präferenzen der 
Bürger für kommunale Leistungen sind unterschiedlich und ein hoher Nivellierungsgrad vermindert die Anstrengungen der Gemeinden, ihr Leistungsniveau aus eigener Kraft zu verbessern.

In Rheinland-Pfalz existieren verschiedene Arten von Schlüsselzuweisungen, denen unterschiedliche Funktionen zukommen. Die Schlüsselzuweisungen A sollen eine Mindestfinanzausstattung der empfangsberechtigten Gebietskörperschaften in Höhe von 73 \% (bis zum 31.12.1995: $71 \%$ ) der landesdurchschnittlichen Steuerkraft je Einwohner sicherstellen. Die Bedeutung einer solchen "Sockelgarantie" liegt darin, krasse regionale Unterschiede bezüglich Finanzkraft und Infrastruktur zu vermeiden, die mit der grundgesetzlichen Forderung nach "Wahrung der Einheitlichkeit der Lebensverhältnisse" nicht mehr vereinbar wären. Gemessen an diesem Ziel ist das rheinland-pfälzische Niveau der Mindestausstattung, das im Zeitablauf zwischen 71 und $75 \%$ schwankte, relativ niedrig.

Die zweite Form allgemeiner Zuweisungen sind die Finanzzuweisungen nach der Einwohnerzahl (Schlüsselzuweisungen B1). Sie lassen sich als genereller Kostenersatz der Länder für die den Gemeinden übertragenen Auftragsangelegenheiten interpretieren. Unterstellt wird hier, daß der Aufwand für Auftragsangelegenheiten einen relativ engen Zusammenhang zur Bevölkerungszahl der Gemeinden aufweist. Die Schlüsselzuweisungen B1 betragen 16,50 DM je Einwohner für verbandsfreie Gemeinden und Verbandsgemeinden, 17,00 DM für große kreisangehörige Städte und 19,50 DM für kreisfreie Städte. Sie werden ohne Rücksicht auf die Finanzkraft gezahlt und tragen daher nur wenig zur Annäherung der Finanzkraftpositionen bei.

Diesem zentralen Ziel des kommunalen Finanzausgleichs dienen vor allem die Schlüsselzuweisungen B2, die im Vordergrund der Auseinandersetzungen um den rheinland-pfälzischen Finanzaus- 
gleich stehen. In die Betrachtung einbeziehen kann man auch die Investitionsschlüsselzuweisungen, deren Verteilung nach den Regeln für die Schlüsselzuweisungen B2 erfolgt. Zwar sind sie mit einer Verpflichtung zum Einsatz für Investitionen verbunden, unterliegen ansonsten aber keiner engeren Zweckbindung. Solange die kommunalen Gebietskörperschaften von sich aus wenigstens Investitionen in Höhe der Investitionsschlüsselzuweisungen tätigen, ist die Verwendungsauflage bedeutungslos, und es gibt materiell keinen Unterschied zu den Schlüsselzuweisungen B2.

\section{b. Berechnung und Verteilung der Schlüsselzuweisungen B2}

Bei der Berechnung der Schlüsselzuweisungen B2 wird von einem normierten Finanzbedarf und der Steuerkraft unter Einschluß der Schlüsselzuweisungen A (Finanzkraft) ausgegangen. Die einbezogenen Gebietskörperschaften erhalten Zuweisungen in Höhe von $50 \%$ der Differenz zwischen Bedarfsmeßzahl und Finanzkraftmeßzahl. Übersteigt die Finanzkraftmeßzahl die Bedarfsmeßzahl, werden keine Schlüsselzuweisungen B2 gewährt. Die Bedarfsmeßzahl ist das Produkt aus Grundbetrag und Gesamtansatz, der sich aus dem einwohnerbezogenen Haupt- und den funktions- bzw. aufgabenbezogenen Leistungsansätzen zusammensetzt. Der Grundbetrag resultiert nicht aus echten Bedarfsuntersuchungen, sondern ist eine rein statistische Größe, die so festgelegt wird, daß die für Schlüsselzuweisungen bereitgestellten Mittel gerade verbraucht werden.

Bei der Konstruktion des Hauptansatzes geht man traditionell davon aus, daß die Pro-Kopf-Ausgaben der Gemeinden mit steigender Einwohnerzahl überproportional zunehmen. Dementsprechend wird im Hauptansatz oftmals ein nach der Gemeindegröße gestaffelter Betrag angesetzt, d. h. die tatsächliche Einwohnerzahl wird mit steigender Gemeindegröße höher bewertet. Der rhein- 
land-pfälzische Finanzausgleich weicht von dieser Regelung ab, indem er grundsätzlich einen für alle Bürger gleichen Pro-Kopf-Finanzbedarf unterstellt.

Diese Vorgehensweise ist aus finanzwissenschaftlicher Sicht nicht zu beanstanden, denn die auf Brecht und Popitz zurückgehende These, daß der Finanzbedarf je Einwohner mit zunehmender Gemeindegröße ansteige, läßt sich empirisch immer nur im Hinblick auf steigende Ausgaben, nicht aber im Hinblick auf einen steigenden Finanzbedarf belegen. Außerdem folgt aus der grundgesetzlichen Forderung nach einheitlichen Lebensbedingungen eher ein für alle Gemeinden gleicher Bedarf je Einwohner. Die Berücksichtigung der besonderen, auch der zentralörtlichen Funktionen größerer Gemeinden kann immer noch in den Nebenansätzen (Leistungsansätzen) erfolgen.

Die Nebenansätze werden allerdings problematisch, wenn im Sinne einer Perfektionierung des Systems eine Vielzahl von Ansätzen geschaffen wird und dann die Mehrzahl der Gemeinden solche Nebenansätze erhält. Die differenzierende Wirkung bleibt dann zunehmend aus. Darüber hinaus sind Nebenansätze ein recht starres Instrument, das sich veränderten Bedingungen oftmals nicht rechtzeitig anpassen läßt.

Die Finanzkraftmeßzahl ergibt sich aus der Steuerkraft und den Schlüsselzuweisungen $A$. Bei der Steuerkraftermittlung werden die Einnahmen aus der Grundsteuer, der Gewerbesteuer und des Gemeindeanteils an der Einkommensteuer zusammengerechnet. Grundlage ist bei den Realsteuern nicht das tatsächliche Aufkommen, sondern das Aufkommen zu landeseinheitlichen (durchschnittlichen) „Nivellierungshebesätzen“. Ziel dieser Vorgehensweise ist es, eine mehr oder weniger starke Anspannung der eigenen Steuerquellen durch die Festsetzung von unterschiedlichen Hebesätzen nicht auf die Höhe der Zuweisungen durchschlagen 
zu lassen. Damit wird eine Unabhängigkeit der Steuerkraftmeßzahl von der kommunalen Steuerpolitik erreicht.

Die Finanzzuweisungen errechnen sich aus der Differenz zwischen Bedarfsmeßzahl und Finanzkraftmeßzahl. Wie auch in anderen Bundesländern, werden dabei in Rheinland-Pfalz nur $50 \%$ dieser Differenz ausgeglichen, nicht zuletzt weil bei einem vollen Ausgleich damit zu rechnen wäre, daß die Gemeinden das Interesse an der Ausschöpfung und der Pflege der eigenen Steuerquellen verlieren könnten. Andererseits bedeutet die Beschränkung auf einen Teilausgleich für besonders steuerschwache Gemeinden isoliert gesehen eine unzulängliche Ausstattung mit Finanzmitteln. Dies unterstreicht noch einmal die Bedeutung der Sockelgarantie in Form der Schlüsselzuweisungen $A$.

Im kreisangehörigen Bereich teilen sich Gemeinden und Zentralkreise die nach einem einheitlichen Schema berechneten Schlüsselzuweisungen B2. Daher müssen die Finanzkraft- und Bedarfsmeßzahlen auf Zentralkreise und kreisangehörige Gemeinden aufgeteilt werden, was derzeit im Verhältnis $69 \mathrm{zu} 31$ geschieht (bis 31.12.1992: 70 zu 30). Bei der Bedarfsmeßzahl beschränkt sich die Aufteilung allerdings auf den Hauptansatz. Da die Leistungsansätze im wesentlichen den Gemeinden und Städten zugute kommen und die Zentralkreise auch keine Schlüsselzuweisungen A erhalten, ist der Schlüssel 69/31 nicht gleichzusetzen mit dem Verhältnis der tatsächlich gezahlten Zuweisungen. Es handelt sich lediglich um eine Rechengröße, die dem Ziel dient, die Zentralkreise in bestimmtem Umfang mit Schlüsselzuweisungen auszustatten, ursprünglich geleitet von der Absicht, einen rekurrenten Anschluß an das alte Finanzausgleichsgesetz herzustellen.

Die Systeme der Verteilung der Schlüsselzuweisungen unterscheiden sich in den einzelnen Bundesländern erheblich. Zwar erfolgt die Finanzierung der Gemeindeverbände hauptsächlich 
durch Schlüsselzuweisungen der Länder und Umlagen der Gemeinden. Die Schlüsselzuweisungen werden aber häufig nach Gebietskörperschaftsgruppen getrennt ermittelt und ausgezahlt. Bei ihrer Verteilung auf die Gemeindeverbände wird dann ein ähnliches Verfahren wie bei den Zuweisungen an die Gemeinden angewandt.

Da die Gemeindeverbände - abgesehen von einigen kleineren Steuern in einzelnen Ländern - keine eigenen Steuereinnahmen haben, errechnet man anstelle einer Steuerkraftmeßzahl eine Umlagekraftmeßzahl aus den Steuerkraftmeßzahlen der Gemeinden und einem bestimmten Prozentsatz der Finanzzuweisungen an die Gemeinden. Die Differenz zwischen Bedarfsmeßzahl und Umlagekraftmeßzahl wird dann teilweise durch Schlüsselzuweisungen ausgeglichen, wobei auch Sockelgarantien gewährt werden können. Die Vor- und Nachteile solcher Verfahren gegenüber dem rheinland-pfälzischen System werden noch zu überprüfen sein (vgl. Kapitel D.1.).

\section{Die Funktion der Kreisumlage im Finanzausgleich}

Im Gegensatz zu den kreisangehörigen Gemeinden verfügen die Zentralkreise kaum über nennenswerte Steuereinnahmen. Ihnen steht lediglich das Aufkommen einiger örtlicher Verbrauch- und Aufwandsteuern sowie (bis zum 31.12.1996) das Aufkommen aus der Grunderwerbsteuer zu. Die Finanzkraft der Zentralkreise konstituiert sich erst im Finanzausgleich. Nach Verteilung der Schlüsselzuweisungen verbleibt immer noch eine erhebliche Finanzierungslücke, welche durch den Rückgriff auf die Finanzkraft der kreisangehörigen Gemeinden geschlossen werden muß.

Diesem Zweck dient die Kreisumlage. Als Umlagegrundlagen werden die Steuerkraftmeßzahlen sowie die Schlüsselzuweisungen $A$ und $B 2$ herangezogen. Die von den Gemeindeverbänden 
beschlossenen Umlagesätze müssen für alle Umlagepflichtigen gleich sein. Allerdings sieht das rheinland-pfälzische Finanzausgleichsgesetz vor, daß die Umlagesätze für die einzelnen Umlagegrundlagen verschieden hoch (Splitting) oder für die über dem Landesdurchschnitt liegende Steuerkraftmeßzahl progressiv festgesetzt werden kann. Damit steht den Zentralkreisen die Möglichkeit offen, die Kreisumlage nicht nur fiskalisch, sondern auch verteilungspolitisch einzusetzen.

Splitting und Progression sind aus finanzwissenschaftlicher Sicht nicht unproblematisch ${ }^{1}$. Finanzkräftige Gemeinden können zu relativ höheren Umlagebeträgen herangezogen und finanzschwache Gemeinden von ihren Umlagepflichten relativ entlastet werden. Die Möglichkeit des Splittings oder der Progressionsstaffel dürfte insgesamt kaum zu systematischen Ergebnissen führen. Landkreise, die diese Instrumente anwenden, belasten damit ihre finanzstarken Gemeinden gegenüber vergleichbaren Kommunen, die in ihren Landkreisen nicht dem Splitting bzw. der Progressionsstaffel unterliegen. Auch ist bei der Beurteilung der Instrumente zu beachten, daß das Splitting faktisch ausschließlich die Gewerbesteuer betrifft, bei der erhebliche Unterschiede in der lokalen Steuerkraft bestehen.

Es sei dahingestellt, ob der Einbau distributiver Elemente in die Kreisumlage vorteilhaft ist oder nicht. Vor dem Hintergrund des Finanzbedarfs der Zentralkreise muß vor allem ihre traditionelle fiskalische Funktion beachtet und gewürdigt werden. Die Kreisumlage dient primär einer aufgabengerechten Verteilung der im Gesamtkreis vorhandenen Finanzkraft zwischen dem Zentralkreis und der Gesamtheit der kreisangehörigen Gemeinden (fiskalischer Finanzausgleich). Dabei muß sie so eingesetzt werden, daß

1 Vgl. K. Littmann, Über das Elend kommunaler Umlagen, Schriftenreihe der Hochschule für Verwaltungswissenschaften Speyer, Bd. 122, S. $363 \mathrm{ff}$. 
die Finanzkraftrelation zwischen Zentralkreis und kreisangehörigen Gemeinden nach Erhebung der Kreisumlage möglichst genau mit der im jeweiligen Gesamtkreis vorliegenden Aufgaben- und Lastenverteilung übereinstimmt. Angesichts dieser finanzausgleichspolitischen Funktion ist eine abschließende finanzwissenschaftliche Bewertung des Finanzausgleichs im kreisangehörigen Bereich ohne die Berücksichtigung der Kreisumlage nicht möglich. 
Wolfgang Scherf - 978-3-631-75194-7

Downloaded from PubFactory at 01/11/2019 07:16:26AM

via free access 
C. Interdependenzen zwischen Schlüsselzuweisungen und Kreisumlage im Finanzausgleich

\section{Die Abhängigkeit der Kreisumlage von den Schlüsselzu- weisungen}

Im folgenden werden Funktionsweise und Wirkungen des kommunalen Finanzausgleichs in Rheinland-Pfalz zunächst im Überblick dargestellt und anschließend anhand verschiedener Modellrechnungen diskutiert. Dabei ist nach verschiedenen Wirkungsebenen zu unterscheiden, und zwar nach den Wirkungen zwischen den Gesamtkreisen (auch im Vergleich zu den kreisfreien Städten), nach den Wirkungen zwischen einem Zentralkreis und seinen Gemeinden sowie nach den Wirkungen innerhalb der Gruppe der Gemeinden eines Zentralkreises.

\section{a. Schlüsselzuweisungen und Kreisumlage auf der Ebene der Gesamtkreise}

Generell sind die Schlüsselzuweisungen ein Instrument des Finanzausgleichs, das zum einen der fiskalischen Funktion einer Aufstockung der kommunalen Finanzkraft, zum anderen der Korrektur von Abweichungen zwischen Finanzkraft und Finanzbedarf dient. Da Zentralkreis und kreisangehörige Gemeinden insgesamt die gleichen öffentlichen Aufgaben zu erfüllen haben wie die kreisfreien Städte, muß der Finanzausgleich so gestaltet sein, daß zwischen dem Gesamtkreis und den kreisfreien Städten keine Verzerrungen auftreten.

Auf der Ebene der Gesamtkreise stellt sich also die Frage, ob sie im System der Schlüsselzuweisungen grundsätzlich den kreisfreien Städten gleichgestellt sind. Da ein solcher Vergleich infolge der übereinstimmenden Aufgabenstellung sachlich geboten ist, ergibt sich bereits an dieser Stelle die Notwendigkeit, Zentralkreis 
und kreisangehörige Gemeinden nicht isoliert, sondern im Verbund zu betrachten.

Bei der Überprüfung konkreter Regelungen für die Verteilung der Schlüsselzuweisungen auf der Ebene der Gesamtkreise sind folgende Eigenschaften finanzausgleichspolitisch erwünscht:

(1) Bei insgesamt gleichem Finanzbedarf und gleicher Finanzkraft (gemessen in DM pro Einwohner) sollten kreisfreie Städte und Gesamtkreise gleich hohe Schlüsselzuweisungen zum Abbau der Differenz zwischen Finanzbedarf und Finanzkraft erhalten.

(2) Diese Schlüsselzuweisungen sollten eine Nivellierung der Finanzkraftrelationen in dem Sinne bewirken, daß Gesamtkreise mit unterschiedlicher Finanzkraft nach Verteilung der Schlüsselzuweisungen geringere Differenzen aufweisen als zuvor. Die Reihenfolge der Gesamtkreise darf dabei nicht verändert werden.

Die zweite Eigenschaft muß auch für die kreisfreien Städte erfüllt sein, und zwar sowohl untereinander als auch im Verhältnis zu den Gesamtkreisen.

Auf der Ebene der Gesamtkreise besteht im übrigen kein Zusammenhang zwischen Schlüsselzuweisungen und Kreisumlage, weil es sich bei der Erhebung der Kreisumlage um einen gesamtkreisinternen Vorgang handelt. Eine Nivellierungsprüfung für die Gesamtkreise (gegebenenfalls ergänzt um die kreisfreien Städte) hat die Kreisumlage deshalb weder „vor" noch „im" noch "nach" Finanzausgleich zu berücksichtigen.

Hervorzuheben ist, daß es keinen Sinn macht, die genannten Kriterien für eine Nivellierungsprüfung einfach auf Zentralkreise und kreisangehörige Gemeinden zu übertragen. Diese Vorgehensweise verbietet sich schon deshalb, weil die Regulierung der Fi- 
nanzkraft innerhalb der Gesamtkreise sich an der jeweiligen Aufgabenverteilung zu orientieren hat. Während bei einem Vergleich zwischen Gesamtkreisen untereinander sowie im Verhältnis zu den kreisfreien Städten von übereinstimmenden Aufgaben auszugehen ist, muß innerhalb der Gesamtkreise differenziert werden. Unter sonst gleichen Bedingungen kann sich beispielsweise ein Vergleich zwischen Zentralkreisen als irreführend erweisen, wenn die Anteile der vom jeweiligen Zentralkreis übernommenen Aufgaben voneinander abweichen. Da solche Abweichungen mit entgegengerichteten Unterschieden auf der Gemeindeebene einhergehen, verbietet sich auch dort ein Vergleich ohne Berücksichtigung der Aufgabenverteilung innerhalb der Gesamtkreise.

\section{b. Schlüsselzuweisungen und Kreisumlage im Verhältnis zwischen Zentralkreis und Gemeinden}

Betrachtet man zunächst das Verhältnis zwischen einem Zentralkreis und seinen kreisangehörigen Gemeinden, so ist von einem sachgerechten Finanzausgleich zu fordern, daß beide Ebenen nach Finanzausgleich eine möglichst übereinstimmende Relation zwischen Finanzbedarf und Finanzkraft (Deckungsquote) aufweisen. Da die Verteilung der Finanzausstattung des Gesamtkreises auf Zentralkreis und Gemeinden einerseits von den Schlüsselzuweisungen und andererseits von der Kreisumlage bestimmt wird, ist es nicht nur naheliegend, sondern wiederum sachlich zwingend, diese beiden Instrumente in ihrer Verbundwirkung zu betrachten.

Gegen eine isolierte Analyse der Schlüsselzuweisungen wie auch der Kreisumlage sprechen vor allem zwei Gründe:

(1) Bei gegebenem Anteil des Zentralkreises an den im Gesamtkreis zu erfüllenden öffentlichen Aufgaben entscheidet die Ausstattung des Zentralkreises mit Schlüsselzuweisungen 
über den Finanzbedarf, der mittels der Kreisumlage gedeckt werden muß. Eine relativ hohe Ausstattung mit Schlüsselzuweisungen senkt das erforderliche Niveau der Kreisumlage und umgekehrt.

(2) Bei der Verteilung der Schlüsselzuweisungen kann auf unterschiedliche Aufgabenverteilungen innerhalb der Gesamtkreise, die zum Teil auf freiwilligen Entscheidungen des Kreistages und der Gemeinderäte beruhen, keine Rücksicht genommen werden. Infolgedessen gibt es auch keinen Verteilungsschlüssel, der schon nach Verteilung der Schlüsselzuweisungen eine angemessene Regulierung der Finanzkraft zwischen Zentralkreis und kreisangehörigen Gemeinden ermöglicht. Dazu bedarf es immer eines Ausbalancierens mittels der Kreisumlage.

Vor diesem Hintergrund ist die Kreisumlage vor allem ein Instrument des Finanzausgleichs innerhalb der Gesamtkreise, das für eine aufgabengerechte Mittelverteilung auf Zentralkreis und Gemeinden zu sorgen hat. Aus dieser Funktion der Kreisumlage resultiert aber auch logisch zwingend die Notwendigkeit, erstens die jeweilige Aufgabenverteilung und zweitens die jeweilige Finanzausstattung vor Kreisumlage in Rechnung zu stellen. Da diese Faktoren zwischen den Gesamtkreisen differieren, verbietet sich von vornherein ein Vergleich auf der Basis der Durchschnittswerte.

\section{c. Schlüsselzuweisungen und Kreisumlage auf der Ebene der kreisangehörigen Gemeinden}

Wenn Schlüsselzuweisungen B2 und Kreisumlage zusammen für eine angemessene Finanzausstattung aller am Finanzausgleich beteiligten Gebietskörperschaften im Sinne gleicher Relationen zwischen Finanzbedarf und Finanzkraft sorgen sollen, stellt sich 
die Frage, ob und inwieweit dies auch für die kreisangehörigen Gemeinden innerhalb eines Landkreises erreicht werden kann. Bei der Analyse dieser Frage wird von Splitting oder Progression abgesehen, um eine Vermischung des hier in Rede stehenden fiskalischen Finanzausgleichs mit darüber hinausgehenden distributiven Aspekten zu vermeiden. Die Kreisumlagesätze und die Umlagegrundlagen sind also innerhalb eines Landkreises für alle Gemeinden gleich. Der Klarheit halber sei angemerkt, daß die Kreisumlagesätze in unterschiedlichen Landkreisen durchaus unterschiedlich hoch sein können.

Sofern sie alle Umlagegrundlagen gleichmäßig belastet, ändert die Kreisumlage - völlig unabhängig von ihrer Höhe - nichts an der Finanzkraftrangfolge der kreisangehörigen Gemeinden innerhalb eines Landkreises. Sie kann daher für sich genommen als verteilungsneutral angesehen werden. Die Höhe der Kreisumlage ist allerdings keine vorgegebene Größe, sondern hängt auch von der Verteilung der Schlüsselzuweisungen auf die verschiedenen Ebenen der Gesamtkreise ab. Infolgedessen stellt sich zum einen die Frage nach den Wirkungen der Zuweisungen ausgehend von einem gegebenen Verteilungsschlüssel (z. B. 69/31), zum anderen die Frage nach den Auswirkungen einer möglichen Veränderung des Verteilungsschlüssels.

Der Verteilungsschlüssel legt fest, welchen Anteil der den kommunalen Gebietskörperschaften im kreisangehörigem Raum insgesamt zufließenden Schlüsselzuweisungen B2 die Zentralkreise und welchen die kreisangehörigen Gemeinden bzw. die Verbandsgemeinden erhalten. Damit hat der Verteilungsschlüssel im übrigen die gleiche Funktion wie die Aufteilung einer entsprechenden Schlüsselmasse für den kreisangehörigen Raum durch die Bildung von zwei Säulen oder Töpfen. Gleichzeitig bewirkt der Verteilungsschlüssel, daß die Aufteilung der Schlüsselzuweisun- 
gen innerhalb eines jeden Gesamtkreises auf den Zentralkreis und seine Gemeinden landesweit einheitlich erfolgt. Innerhalb eines Gesamtkreises sorgt der Verteilungsschlüssel ferner dafür, daß jede einzelne Gemeinde die durch sie "verursachten" Schlüsselzuweisungen B2 nur in der Höhe erhält, die der Aufteilung nach dem Verteilungsschlüssel entspricht. Der Rest - eben der Anteil des Zentralkreises - fließt diesem direkt zu.

Nur der den Gemeinden zustehende Teil ist für den Finanzausgleich auf Gemeindeebene unmittelbar relevant. Er trägt dazu bei, daß die Differenzen, die in der Finanzkraft vor Schlüsselzuweisungen B2 bestanden haben, nach Schlüsselzuweisungen kleiner ausfallen. Mit Blick auf diese Ausgleichsfunktion ist festzustellen, daß die Finanzkraftrangfolge der Gemeinden vor Verteilung der Schlüsselzuweisungen B2 durch die Schlüsselzuweisungen nicht verändert werden kann, sofern die Ausgleichsquote unter $100 \%$ liegt und die Finanzkraft sachgerecht ermittelt wurde. Im rheinland-pfälzischen Finanzausgleich ist eine Übernivellierung auf dieser Ebene also ausgeschlossen, weil schon der Ausgleichssatz für den Gesamtkreis in Höhe von 50 \% solche Wirkungen nicht zuläßt.

Dies gilt natürlich verstärkt, wenn die Schlüsselzuweisungen B2 den Gemeinden nicht vollständig, sondern eben nur in einer dem Verteilungsschlüssel entsprechenden Höhe zufließen. Auch die Kreisumlage kann innerhalb eines Gesamtkreises, sofern von Splitting oder Progression abgesehen wird, nie zu einer Veränderung in der Finanzkraftrangfolge der Gemeinden eines Landkreises führen, wenn die Schlüsselzuweisungen B2 mit in die Umlagegrundlagen einbezogen werden.

Bei gegebenem Verteilungsschlüssel werden die kreisangehörigen Gemeinden untereinander finanzausgleichspolitisch gesehen zielgerecht behandelt. Es findet eine erwünschte Nivellierung der 
relativen Finanzkraft statt, deren Ausmaß durch den Ausgleichssatz und den Gemeindeanteil an den Schlüsselzuweisungen determiniert ist. Der Verteilungsschlüssel hat nur insofern Bedeutung, als er mit darüber entscheidet, in welchem Ausmaß die relativen Finanzkraftpositionen der Gemeinden einander angenähert werden: Je größer der Gemeindeanteil an den Schlüsselzuweisungen, desto stärker der Abbau von Finanzkraftdifferenzen zwischen den Gemeinden durch den Finanzausgleich, weil insbesondere die "armen" Gemeinden davon profitieren. Diese Mechanik wird durch die Kreisumlage verstärkt. Ein höherer Gemeindeanteil an den Schlüsselzuweisungen geht zwangsläufig mit einem niedrigeren Anteil der Zentralkreise einher. Die Folge ist ein Anstieg des Kreisumlagesätze, der sich zu Lasten der „reichen“ Gemeinden auswirkt, ohne daß diese allerdings in der Finanzkraftrangfolge zurückfallen.

Aus diesem Sachverhalt lassen sich allerdings keine zwingenden Schlußfolgerungen hinsichtlich der adäquaten Höhe des Verteilungsschlüssels ableiten. Dieser berührt nur die relativen Finanzkraftpositionen der Gemeinden, nicht deren durchschnittliche Ausstattung. Da das erwünschte Ausmaß eines Abbaus von Finanzkraftdifferenzen - jeweils bezogen auf den Finanzbedarf innerhalb gewisser Grenzen der politischen Entscheidung offensteht, hat der Gesetzgeber auch bei der Wahl des Verteilungsschlüssels einen Entscheidungsspielraum. Dieser Spielraum ist groß, weil Übernivellierungseffekte auf der Gemeindeebene gar nicht zustande kommen können.

Die Überlegungen zu den Interdependenzen zwischen Schlüsselzuweisungen und Kreisumlage lassen sich folgendermaßen zusammenfassen:

(1) Von ihrer Aufgabenstellung her vergleichbar sind Gesamtkreise untereinander sowie mit kreisfreien Städten. Die Schlüs- 
selzuweisungen müssen daher so gestaltet sein, daß Gesamtkreise und kreisfreie Städte gleich behandelt werden. Darüber hinaus sollen sie Finanzkraftdifferenzen abbauen, ohne die Finanzkraftreihenfolge zu verändern.

(2) Von ihrer Aufgabenstellung her nicht ohne weiteres vergleichbar sind die Zentralkreise untereinander oder die kreisangehörigen Gemeinden verschiedener Gesamtkreise, denn die Aufgabenanteile dieser Ebenen variieren zwischen den Gesamtkreisen. Folglich kann nur geprüft werden, ob der Finanzausgleich in der Lage ist, eine aufgabenorientierte Finanzausstattung innerhalb eines Gesamtkreises zu gewährleisten. Diese Frage betrifft zum einen das Verhältnis zwischen Zentralkreis und kreisangehörigen Gemeinden, zum anderen die kreisangehörigen Gemeinden untereinander.

(3) Infolge der Aufgaben- und Einnahmenverflechtung zwischen Zentralkreis und kreisangehörigen Gemeinden dürfen Schlüsselzuweisungen und Kreisumlage nicht unabhängig voneinander gesehen werden. Bei gegebener Aufgabenverteilung hängt der Umlagebedarf eines Zentralkreises von seiner Ausstattung mit Schlüsselzuweisungen $a b$, und bei gegebenen Schlüsselzuweisungen bestimmt die Aufgabenverteilung den Umlagebedarf. Der Kreisumlage kommt daher nicht nur eine Spitzenausgleichsfunktion zu, sondern sie hat eine ganz zentrale Bedeutung für die Verteilung der Finanzausstattung innerhalb des Gesamtkreises.

(4) Demgegenüber ist die Wahl des Verteilungsschlüssels für die Schlüsselzuweisungen ein nachrangiges Problem. Bei korrekter Bemessung der Kreisumlage betrifft sie nur das Ausmaß der Finanzkraftnivellierung auf der Ebene der kreisangehörigen Gemeinden, nicht aber die relative Position der Zentralkreise oder der Gesamtkreise. 


\section{Entwicklung eines Modells zur Analyse der Ausgleichs- effekte}

Die bislang in verbaler Argumentation dargelegten Zusammenhänge zwischen Schlüsselzuweisungen und Kreisumlage werden im folgenden durch verschiedene Modellrechnungen illustriert. Aufgabe dieser Modellrechnungen ist es, die Vorgänge auf den verschiedenen Ebenen des Finanzausgleichssystems transparent zu machen und damit die Notwendigkeit einer integrierten Gesamtschau zu unterstreichen. Darüber hinaus lassen sich bei Verwendung realitätsnaher Werte die quantitativen Aspekte des Ausgleichsverfahrens mit den qualitativen verknüpfen. Schließlich kann das in diesem Abschnitt entwickelte Gerüst später zur Diskussion der im Rahmen fiktiver Finanzkraftberechnungen abgeleiteten „Übernivellierungseffekte“ herangezogen werden (vgl. Abschnitt D.3.a.).

Die Modellrechnungen konzentrieren sich auf das Zusammenspiel der Schlüsselzuweisungen nach dem Finanzbedarf (Schlüsselzuweisungen B2) mit der Kreisumlage. Außer Betracht bleiben die Schlüsselzuweisungen zum Vorwegausgleich unterdurchschnittlicher Steuerkraft (Schlüsselzuweisungen A). Sie sind - neben den kommunalen Steuereinnahmen - in den Ausgangswerten für die Finanzkraft enthalten. Der Verzicht auf eine gesonderte Berücksichtigung dieser Zuweisungen ist unproblematisch, da sie nur eine Mindestfinanzausstattung sicherstellen, aber keine Änderung der Finanzkraftrangfolge bewirken können. Infolgedessen spielen sie für eine Nivellierungsprüfung keine Rolle.

Ebenfalls unberücksichtigt bleiben die Schlüsselzuweisungen nach der Einwohnerzahl (Schlüsselzuweisungen B1) und die Investitionsschlüsselzuweisungen, deren Verteilung analog zu den Schlüsselzuweisungen B2 erfolgt. Auch diese Vereinfachungen dienen ausschließlich der besseren Nachvollziehbarkeit der Über- 
legungen; sie haben keine Bedeutung für die Ergebnisse der Untersuchung.

Der Modellaufbau läßt sich folgendermaßen skizzieren:

(1) Ausgangspunkt des Finanzausgleichs ist die Finanzkraft vor Schlüsselzuweisungen B2, welche sich aus der Steuerkraft und den Schlüsselzuweisungen A ergibt. Die Finanzkraft wird jeweils in DM pro Einwohner ausgedrückt und ist daher unmittelbar für Vergleichszwecke geeignet.

(2) Die Finanzkraft vor Schlüsselzuweisungen B2 wird mit dem als einheitlich unterstellten Finanzbedarf (ebenfalls in DM pro Einwohner) konfrontiert. Im Falle einer Unterschreitung des Finanzbedarfs erfolgt ein Ausgleich der Differenz zu $50 \%$ durch Schlüsselzuweisungen. Der Finanzbedarf ist im übrigen keine objektive Größe, sondern wird mit Blick auf die verfügbare Schlüsselmasse festgelegt.

(3) Die Finanzkraft vor Schlüsselzuweisungen B2 und der Finanzbedarf lassen sich für die Landkreise nur auf Gemeinde- und auf Gesamtkreisebene sinnvoll ansetzen. Der Zentralkreis hat vor Finanzausgleich keine Finanzkraft, denn diese ergibt sich erst im Finanzausgleich nach der Verteilung der Schlüsselzuweisungen B2 und der Erhebung der davon abhängigen Kreisumlage.

(4) Die Schlüsselzuweisungen B2 nach Finanzbedarf werden auf Zentralkreise und kreisangehörige Gemeinden gemäß Verteilungsschlüssel (in der Regel 69/31) aufgeteilt. Es ergibt sich daraus die Finanzkraft nach Schlüsselzuweisungen. Sie entspricht keineswegs der letztlich anzustrebenden Finanzkraftverteilung, denn auf dieser Stufe des Finanzausgleichs fehlt noch die aufgabenorientierte Regulierung der Finanzkraft zwischen Zentralkreis und Gemeinden. 
(5) Die Lösung dieses Problems erfolgt auf der nächsten und letzten Stufe des Finanzausgleichs mit Hilfe der Kreisumlage. Unterstellt wird dabei ein bestimmter Aufgaben- und Ausgabenanteil (in der Regel $40 \%$ ) für den Zentralkreis. Die erforderliche Kreisumlage resultiert aus diesem Aufgaben- und Ausgabenanteil unter Berücksichtigung der Ausstattung des Zentralkreises mit Schlüsselzuweisungen.

Die Annahme eines bestimmten Aufgaben- und Ausgabenanteils der Zentralkreise dient im übrigen ausschließlich der korrekten Vergleichbarkeit. Es können auch andere Werte als $40 \%$ verwendet werden, ohne die qualitativen Ergebnisse zu verändern. Insbesondere darf der Aufgaben- und Ausgabenanteil nicht als festgeschriebene (Durchschnitts-) Größe verstanden werden, denn der Finanzausgleich läßt gerade in dieser Hinsicht differenzierte Lösungen zu (vgl. dazu Abschnitt C.6.).

(6) Erst die Finanzkraft nach Erhebung der Kreisumlage ist ein adäquater Indikator für die Ausgleichseffekte des Gesamtsystems. Gewürdigt werden muß sie vor dem Hintergrund der Aufgabenverteilung im Gesamtkreis, in der die Gesamtkreise untereinander erheblich differieren können. Nur um diesen Effekt auszuschalten, wird meist ein gleicher Ausgabenanteil für die Zentralkreise vorausgesetzt. Damit lassen sich die Überlegungen konzentrieren (aber auch verkürzen) auf die Wechselwirkungen zwischen Schlüsselzuweisungen und Kreisumlage.

\section{Vergleich zwischen Gesamtkreisen und kreisfreien Städten}

Aus der Identität ihrer Aufgabenstellung ergibt sich, daß Gesamtkreise und kreisfreie Städte im Finanzausgleich gleich behandelt werden müssen. Tabelle 1 zeigt, daß diese Forderung durch das 
Tabelle 1: Vergleich zwischen Gesamtkreis und kreisfreier Stadt

\begin{tabular}{|c|c|c|c|c|c|c|c|c|c|}
\hline \multirow[t]{2}{*}{$\begin{array}{c}\text { Gebietskörper- } \\
\text { schaften }\end{array}$} & \multicolumn{2}{|c|}{$\begin{array}{c}\text { Finanzkraft vor } \\
\text { SZW B2 [1] }\end{array}$} & \multirow{2}{*}{$\begin{array}{r}\begin{array}{r}\text { Finanz- } \\
\text { bedarf }\end{array} \\
\mathrm{DM} / \mathrm{E}\end{array}$} & \multirow{2}{*}{$\frac{\text { SZW B2 }}{\text { DM/E }}$} & \multicolumn{2}{|c|}{$\begin{array}{c}\text { Finanzkraft nach } \\
\text { SZW B2 }\end{array}$} & \multirow{2}{*}{$\begin{array}{r}\begin{array}{c}\text { Kreisum- } \\
\text { lage [2] }\end{array} \\
\mathrm{DM} / \mathrm{E}\end{array}$} & \multicolumn{2}{|c|}{$\begin{array}{c}\text { Finanzkraft nach } \\
\text { Kreisumlage }\end{array}$} \\
\hline & $\mathrm{DM} / \mathrm{E}$ & FK [3] & & & $\mathrm{DM} / \mathrm{E}$ & FK [3] & & $D M / E$ & FK [3] \\
\hline Gesamtkreis & 1.000 & $100,0 \%$ & 1.400 & 200 & 1.200 & $100,0 \%$ & $32,2 \%[4]$ & 1.200 & $100,0 \%$ \\
\hline Zentralkreis & & & & 138 & 138 & & 342 & 480 & $100,0 \%$ \\
\hline Gemeinden & 1.000 & $100,0 \%$ & 1.400 & 62 & 1.062 & $100,0 \%$ & -342 & 720 & $100,0 \%$ \\
\hline Gemeinde 1 & 800 & $80,0 \%$ & 1.400 & 93 & 893 & $84,1 \%$ & -288 & 605 & $84,1 \%$ \\
\hline Gemeinde 2 & 1.000 & $100,0 \%$ & 1.400 & 62 & 1.062 & $100,0 \%$ & -342 & 720 & $100,0 \%$ \\
\hline Gemeinde 3 & 1.200 & $120,0 \%$ & 1.400 & 31 & 1.231 & $115,9 \%$ & -396 & 835 & $115,9 \%$ \\
\hline Kreisfreie Stadt & 1.000 & $100,0 \%$ & 1.400 & 200 & 1.200 & $100,0 \%$ & & & \\
\hline
\end{tabular}

[1] Steuerkraft zuzüglich Schlüsselzuweisungen A. SZW = Schlüsselzuweisungen.

[2] Der Zentralkreis übernimmt $40 \%$ der Gesamtkreisausgaben.

[3] Finanzkraft bezogen auf den Durchschnitt der jeweiligen Gebietskörperschaftsgruppe.

[4] Erforderlicher Kreisumlagesatz zur Finanzierung der Zentralkreisausgaben gemäß [2]. 
rheinland-pfälzische System der Schlüsselzuweisungen B2 nach Finanzbedarf erfüllt wird. Gesamtkreis und kreisfreie Stadt verfügen im vorliegenden Fall über die gleiche Finanzkraft vor Schlüsselzuweisungen B2 in Höhe von 1.000 DM pro Einwohner. Auf der Ebene des Gesamtkreises resultiert diese Finanzkraft aus dem mit der Einwohnerzahl gewichteten Durchschnitt seiner Gemeinden. Es werden drei Gemeinden gleicher Größe, aber unterschiedlicher Finanzkraft vorausgesetzt. Der Begriff "Gemeinden“ umfaßt im folgenden die Verbandsgemeinden und die verbandsfreien Gemeinden.

Bei der Bemessung der Schlüsselzuweisungen B2 werden der (einheitliche) Finanzbedarf in Höhe von 1.400 DM pro Einwohner und die jeweiligen Finanzkraftzahlen miteinander verglichen. Die Hälfte einer positiven Differenz zwischen Finanzbedarf und Finanzkraft wird durch Schlüsselzuweisungen ausgeglichen. Im vorliegenden Fall erhalten Gesamtkreis wie kreisfreie Stadt 200 DM pro Einwohner an Schlüsselzuweisungen, welche die Lücke zwischen Finanzbedarf und Finanzkraft in Höhe von 400 DM pro Einwohner zur Hälfte schließen. Zwischen Gesamtkreisen und kreisfreien Städten treten also keine Verzerrungen ein.

Auf der Ebene des Gesamtkreises werden die Schlüsselzuweisungen, deren Gesamtvolumen pro Kreiseinwohner von der durchschnittlichen Finanzkraft der kreisangehörigen Gemeinden abhängt, nun im Verhältnis 69 zu 31 auf Zentralkreis und Gemeinden aufgeteilt. Mithin erhalten der Zentralkreis 138 DM pro Einwohner und seine Gemeinden im Durchschnitt 62 DM pro Einwohner. Die Gemeinden werden dabei in Abhängigkeit von ihrer spezifischen Finanzkraft bedient, d. h. die unterdurchschnittlich finanzstarke Gemeinde 1 erhält höhere, die überdurchschnittlich finanzstarke Gemeinde 3 geringere Schlüsselzuweisungen pro Einwohner als die Durchschnittsgemeinde 2. Damit erfolgt unter den 
kreisangehörigen Gemeinden eine Angleichung der relativen Finanzkraftpositionen: Die Spanne von 80 bis $120 \%$ vor Schlüsselzuweisungen B2 reduziert sich auf 84,1 bis $115,9 \%$ nach Schlüsselzuweisungen.

Eine aufgabengerechte Verteilung zwischen Zentralkreis und Gemeinden setzt voraus, daß auf der nächsten Stufe des Finanzausgleichs die Kreisumlage so festgesetzt wird, daß dem Zentralkreis insgesamt ein seinem Aufgabenanteil entsprechender Anteil an der Finanzkraft des Gesamtkreises nach Schlüsselzuweisungen zur Verfügung steht. In der Modellrechnung sind dies $40 \%$ von 1.200 DM, also 480 DM pro Einwohner. Nach Abzug von 138 DM bereits erhaltener Schlüsselzuweisungen muß der Zentralkreis also 342 DM pro Einwohner über die Kreisumlage erhalten. Diese knüpft an der Finanzausstattung der kreisangehörigen Gemeinden nach Schlüsselzuweisungen an, die sich in der Summe auf 1.062 DM pro Einwohner beläuft. Daraus resultiert der erforderliche Umlagesatz von 342/1.062 bzw. 32,2 \%.

Die Erhebung der proportionalen Kreisumlage sorgt hier für eine problemgerechte Verlagerung der Finanzkraft innerhalb des Gesamtkreises zwischen Gemeinden und Zentralkreis. Betrachtet man - wie in Tabelle 1 unterstellt - einen Gesamtkreis mit durchschnittlicher absoluter Finanzkraft, der eine relative Finanzkraft von $100 \%$ aufweist, so ergibt sich nach proportionaler Kreisumlage, daß sowohl der Zentralkreis als auch die durchschnittliche Gemeinde eine relative Finanzkraft von $100 \%$ gemessen am jeweiligen Durchschnitt ihrer Gebietskörperschaftsgruppen erreichen. Innerhalb der Gruppe der Gemeinden bleiben die nach Schlüsselzuweisungen eingetretenen Finanzkraftrelationen aufgrund der Verwendung eines einheitlichen Umlagesatzes erhalten. 
Folgende Ergebnisse der Modellrechnung verdienen Beachtung:

(1) Der rheinland-pfälzische Finanzausgleich bewirkt eine Gleichbehandlung von Gesamtkreisen und kreisfreien Städten im Schlüsselzuweisungsverfahren.

(2) Die Aufteilung der Schlüsselzuweisungen innerhalb des Gesamtkreises auf Zentralkreis und Gemeinden kann - unabhängig vom Verteilungsschlüssel - nur vorläufigen Charakter haben, weil die Verteilung der Finanzkraft zwischen diesen beiden Ebenen abschließend erst durch die Kreisumlage erfolgt.

(3) Bei aufgabenorientierter Festsetzung der Kreisumlage ergeben sich nach Finanzausgleich sowohl eine angemessene Finanzausstattung von Zentralkreis und Gemeinden insgesamt als auch eine zielkonforme Annäherung der relativen Finanzkraftpositionen auf der Gemeindeebene.

\section{Vergleich zwischen Gesamtkreisen mit unterschiedlicher Finanzkraft}

Die bislang abgeleiteten Ergebnisse deuten nicht auf finanzausgleichspolitisch problematische Eigenschaften des rheinland-pfälzischen Systems. Allerdings liefert Tabelle 1 noch keine Informationen über die Wirkungen des Finanzausgleichs zwischen Gesamtkreisen mit unterschiedlicher Finanzkraft vor Schlüsselzuweisungen B2. Einen solchen Vergleich ermöglicht Tabelle 2, in der die verschiedenen miteinander verzahnten Stufen des Ausgleichsverfahrens am Beispiel eines finanzstarken Gesamtkreises A und eines finanzschwachen Gesamtkreises B analysiert werden.

Gesamtkreis A verfügt vor Schlüsselzuweisungen B2 über eine relative Finanzkraft von $110 \%$, Gesamtkreis B verfügt über $90 \%$. 
Tabelle 2: Vergleich zwischen Gesamtkreisen mit unterschiedlicher Finanzkraft

\begin{tabular}{|l|rr|r|r|rr|r|r|r|}
\hline $\begin{array}{c}\text { Gebietskörper- } \\
\text { schaften }\end{array}$ & \multicolumn{2}{|c|}{$\begin{array}{c}\text { Finanzkraft vor } \\
\text { SZW B2 [1] }\end{array}$} & $\begin{array}{r}\text { Finanz- } \\
\text { bedarf }\end{array}$ & SZW B2 & $\begin{array}{r}\text { Finanzkraft nach } \\
\text { SZW B2 }\end{array}$ & $\begin{array}{r}\text { Kreisum- } \\
\text { lage [2] }\end{array}$ & $\begin{array}{c}\text { Finanzkraft nach } \\
\text { Kreisumlage }\end{array}$ \\
\hline & DM/E & FK [3] & DM/E & DM/E & DM/E & FK [3] & DM/E & DM/E & FK [3] \\
\hline Gesamtkreis A & 1.100 & $110,0 \%$ & 1.400 & 150 & 1.250 & $104,2 \%$ & $34,6 \%[4]$ & 1.250 & $104,2 \%$ \\
Zentralkreis A & & & & 104 & 104 & & 397 & 500 & $104,2 \%$ \\
Gemeinden A & 1.100 & $110,0 \%$ & 1.400 & 47 & 1.147 & $108,0 \%$ & -397 & 750 & $104,2 \%$ \\
\hline Gemeinde 1 & 880 & $80,0 \%$ & 1.400 & 81 & 961 & $83,8 \%$ & -332 & 628 & $83,8 \%$ \\
Gemeinde 2 & 1.100 & $100,0 \%$ & 1.400 & 47 & 1.147 & $100,0 \%$ & -397 & 750 & $100,0 \%$ \\
Gemeinde 3 & 1.320 & $120,0 \%$ & 1.400 & 12 & 1.332 & $116,2 \%$ & -461 & 872 & $116,2 \%$ \\
\hline Gesamtkreis B & 900 & $90,0 \%$ & 1.400 & 250 & 1.150 & $95,8 \%$ & $29,4 \%[4]$ & 1.150 & $95,8 \%$ \\
Zentralkreis B & & & & 173 & 173 & & 288 & 460 & $95,8 \%$ \\
Gemeinden B & 900 & $90,0 \%$ & 1.400 & 78 & 978 & $92,0 \%$ & -288 & 690 & $95,8 \%$ \\
\hline Gemeinde 1 & 720 & $80,0 \%$ & 1.400 & 105 & 825 & $84,4 \%$ & -243 & 583 & $84,4 \%$ \\
Gemeinde 2 & 900 & $100,0 \%$ & 1.400 & 78 & 978 & $100,0 \%$ & -288 & 690 & $100,0 \%$ \\
Gemeinde 3 & 1.080 & $120,0 \%$ & 1.400 & 50 & 1.130 & $115,6 \%$ & -332 & 797 & $115,6 \%$ \\
\hline
\end{tabular}

[1] Steuerkraft zuzüglich Schlüsselzuweisungen A. SZW = Schlüsselzuweisungen.

[2] Der Zentralkreis übernimmt $40 \%$ der jeweiligen Gesamtkreisausgaben.

[3] Finanzkraft bezogen auf den Durchschnitt der jeweiligen Gebietskörperschaftsgruppe.

[4] Erforderlicher Kreisumlagesatz zur Finanzierung der Zentralkreisausgaben gemäß [2]. 
Tabelle 2 zeigt zunächst einmal, daß die Schlüsselzuweisungen B2 den Abstand zwischen den beiden Gesamtkreisen in finanzausgleichspolitisch erwünschter Weise reduzieren. Nach Schlüsselzuweisungen B2 belaufen sich die entsprechenden relativen Finanzkraftzahlen auf 104,2 \% bzw. 95,8 \%. Eine Voll- oder gar Übernivellierung auf der Ebene der Gesamtkreise ist bei einem Ausgleichssatz von $50 \%$ natürlich ausgeschlossen.

Interessant ist nun der Blick auf die Zentralkreise, die $69 \%$ der jeweiligen Schlüsselzuweisungen an die Gesamtkreise erhalten. Da sich die Zuweisungen an der Differenz zwischen Finanzbedarf und kreisdurchschnittlicher Finanzkraft orientieren, erhalten die Zentralkreise in finanzstarken Gesamtkreisen relativ geringe und die Zentralkreise in finanzschwachen Gesamtkreisen relativ hohe Schlüsselzuweisungen. Die Schlüsselzuweisungen verhalten sich also umgekehrt proportional zur Finanzkraft der Gesamtkreise vor Schlüsselzuweisungen. Anders ausgedrückt: Je höher die Steuerkraft, desto geringer ist zwangsläufig der Anspruch auf Schlüsselzuweisungen $\mathrm{B} 2$.

Eine Nivellierungsprüfung auf der Ebene der Zentralkreise und der Schlüsselzuweisungen B2 ist im rheinland-pfälzischen System des kommunalen Finanzausgleichs schon deshalb nicht sinnvoll, weil aussagefähige Kennzahlen, wie sie für Gesamtkreise oder für Gemeinden vorliegen, für Zentralkreise nicht gebildet werden können. Deshalb kann auch keine vernünftige Aussage darüber getroffen werden, ob und inwieweit die Schlüsselzuweisungen B2 eine Annäherung oder gar Umkehrung der Finanzkraftrangfolge der Zentralkreise bewirken (vgl. dazu die Auseinandersetzung mit der "Übernivellierungsthese" in Kapitel D.3.).

Auf der Gemeindeebene führen die Schlüsselzuweisungen wiederum zu den erwünschten Verteilungseffekten. Im Durchschnitt 
gewinnen die Gemeinden des „armen" Gesamtkreises: Ihre Finanzkraft steigt von 90 auf $92 \%$, während die relative Finanzkraft der Gemeinden des "reichen“ Landkreises von 110 auf $108 \%$ sinkt. Zwischen den Gemeinden eines Gesamtkreises kommt es ebenfalls zu einer Annäherung der Finanzkraftpositionen durch die Schlüsselzuweisungen, die im finanzschwachen Gesamtkreis B etwas stärker ausfällt als im finanzstarken Gesamtkreis A.

Bei der Regulierung der Finanzkraft zwischen Zentralkreis und kreisangehörigen Gemeinden mit Hilfe der Kreisumlage ergeben sich aus der Verteilung der Schlüsselzuweisungen notwendigerweise unterschiedliche Kreisumlagesätze. Bei gleichem Ausgabenanteil der Zentralkreise kommt der überdurchschnittlich mit Schlüsselzuweisungen ausgestattete Zentralkreis B mit einer deutlich geringeren Kreisumlage aus, wenn er den Umlagesatz so festlegt, daß sein Anteil an der Finanzkraft des Gesamtkreises seinem Aufgaben- und Ausgabenanteil entspricht. Die Werte einer in diesem Sinne korrekt bemessenen Kreisumlage belaufen sich in der Modellrechnung auf 34,6\% für den Landkreis A und $29,4 \%$ für den Landkreis $B$.

Unter Verwendung der korrekten Umlagesätze ergibt sich nach Finanzausgleich, daß Zentralkreis und Gemeinden insgesamt jeweils über die gleiche relative Finanzkraft verfügen. Beide Ebenen sind folglich gleichmäßig an einer über- bzw. unterdurchschnittlichen Finanzkraft ihres Gesamtkreises beteiligt (104,2 \% bzw. 95,8 \%). Da eine proportionale Kreisumlage die relativen Positionen der kreisangehörigen Gemeinden nicht berührt, bleibt es unter den Gemeinden bei der durch die Schlüsselzuweisungen bewirkten Annäherung der Positionen.

Aufgrund der Modellrechnungen ergeben sich folgende Schlußfolgerungen: 
(1) Das rheinland-pfälzische System bewirkt auf der Ebene der Gesamtkreise eine zielgerechte Annäherung der Finanzkraftpositionen. Eine Voll- oder Übernivellierung ist dabei ausgeschlossen.

(2) Zentralkreise in finanzschwachen Gesamtkreisen erhalten zwangsläufig höhere Schlüsselzuweisungen als Zentralkreise in finanzstarken Gesamtkreisen. Diese Systemeigenschaft ist finanzausgleichspolitisch von nachrangiger Bedeutung, da mit den Schlüsselzuweisungen eine abschließende Regelung der Finanzausstattung der Zentralkreise weder beabsichtigt noch möglich ist.

(3) Mittels der Kreisumlage wird die Finanzkraft zwischen Zentralkreis und Gemeinden reguliert. Geschieht dies in zielkonformer Weise unter Berücksichtigung der Aufgabenverteilung, so partizipieren der Zentralkreis und seine Gemeinden nach Finanzausgleich gleichmäßig an der im Gesamtkreis vorhandenen Finanzkraft.

(4) Auch innerhalb der Gruppe der kreisangehörigen Gemeinden bewirkt das System per saldo einen Ausgleich im Sinne einer Annäherung der Finanzkraftpositionen. Dabei ist zu berücksichtigen, daß der effektive Finanzbedarf der Gemeinden von ihrem Anteil an den im Gesamtkreis zu erfüllenden Aufgaben abhängt.

\section{Verteilungsschlüssel 69/31 und Finanzkraft kreis- angehöriger Gemeinden}

Im Abschnitt C.1.c. wurde bereits darauf hingewiesen, daß die Distributionswirkungen der Schlüsselzuweisungen im Bereich der kreisangehörigen Gemeinden auch von der Höhe des Gemeindeanteils an diesen Zuweisungen abhängen. Tabelle 3 illustriert die- 
Tabelle 3: Verteilungsschlüssel und Finanzkraft kreisangehöriger Gemeinden

\begin{tabular}{|c|c|c|c|c|c|c|c|c|c|}
\hline \multirow[t]{2}{*}{$\begin{array}{c}\text { Gebietskörper- } \\
\text { schaften }\end{array}$} & \multicolumn{2}{|c|}{$\begin{array}{c}\text { Finanzkraft vor } \\
\text { SZW B2 [1] }\end{array}$} & \multirow{2}{*}{$\begin{array}{r}\begin{array}{c}\text { Finanz- } \\
\text { bedarf }\end{array} \\
\text { DM/E }\end{array}$} & \multirow{2}{*}{$\begin{array}{c}\text { SZW B2 } \\
\mathrm{DM} / \mathrm{E}\end{array}$} & \multicolumn{2}{|c|}{$\begin{array}{c}\text { Finanzkraft nach } \\
\text { SZW B2 }\end{array}$} & \multirow{2}{*}{$\begin{array}{r}\begin{array}{c}\text { Kreisum- } \\
\text { lage [2] }\end{array} \\
\text { DM/E }\end{array}$} & \multicolumn{2}{|c|}{$\begin{array}{c}\text { Finanzkraft nach } \\
\text { Kreisumlage }\end{array}$} \\
\hline & DM/E & FK [3] & & & $\mathrm{DM} / \mathrm{E}$ & FK [3] & & $\mathrm{DM} / \mathrm{E}$ & FK [3] \\
\hline Schlüssel 69/31 & 1.000 & $100,0 \%$ & 1.400 & 200 & 1.200 & $100,0 \%$ & $32,2 \%[4]$ & 1.200 & $100,0 \%$ \\
\hline Zentralkreis & & & & 138 & 138 & & 342 & 480 & $100,0 \%$ \\
\hline Gemeinden & 1.000 & $100,0 \%$ & 1.400 & 62 & 1.062 & $100,0 \%$ & -342 & 720 & $100,0 \%$ \\
\hline Gemeinde 1 & 800 & $80,0 \%$ & 1.400 & 93 & 893 & $84,1 \%$ & -288 & 605 & $84,1 \%$ \\
\hline Gemeinde 2 & 1.000 & $100,0 \%$ & 1.400 & 62 & 1.062 & $100,0 \%$ & -342 & 720 & $100,0 \%$ \\
\hline Gemeinde 3 & 1.200 & $120,0 \%$ & 1.400 & 31 & 1.231 & $115,9 \%$ & -396 & 835 & $115,9 \%$ \\
\hline Schlüssel 40/60 & 1.000 & $100,0 \%$ & 1.400 & 200 & 1.200 & $100,0 \%$ & $35,7 \%[4]$ & 1.200 & $100,0 \%$ \\
\hline Zentralkreis & & & & 80 & 80 & & 400 & 480 & $100,0 \%$ \\
\hline Gemeinden & 1.000 & $100,0 \%$ & 1.400 & 120 & 1.120 & $100,0 \%$ & -400 & 720 & $100,0 \%$ \\
\hline Gemeinde 1 & 800 & $80,0 \%$ & 1.400 & 180 & 980 & $87,5 \%$ & -350 & 630 & $87,5 \%$ \\
\hline Gemeinde 2 & 1.000 & $100,0 \%$ & 1.400 & 120 & 1.120 & $100,0 \%$ & -400 & 720 & $100,0 \%$ \\
\hline Gemeinde 3 & 1.200 & $120,0 \%$ & 1.400 & 60 & 1.260 & $112,5 \%$ & -450 & 810 & $112,5 \%$ \\
\hline
\end{tabular}

[1] Steuerkraft zuzüglich Schlüsselzuweisungen A. SZW = Schlüsselzuweisungen.

[2] Der Zentralkreis übernimmt $40 \%$ der jeweiligen Gesamtkreisausgaben.

[3] Finanzkraft bezogen auf den Durchschnitt der jeweiligen Gebietskörperschaftsgruppe.

[4] Erforderlicher Kreisumlagesatz zur Finanzierung der Zentralkreisausgaben gemäß [2]. 
sen Sachverhalt anhand einer Modellrechnung mit dem praktizierten Schlüssel 69/31 und einem alternativen, an der Ausgabenquote orientierten Schlüssel 40/60 für denselben Gesamtkreis.

Gemessen am Schlüssel 69/31 verursacht der Schlüssel 40/60 zunächst eine Senkung der Schlüsselzuweisungen an den Zentralkreis bei entsprechender Aufstockung des Zuweisungsvolumens für die Gemeinden. Vergleicht man die relative Finanzkraft der Gemeinden nach Schlüsselzuweisungen, so zeigt sich, daß diese bei Verwendung des Schlüssels 40/60 näher beieinanderliegen. Der Grund dafür ist einfach: Die Gemeinden erhalten nun $60 \%$ von der Hälfte der Differenz zwischen Finanzbedarf und Finanzkraft (in DM pro Einwohner) durch Schlüsselzuweisungen; zuvor waren es nur $31 \%$.

Der höhere Anteil der Gemeinden an den Schlüsselzuweisungen geht allerdings mit einem höheren Kreisumlagesatz einher, denn der Zentralkreis muß nun verstärkt auf die Kreisumlage zurückgreifen, um einen unveränderten aufgabengerechten Anteil an der Finanzkraft des Gesamtkreises zu erhalten. Die höhere Kreisumlage korrigiert den "Vorteil" eines höheren Gemeindeanteils an den Schlüsselzuweisungen für die Gemeinden insgesamt. Erhalten bleibt jedoch der stärkere Nivellierungseffekt zwischen den kreisangehörigen Gemeinden. In der Modellrechnung reduzieren sich die Finanzkraftdifferenzen ausschließlich infolge der Verwendung des anderen Schlüssels von einer Spanne zwischen 84,1\% und $115,9 \%$ auf eine Spanne zwischen $87,5 \%$ und $112,5 \%$.

Eindeutig zu beurteilen sind diese Auswirkungen einer Veränderung des Verteilungsschlüssels 69/31 nicht, da ein Maßstab für die Sachgerechtigkeit der Nivellierungseffekte im Gemeindebereich - abgesehen vom hier nicht verletzten Übernivellierungsverbot - nicht existiert. Ein solcher Maßstab ließe sich nur gewinnen, wenn es möglich wäre, den Teil der Ausgleichseffekte zu bestim- 
men, der auf der Gemeindeebene ankommen und nicht bei den Zentralkreisen „versickern" soll. Am ehesten in Betracht zu ziehen wäre in diesem Zusammenhang noch der jeweilige Anteil an den gesamten Kreisausgaben. Da dieser Anteil jedoch zwischen den Landkreisen variiert, könnte man für praktische Zwecke nur mit einer Durchschnittsgröße operieren. Der Kreisumlage würde dann weiterhin die Aufgabe zufallen, die Finanzkraftverteilung im Gesamtkreis aufgabenorientiert zu regulieren.

Man muß sich allerdings darüber im klaren sein, daß eine stärker an den Aufgabenanteilen orientierte Schlüsselgröße für die Finanzzuweisungen generell den Anteil der Zentralkreise senken und damit den Umlagebedarf erhöhen würde. Finanzpsychologisch vorteilhaft wäre dies nicht, weil den Gemeinden zunächst mehr gegeben, anschließend aber auch mehr genommen würde. Die ohnehin von vielen Gemeinden als belastend empfundene Kreisumlage würde noch mehr an Gewicht gewinnen, was den latenten Konflikt zwischen Zentralkreisen und Gemeinden verschärfen und damit den Finanzbeziehungen im Gesamtkreis schaden könnte.

\section{Unterschiede in der Aufgabenverteilung zwischen Zentralkreis und Gemeinden}

Bislang wurde für Vergleichszwecke von einem gegebenen Anteil der Zentralkreise an den Gesamtkreisausgaben ausgegangen. Schon unter dieser Voraussetzung hat sich gezeigt, daß ein angemessener, an den jeweiligen Aufgaben orientierter kommunaler Finanzausgleich ohne entsprechenden Einsatz der Kreisumlage nicht erreicht werden kann. Dies gilt erst recht unter Berücksichtigung unterschiedlicher Aufgabenverteilungen innerhalb der Gesamtkreise. 
Tabelle 4 zeigt den Zusammenhang zwischen Kreisumlage und Aufgabenverteilung zwischen dem Zentralkreis und seinen Gemeinden. Die beiden Landkreise $A$ und $B$ unterscheiden sich einzig und allein darin, daß der Zentralkreis A $45 \%$, der Zentralkreis $B$ jedoch nur $35 \%$ der Gesamtkreisausgaben zu übernehmen hat. Bei der Verteilung der Schlüsselzuweisungen erhalten die beiden Zentralkreise das gleiche Pro-Kopf-Volumen, was den Zentralkreis $B$ relativ begünstigt. Diesen Vorteil muß er jedoch in Form einer geringeren Kreisumlage seinen Gemeinden zurückerstatten, denn sein „korrekter" Umlagesatz liegt bei 26,6\% gegenüber dem deutlich höheren Wert des Zentralkreises A mit 37,9\%.

Die erheblichen Differenzen bei der Kreisumlage sind erforderlich, um den in der Modellrechnung ebenso erheblichen Unterschieden in den Ausgabenanteilen gerecht zu werden. Sie sorgen dafür, daß Zentralkreis $A$ nach Erhebung der Kreisumlage eine überdurchschnittliche Finanzkraft (112,5\%) aufweist, seine Gemeinden dagegen eine unterdurchschnittliche $(91,7 \%)$. Umgekehrt verhält es sich bei Zentralkreis B $(87,5 \%)$ und seinen Gemeinden $(108,3 \%)$. Bezogen auf inren unterschiedlichen Finanzbedarf bleibt die relative Finanzkraft der Gemeinden dabei übrigens unberührt, $d$. h. die Kreisumlage verhält sich trotz der Niveauunterschiede in dieser Hinsicht weiterhin neutral.

Angesichts der in Tabelle 4 aufgezeigten Abhängigkeit der Kreisumlage von der Aufgabenverteilung im Gesamtkreis verbietet sich ein isolierter Vergleich der Finanzkraftzahlen für die Zentralkreise oder für die Gemeinden. Aussagefähig sind diese Zahlen nur vor dem Hintergrund der in den einzelnen Zentralkreisen vorliegenden spezifischen Bedingungen.

Beispielsweise verfügt Gemeinde $A 3$ vor Schlüsselzuweisungen B2 über eine Finanzkraft von 1.200 DM pro Einwohner, nach Finanzausgleich aber nur noch über $765 \mathrm{DM}$. Gemeinde $\mathrm{B} 2$ mit ei- 
Tabelle 4: Unterschiede in der Aufgabenverteilung zwischen Zentralkreis und Gemeinden

\begin{tabular}{|c|c|c|c|c|c|c|c|c|c|}
\hline \multirow[t]{2}{*}{$\begin{array}{c}\text { Gebietskörper- } \\
\text { schaften }\end{array}$} & \multicolumn{2}{|c|}{$\begin{array}{c}\text { Finanzkraft vor } \\
\text { SZW B2 [1] }\end{array}$} & \multirow{2}{*}{$\begin{array}{r}\begin{array}{r}\text { Finanz- } \\
\text { bedarf }\end{array} \\
\mathrm{DM} / \mathrm{E}\end{array}$} & \multirow{2}{*}{$\frac{\text { SZW B2 }}{\text { DM/E }}$} & \multicolumn{2}{|c|}{$\begin{array}{c}\text { Finanzkraft nach } \\
\text { SZW B2 }\end{array}$} & \multirow{2}{*}{$\begin{array}{r}\begin{array}{c}\text { Kreisum- } \\
\text { lage [2] }\end{array} \\
\text { DM/E }\end{array}$} & \multicolumn{2}{|c|}{$\begin{array}{c}\text { Finanzkraft nach } \\
\text { Kreisumlage }\end{array}$} \\
\hline & $D M / E$ & FK [3] & & & $\mathrm{DM} / \mathrm{E}$ & FK [3] & & $D M / E$ & FK [3] \\
\hline Gesamtkreis A & 1.000 & $100,0 \%$ & 1.400 & 200 & 1.200 & $100,0 \%$ & $37,9 \%[4]$ & 1.200 & $100,0 \%$ \\
\hline Zentralkreis A & & & & 138 & 138 & & 402 & 540 & $112,5 \%$ \\
\hline Gemeinden A & 1.000 & $100,0 \%$ & 1.400 & 62 & 1.062 & $100,0 \%$ & -402 & 660 & $91,7 \%$ \\
\hline Gemeinde 1 & 800 & $80,0 \%$ & 1.400 & 93 & 893 & $84,1 \%$ & -338 & 555 & $84,1 \%$ \\
\hline Gemeinde 2 & 1.000 & $100,0 \%$ & 1.400 & 62 & 1.062 & $100,0 \%$ & -402 & 660 & $100,0 \%$ \\
\hline Gemeinde 3 & 1.200 & $120,0 \%$ & 1.400 & 31 & 1.231 & $115,9 \%$ & -466 & 765 & $115,9 \%$ \\
\hline Gesamtkreis B & 1.000 & $100,0 \%$ & 1.400 & 200 & 1.200 & $100,0 \%$ & $26,6 \%[4]$ & 1.200 & $100,0 \%$ \\
\hline Zentralkreis B & & & & 138 & 138 & & 282 & 420 & $87,5 \%$ \\
\hline Gemeinden B & 1.000 & $100,0 \%$ & 1.400 & 62 & 1.062 & $100,0 \%$ & -282 & 780 & $108,3 \%$ \\
\hline Gemeinde 1 & 800 & $80,0 \%$ & 1.400 & 93 & 893 & $84,1 \%$ & -237 & 656 & $84,1 \%$ \\
\hline Gemeinde 2 & 1.000 & $100,0 \%$ & 1.400 & 62 & 1.062 & $100,0 \%$ & -282 & 780 & $100,0 \%$ \\
\hline Gemeinde 3 & 1.200 & $120,0 \%$ & 1.400 & 31 & 1.231 & $115,9 \%$ & -327 & 904 & $115,9 \%$ \\
\hline
\end{tabular}

[1] Steuerkraft zuzüglich Schlüsselzuweisungen A. SZW = Schlüsselzuweisungen.

[2] Zentralkreis A übernimmt $45 \%$, Zentralkreis B übernimmt $35 \%$ der Gesamtkreisausgaben.

[3] Finanzkraft bezogen auf den Durchschnitt der jeweiligen Gebietskörperschaftsgruppe.

[4] Erforderlicher Kreisumlagesatz zur Finanzierung der Zentralkreisausgaben gemäß [2]. 
ner Ausgangsfinanzkraft von $1.000 \mathrm{DM}$ pro Einwohner hat nach Kreisumlage dagegen noch $780 \mathrm{DM}$. Scheinbar wurden hier die Finanzkraftrelationen auf den Kopf gestellt. Tatsächlich bedeuten 765 DM für Gemeinde A 3 jedoch, daß sie zu den überdurchschnittlich finanzstarken Gemeinden zählt, denn diesem Betrag stehen nur $660 \mathrm{DM}$ an durchschnittlicher Pro-Kopf-Finanzkraft gegenüber. Die 780 DM für Gemeinde B 2 entsprechen dagegen gerade dem Durchschnitt, der in Landkreis $B$ höher liegt, weil der Zentralkreis weniger Ausgaben an sich gezogen hat.

Im Hinblick auf die Ausgleichseffekte innerhalb der Gesamtkreise läßt sich zusammenfassend festhalten:

(1) Das Ausmaß der Nivellierungseffekte im Bereich der kreisangehörigen Gemeinden variiert mit dem Schlüssel für die Finanzzuweisungen: Je größer der Anteil der Zentralkreise, desto geringer die Ausgleichseffekte zwischen den Gemeinden. Dieser Tatbestand spricht grundsätzlich dafür, den Schlüssel 69/31 zu modifizieren, sofern eine stärkere Nivellierung auf der Gemeindeebene angestrebt wird.

(2) Eine Erhöhung des Anteils der Gemeinden an den Schlüsselzuweisungen impliziert einen Anstieg der durchschnittlichen Kreisumlagesätze zur Kompensation der den Zentralkreisen entstehenden Einnahmenverluste. Dies ist angesichts der inzwischen erreichten Höhe der Umlagesätze finanzpolitisch als problematisch einzustufen, denn die Spannungen zwischen Gemeinden und Zentralkreisen dürften tendenziell zunehmen.

(3) Differenzen zwischen den Kreisumlagesätzen können einerseits auf der Anfangsausstattung der Zentralkreise mit Schlüsselzuweisungen, andererseits auf unterschiedlichen Aufgabenverteilungen im Gesamtkreis beruhen. Zentrale Funktion der Kreisumlage ist es, unter Berücksichtigung dieser Unter- 
schiede eine sachgerechte Verteilung der verfügbaren Mittel im Gesamtkreis herbeizuführen. Die Modellrechnungen belegen, daß dies mittels einer proportionalen Kreisumlage ohne Rückgriff auf Splitting und Progression möglich ist.

(4) Auch innerhalb der Gesamtkreise hat das rheinland-pfälzische System bei zielkonformem Einsatz der Kreisumlage keine Voll- oder gar Übernivellierungseffekte zur Folge. Diese erweisen sich bei den Zentralkreisen als Resultat einer unangemessenen Verkürzung der Betrachtung auf eine Stufe des Ausgleichsverfahren, die erst in Verbindung mit der folgenden Stufe ein Gesamturteil erlaubt. Zum anderen können Fehlurteile darauf basieren, daß bei einem Vergleich zwischen Gemeinden, die unterschiedlichen Kreisen angehören, die Differenzen in der Aufgabenverteilung zwischen Zentralkreis und Gemeinden vernachlässigt werden. 


\section{Auseinandersetzung mit der Kritik am kommunalen Finanzausgleich in Rheinland-Pfalz}

Die Darstellung und Analyse des Zusammenwirkens von Kreisumlage und Schlüsselzuweisungen im rheinland-pfälzischen Finanzausgleich ermöglicht eine finanzwissenschaftliche Würdigung der gegen das System vorgetragenen Kritik. Die folgenden Überlegungen orientieren sich insbesondere an den Einwänden, die das Oberverwaltungsgericht Rheinland-Pfalz in seinem Beschluß vom 26.11.1996 im Verwaltungsrechtsstreit des Landkreises Germersheim gegen das Land Rheinland-Pfalz geäußert hat ${ }^{1}$, und an dem diesem Beschluß zugrunde liegenden Gutachten zur Problematik der Schlüsselzuweisungen, das von $\mathrm{G}$. Färber für den Landkreis Germersheim erstellt wurde?

\section{Zur Lösbarkeit der Ausgleichsaufgabe in einem Schritt}

In den meisten Bundesländern erfolgt die Verteilung der Schlüsselmasse zunächst auf die verschiedenen Gebietskörperschaftsgruppen nach gesetzlich festgelegten Prozentsätzen. Bis 1977 wurde auch in Rheinland-Pfalz so verfahren: Die "drei Säulen" des Systems - kreisangehörige Gemeinden, kreisfreie und große kreisangehörige Städte sowie Landkreise (Zentralkreise) - erhielten je einen "Topf" in Höhe von 49,2 \%, 13,6 \% bzw. 37,2 \% der Schlüsselmasse (Stand seit 1.1.1974). Aus diesen Töpfen wurden dann die den einzelnen Mitgliedern einer Gruppe zustehenden Schlüsselzuweisungen vergeben.

1 Vgl. Vorlagebeschluß des 7. Senats des Oberverwaltungsgerichts Koblenz ( $A z$ 7 A 12002/93.OVG); im folgenden zitiert als "OVG-Beschluß".

2 Vgl. G. Färber, Schlüsselzuweisungen an die Landkreise im kommunalen Finanzausgleich von Rheinland Pfalz, Gutachten, Hannover 1994; im folgenden zitiert als "Färber-Gutachten“. 
Das Verfahren macht Sinn, wenn der Pro-Kopf-Bedarf zwischen den Gruppen als unterschiedlich angesehen wird. Geht man jedoch - wie das rheinland-pfälzische System - vom "Einwohner = Einwohner"-Prinzip aus, so entfällt diese Begründung für ein getrenntes Vorgehen. Im Gegenteil: Die Verwirklichung des Prinzips erfordert die Einbeziehung aller Gemeinden und Gemeindeverbände in ein einheitliches Verteilungssystem, das die funktionelle Gliederung im Kreisbereich in Rechnung stellt.

Gegen die Abkehr vom "Drei-Säulen-System" wird nun jedoch eingewandt, daß ein horizontaler, konsistenter Finanzausgleich in einem einzigen Schritt nicht erreichbar sei. Es sei „... mathematisch unlösbar, zwei nicht harmonische Ziele, nämlich die Aufteilung der Gesamtmasse zwischen den Ebenen Landkreise und Gemeinden einerseits sowie die Abbildung der relativen Finanzkraftreihenfolge innerhalb dieser Ebenen gemäß der vorhandenen effektiven Finanzkraft andererseits in einem einzigen geschlossenen Rechensystem widerspruchsfrei zu erfüllen ..." (OVG-Beschluß, S. 51). Diese These ist im Hinblick auf das Problem der Verteilung der Schlüsselzuweisungen irreführend und bezogen auf den gesamten Finanzausgleich unhaltbar.

Die Verteilung der Schlüsselzuweisungen dient nicht der abschließenden Regelung der Finanzausstattung der Zentralkreise und ihrer Gemeinden. Folglich kann auf dieser Stufe des Finanzausgleichs ein widerspruchsfreies Ergebnis weder erwartet werden, noch ist es erforderlich, um eine insgesamt konsistente Lösung herbeizuführen. Wie im folgenden noch näher begründet wird, könnte auch ein Drei-Säulen-System das Verteilungsproblem zwischen Zentralkreisen und Gemeinden nicht besser bewältigen.

Unter Berücksichtigung einer problemgerecht eingesetzten Kreisumlage führt das rheinland-pfälzische System insgesamt zu ver- 
tretbaren und widerspruchsfreien Ergebnissen. Wie die Modellrechnungen belegen, lassen sich diese Ergebnisse durchaus in einem einzigen, durch die Kreisumlage geschlossenen Rechensystem erzielen. Das System umfaßt allerdings alle relevanten Ausgleichsbeziehungen und vermeidet dadurch irreführende Schlußfolgerungen, die sich nur bei einer Verkürzung der Ausgleichsaufgabe auf die Schlüsselzuweisungen ableiten lassen.

Die gegen das "Ein-Topf-Modell“ gerichtete Kritik fällt vollends in sich zusammen, wenn man das System und seine Wirkungen mit dem traditionellen Verfahren vergleicht. Beide Modelle haben das gleiche Problem zu lösen, nämlich die anteilige Zurechnung der Finanzkraft und des Finanzbedarfs im Gesamtkreis auf Gemeinden und Zentralkreis. Die Unterschiede liegen in der Vorgehensweise und den erforderlichen Zwischenschritten, weniger im Ergebnis des Ausgleichsverfahrens. Damit verbunden sind einige relative Vor- und Nachteile, die aber keineswegs eine klare Präferenz für eines der Verfahren begründen können.

Der rheinland-pfälzische Finanzausgleich hat den Vorteil, daß er die Gesamtkreise untereinander und gegenüber den kreisfreien Städten bei der Verteilung der Schlüsselzuweisungen gleich behandelt. Dies ist nicht zuletzt die Folge des Verzichts auf ein gestuftes Verfahren bei der Verteilung der Zuweisungen. Würde man die Schlüsselmasse im ersten Schritt auf die verschiedenen Gebietskörperschaftsgruppen aufteilen und im zweiten Schritt die jeweiligen Töpfe nach Finanzbedarf an kreisfreie Städte, Zentralkreise und Gemeinden ausschütten, so wäre eine Gleichbehandlung im oben angesprochenen Sinne nicht mehr automatisch gewährleistet.

Erhalten beispielsweise die Zentralkreise einen Topf, der zu einer gemessen am durchschnittlichen Aufgabenanteil der Zentralkreise zu hohen Dotierung mit Schlüsselzuweisungen führt, so muß der 
Topf für die kreisangehörigen Gemeinden entsprechend schlechter gefüllt werden, um eine Benachteiligung der kreisfreien Städte auszuschließen. Auch in diesem Fall ergibt sich innerhalb der Gesamtkreise die Notwendigkeit einer nachträglichen Korrektur über die Kreisumlage. Sie muß im Durchschnitt geringer sein, als es bei aufgabenorientierter Bedienung der Töpfe der Fall wäre, um den Nachteil der Gemeinden bei den Schlüsselzuweisungen auszugleichen.

Der Bedarf an einem kompensierenden Einsatz der Kreisumlage kann nur dann minimiert - nicht völlig beseitigt - werden, wenn es bei der Aufteilung der Schlüsselmasse auf die drei Säulen gelingt, den durchschnittlichen Finanzbedarf der den einzelnen Säulen zugehörigen Körperschaften genau zu treffen. Gerade für Zentralkreise und kreisangehörige Gemeinden macht das Schwierigkeiten, weil der Bedarf dieser Gebietskörperschaften von der Aufgabenverteilung zwischen ihnen bestimmt wird, die zudem häufigen Veränderungen unterworfen ist. Verschieben sich die Aufgabenund damit die Finanzbedarfsrelationen, so müssen im Drei-Säulen-System die auf die einzelnen Säulen entfallenden Quoten genauso angepaßt werden wie es im rheinland-pfälzischen Ein-TopfSystem über die Kreisumlage geschieht. Der Anpassungsbedarf verlagert sich nur auf einen anderen Mechanismus, welcher - bei identischen Ausgleichszielen - so eingesetzt werden muß, daß per saldo die gleichen Ergebnisse nach Finanzausgleich eintreten.

Weitere Schwierigkeiten kommen ins Spiel, wenn man realistischerweise davon ausgeht, daß die Aufgabenverteilung innerhalb der Gesamtkreise unterschiedlich ist. Beispielsweise kann der Zentralkreis des Gesamtkreises A mehr Aufgaben übernehmen und damit im Vergleich zu seinen Gemeinden einen höheren Finanzbedarf aufweisen als der Zentralkreis des Gesamtkreises B 
(vgl. Abschnitt C.6.). In diesem Fall führt die im Drei-Säulen-System notwendige, aber hier eben nicht zutreffende Unterstellung, daß alle Zentralkreise denselben Finanzbedarf pro Einwohner haben, dazu, daß die Zentralkreise mit überdurchschnittlich vielen Aufgaben und entsprechend überdurchschnittlichem Finanzbedarf zu geringe Schlüsselzuweisungen empfangen. Im Idealfall - aber keineswegs notwendigerweise - erhalten ihre Gemeinden zum Ausgleich zu hohe Schlüsselzuweisungen. Sofern dieser Effekt überhaupt korrigiert werden kann, ist dies wiederum nur über die Kreisumlage möglich, die also auch im Drei-Säulen-System ihren Charakter als aktives und unentbehrliches Instrument des Finanzausgleichs nicht verlieren würde.

Die bisherigen Überlegungen basieren auf der Voraussetzung gegebener und identischer Ausgleichsziele. Denkbar wäre in einem System mit Vorabaufteilung der Schlüsselmasse auch, daß die Verteilung der für die Zentralkreise bestimmten Mittel nach anderen Kriterien vorgenommen wird als die Verteilung der für die kreisangehörigen Gemeinden bestimmten Mittel. Dies hätte jedoch zwangsläufig eine Ungleichbehandlung zwischen den Gesamtkreisen zur Folge. Vermeiden lassen sich solche Verzerrungen bei der Verteilung der Schlüsselzuweisungen nach dem Finanzbedarf nur, wenn die Summe der Zuweisungen der Differenz zwischen kreisdurchschnittlichem Finanzbedarf und durchschnittlicher Finanzkraft multipliziert mit dem Ausgleichssatz entspricht. Dies ist im rheinland-pfälzischen System der Fall, wäre aber in einem Drei-Säulen-System nicht ohne weiteres gewährleistet.

Eine problemgerechte Orientierung am Finanzbedarf der Gesamtkreise würde im Drei-Säulen-System zweierlei implizieren: (1) Die Summe der Schlüsselzuweisungen an Zentralkreise und kreisangehörige Gemeinden muß so bemessen werden, daß die Gesamtkreise gegenüber den kreisfreien Städten weder bevorzugt noch 
benachteiligt sind. (2) Die Verteilung der jeweiligen Töpfe auf die Gebietskörperschaftsgruppen hat so zu erfolgen, daß Gesamtkreise mit gleicher Finanzkraft per saldo gleich hohe Zuweisungen nach dem Finanzbedarf erhalten.

Ein solches Drei-Säulen-System würde sich vom rheinland-pfälzischen Finanzausgleich nicht grundlegend unterscheiden. Bei einer Vorabverteilung der dem kreisangehörigen Bereich zufließenden Schlüsselmasse im Verhältnis 69 zu 31 gäbe es überhaupt keine Differenzen. Eine andere Vorabverteilung hätte dieselben Folgen wie ein entsprechend modifizierter Verteilungsschlüssel im rheinland-pfälzischen System. Dies unterstreicht noch einmal die prinzipielle Gleichwertigkeit der Verfahren bei übereinstimmenden Zielen, zeigt aber auch, daß die Problematik des Verteilungsschlüssels durch eine Rückkehr zum Drei-Säulen-System nicht einfach entfällt.

Unter Berücksichtigung dieser Zusammenhänge spricht nichts für die These von der grundsätzlichen Überlegenheit eines mehrstufigen Verfahrens bei der Verteilung der Schlüsselzuweisungen nach dem Finanzbedarf. Ein schrittweises Vorgehen mag auf den ersten Blick transparenter sein und das (Schein-) Problem der Übernivellierung zwischen den Zentralkreisen zum Verschwinden bringen. Dies darf jedoch nicht über die materielle Gleichwertigkeit der Verfahren hinwegtäuschen, die sich bei gegebenen Ausgleichszielen und dementsprechender Gestaltung der Ausgleichsinstrumente einstellen muß. Auch aus dem Blickwinkel der praktischen Umsetzung kann das Drei-Säulen-System keine gravierenden Vorteile reklamieren. Im Gegenteil: Es bedarf schon einer sehr flexiblen, den sich wandelnden Aufgabenverhältnissen angepaßten Handhabung der Töpfe, wenn mit dem heutigen System vergleichbare Ergebnisse erzielt werden sollen. 
Schließlich ist darauf hinzuweisen, daß die mathematische Lösbarkeit der Ausgleichsaufgaben nicht verbessert oder gar erst gewährleistet werden kann, indem man sie auf zwei Rechensysteme verteilt. Werden diese nicht miteinander verzahnt, so fällt die Lösung auf jeder Stufe isoliert gesehen möglicherweise leichter, aber es ergeben sich mit großer Wahrscheinlichkeit Verzerrungen, die - im Gegensatz zum rheinland-pfälzischen Modell nicht relativ einfach kreisintern zu korrigieren sind. Erfolgt aber die notwendige Verzahnung in konsequenter Weise, dann bleibt die scheinbare Vereinfachung des Problems aus, denn der horizontale Finanzausgleich muß dann faktisch die jeweils auf einer Stufe eintretenden Distributionswirkungen so aufeinander abstimmen, wie es auch bei einer Lösung mit einem gemeinsamen Topf erforderlich ist. Hinzu kommt, daß auch ein Drei-Säulen-System die Ausgleichsaufgabe nicht abschließend, $d$. h. ohne weitere Korrekturen mittels der Kreisumlage bewältigen kann.

\section{Die Kreisumlage als Instrument des kreisinternen Finanzausgleichs}

Im Streit um den rheinland-pfälzischen Finanzausgleich spielt die Funktion der Kreisumlage eine herausragende Rolle. Finanzausgleichspolitisch vertretbare Ergebnisse kommen nur zustande, wenn die Kreisumlage als flexibles Instrument der Verteilung der Finanzkraft im Gesamtkreis herangezogen werden kann. Sie dient dann einer aufgabenorientierten Mittelverteilung unter Berücksichtigung der durch die Schlüsselzuweisungen entscheidend mitbestimmten Finanzkraft von Zentralkreis und Gemeinden.

Eine sachgerechte Verteilung der im Gesamtkreis vorhandenen Finanzkraft wäre allerdings nicht zu gewährleisten, wenn man der Kreisumlage die genannten Funktionen nicht zubilligen dürfte. In diesem Zusammenhang sind zwei Aspekte zu diskutieren: 
(1) Die Kreisumlage würde als Instrument des flexiblen kreisinternen Ausgleichs weitgehend ausfallen, wenn man ihr nur die Funktion der "Feinsteuerung" im Finanzausgleich zugestehen könnte (vgl. OVG-Beschluß, S. 40).

(2) Die Kreisumlage hätte auch dann keine umfassenden Regulierungsfunktionen, wenn sie nur Unterschiede in der Aufgabenteilung, nicht aber Unterschiede im Bereich der Schlüsselzuweisungen reflektieren dürfte.

Der zweite Aspekt kommt ins Spiel, wenn man unterstellt, daß der Gesetzgeber die Verteilung der Finanzkraft im Gesamtkreis mit der Festlegung des Verteilungsschlüssels für die Zuweisungen nach dem Finanzbedarf abschließend regeln wollte. Diese Vorstellung steht darüber hinaus hinter den Überlegungen zur "effektiven Finanzkraft" der Zentralkreise, die von einem landesdurchschnittlichen und damit festgeschriebenen Umlagesatz ausgehen (vgl. Färber-Gutachten, S. 30), welcher allein erst einen sachgerechten Vergleich zwischen den Zentralkreisen ermögliche und auch nicht mit dem Ziel einer nachträglichen Korrektur der Schlüsselzuweisungen geändert werden dürfe.

\section{a. „Feinsteuerung" versus aufgabenorientierte Finanz- kraftregulierung}

Im preußischen Finanzausgleich hatte die Kreisumlage die Funktion eines Spitzenausgleichs. Sie diente der Finanzierung von Ausgaben, die weder durch eigene Steuern noch durch staatliche Zuschüsse gedeckt waren. Diese Spitzenausgleichsfunktion ist heute nicht mehr gegeben. Über $30 \%$ der gesamten Zentralkreiseinnahmen entfallen auf die Kreisumlage. Schon aufgrund ihrer quantitativen Bedeutung für die Finanzierung der Kreisausgaben ist sie daher nicht als Restposten, sondern als tragende Säule des Kreisfinanzsystems anzusehen. 
Der Zentralkreis partizipiert mit der Kreisumlage an den allgemeinen Deckungsmitteln der Gemeinden und schränkt natürlich deren Betätigungsfeld ein. Infolgedessen wird die Kreisumlage im Finanzverbund zwischen Gemeinden und Kreisen zwangsläufig zu einem Instrument der Regelung der Finanzausstattung beider Ebenen, das mit dem Ziel einer aufgabengerechten Verteilung knapper Finanzmittel zwischen Zentralkreis und Gemeinden eingesetzt werden muß. Dies ist die Haupt- und nicht etwa die Restfunktion der Kreisumlage im Finanzausgleich, die sie in jedem Fall - unabhängig vom Einfluß anderer Instrumente des Finanzausgleichs auf den kreisinternen Ausgleichsbedarf - zu erfüllen hat. In diesem Zusammenhang von einer "Feinsteuerung" zu sprechen, geht an der quantitativen und qualitativen Funktion der Kreisumlage vorbei.

Anders zu beurteilen als der Ausgleich zwischen Zentralkreis und Gemeinden (fiskalische Funktion) ist ein weitergehender distributiver Einsatz der Kreisumlage mit dem Ziel eines Abbaus von Finanzkraftunterschieden zwischen den kreisangehörigen Gemeinden. Eine proportionale, alle Umlagegrundlagen gleichmäßig belastende Kreisumlage ist in dieser Hinsicht neutral, reicht jedoch aus, um die Hauptaufgabe der Finanzkraftregulierung zwischen Kreis und Gemeinden zu erfüllen. Ob und inwieweit die Kreisumlage in den Dienst darüber hinausgehender Verteilungszwecke gestellt werden sollte, kann daher im vorliegenden Zusammenhang weitgehend außer Betracht bleiben.

Der rheinland-pfälzische Finanzausgleich sieht allerdings entsprechende Möglichkeiten vor. Die Umlagesätze können für die einzelnen Umlagegrundlagen verschieden hoch angesetzt werden (Splitting). Daneben besteht die Möglichkeit einer progressiven Staffelung der Umlagesätze für überdurchschnittlich finanzstarke Gemeinden. Aus finanzwissenschaftlicher Sicht sind beide Mög- 
lichkeiten nicht unproblematisch1, doch richtet sich die Kritik daran nicht gegen die hier in Rede stehende fiskalische Funktion einer proportionalen Kreisumlage.

Allenfalls durch die Hintertür lassen sich Splitting und Progression ins Spiel bringen, nämlich mit dem Argument, Zentralkreise mit einem geringen Anspruch auf Schlüsselzuweisungen könnten sich die erforderlichen und ihren Aufgaben angemessenen Mittel nicht über eine proportionale Umlage beschaffen. So bezweifelt Färber die Sachgerechtigkeit des Finanzausgleichsgesetzes mit der Behauptung, charakteristisch für das System sei eine „erzwungene" Höherbelastung finanzstarker Gemeinden bei der Kreisumlage (vgl. Färber-Gutachten, S. 62). Damit konzediert sie zwar die prinzipielle Berechtigung eines dem kreisinternen Finanzausgleich dienenden Einsatzes einer proportionalen Kreisumlage, bestreitet aber dessen Realisierbarkeit in der praktischen Politik. Auf diesen Aspekt wird an späterer Stelle noch zurückzukommen sein (vgl. Abschnitt D.3.c.).

\section{b. Berücksichtigung der Schlüsselzuweisungen im kreis- internen Finanzausgleich}

Aus finanzwissenschaftlicher Sicht spricht nichts gegen eine aufgabenorientierte Ausbalancierung der im Gesamtkreis vorhandenen Finanzkraft mittels der Kreisumlage. Wird dies zugestanden, so gibt es kaum noch einen überzeugenden Grund, die Berücksichtigung der Schlüsselzuweisungen in diesem Zusammenhang abzulehnen. Im Gegenteil: Der Umlagebedarf eines Zentralkreises ist bei gleicher Aufgabenverteilung von seiner Finanzausstattung vor der Umlageerhebung und mithin von der Verteilung der Schlüsselzuweisungen determiniert. Auf die Berücksichtigung der

1 Vgl. K. Littmann, Über das Elend kommunaler Umlagen, Schriftenreihe der Hochschule für Verwaltungswissenschaften Speyer, Bd. 122, S. $363 \mathrm{ff}$. 
Schlüsselzuweisungen könnte nur verzichtet werden, wenn sich deren Verteilung so gestalten ließe, daß kein Korrekturbedarf innerhalb des Gesamtkreises entsteht.

Die Behauptung, der Gesetzgeber habe über den Verteilungsschlüssel eine abschließende Regelung beabsichtigt, hilft hier nicht weiter. Erstens kann sie vor dem Hintergrund der Entstehungsgeschichte des rheinland-pfälzischen Finanzausgleichsgesetzes nicht überzeugen, denn der Schlüssel wurde primär unter dem Aspekt des rekurrenten Anschlusses an das alte Drei-Säulen-System gewählt. Zweitens ist darauf hinzuweisen, daß ein Verteilungsschlüssel, der eine abschließende Regelung zum Ziel hätte, im Prinzip an der durchschnittlichen Aufgabenverteilung innerhalb der Gesamtkreise anknüpfen müßte. Davon ist der Schlüssel 69/31 so weit entfernt, daß dem Gesetzgeber kaum unterstellt werden kann, er hätte den nach Schlüsselzuweisungen verbleibenden Anpassungsbedarf nicht erkannt und damit bewußt in Kauf genommen, daß die endgültige Regelung den betroffenen Gebietskörperschaften selbst überlassen werden muß.

Gewichtiger erscheint der Einwand, der Gesetzgeber müsse schon auf der Ebene der Schlüsselzuweisungen darauf achten, die Notwendigkeit einer nachträglichen Korrektur zu vermeiden oder doch zu minimieren. Diese Forderung erscheint einsichtig, aber zwingend ist sie nur, wenn ein angemessener kreisinterner Finanzausgleich anders nicht erreicht werden kann. Wie die Analyse des rheinland-pfälzischen Systems gezeigt hat, trifft dieser Befund jedoch nicht zu; es sei denn, man hindert die Zentralkreise an einer systemkonformen Festsetzung der Kreisumlage mit Blick auf ihren Aufgabenanteil und die vorhandene Ausstattung mit Schlüsselzuweisungen (und anderen Einnahmen).

Dies scheint auch die Intention der Überlegungen von G. Färber in ihrem Gutachten für den Landkreis Germersheim zu sein. Dort 
wird argumentiert, es sei bei der Prüfung der Ausgleichseffekte der Schlüsselzuweisungen auf der Ebene der Zentralkreise alleine vertretbar, die effektive Finanzkraft der Zentralkreise an landesdurchschnittlichen und damit festgeschriebenen Umlagesätzen zu messen (vgl. Färber-Gutachten, S. 30). Wichtig ist diese methodische Vorgehensweise insbesondere für die Ableitung von "Übernivellierungseffekten“ auf der Ebene der Zentralkreise, die im folgenden Abschnitt noch genauer analysiert werden. Deren Bedeutung steht und fällt jedoch mit den Funktionen, welche der Kreisumlage zuerkannt werden. Die These von der Funktionswidrigkeit einer flexibel und korrigierend eingesetzten Kreisumlage ist daher weniger als eigenständiger Einwand, sondern vor allem als notwendige Stütze für die "Übernivellierungsthese" zu interpretieren. Überzeugender wird sie dadurch nicht.

\section{3. „Übernivellierung“ bei den Zentralkreisen durch Schlüsselzuweisungen?}

Gegen das rheinland-pfälzische Finanzausgleichsgesetz wird vor allem eingewandt, daß die Verteilung der Schlüsselzuweisungen im Verhältnis 69/31 auf der Ebene der Zentralkreise zu Übernivellierungseffekten führe, die finanzausgleichspolitisch nicht zu rechtfertigen und auch verfassungswidrig seien. Das Färber-Gutachten kommt diesbezüglich zu folgendem Ergebnis: „Der Ansatz von $70 \%$ der gemeindlichen Steuerkraft sowie von $70 \%$ der Schlüsselzuweisungen A (heute jeweils $69 \%$; d. V.) in der Kreisfinanzkraft bei durchschnittlich effektiv nur ca. $30 \%$ Kreisumlagebelastung der kreisangehörigen Gemeinden rechnet den Kreisen Finanzkraft an, über die sie nicht verfügen. Dieser Ansatz bewirkt die Übernivellierung der Kreisfinanzkraft durch Schlüsselzuweisungen B2" (Färber-Gutachten, S. 53). 
Im folgenden wird zunächst der methodische Ansatz zur Begründung der Übernivellierungsthese dargestellt und anhand einer Modellrechnung nachvollzogen. Anschließend erfolgt eine kritische Auseinandersetzung mit den Einwänden gegenüber dem rheinland-pfälzischen Finanzausgleich, die aus der Übernivellierungsthese abgeleitet werden. Dabei geht es auch um die Behauptung, die Vertauschung der Finanzkraftreihenfolge der Zentralkreise könne nicht ohne negative Folgen über höhere Kreisumlagesätze kompensiert werden (vgl. Färber-Gutachten, S. 72).

\section{a. Übernivellierungseffekte auf der Ebene der Zentralkreise?}

Die Behauptung des Färber-Gutachtens und des OVG-Beschlusses, das rheinland-pfälzische Verfahren der Verteilung der Schlüsselzuweisungen führe zu einer Übernivellierung der Finanzkraftdifferenzen zwischen den Zentralkreisen, basiert auf einem Vergleich der Situation der Zentralkreise vor und nach Schlüsselzuweisungen. Da die Zentralkreise - von der quantitativ unbedeutenden Grunderwerbsteuer abgesehen - über eine tatsächliche Finanzkraft (Steuerkraft) vor Finanzausgleich nicht verfügen, kann man innen vor Finanzausgleich allenfalls eine fiktive Finanzkraft zurechnen, die Färber als "effektive" Finanzkraft der Landkreise (Zentralkreise) bezeichnet.

Bei der Messung dieser fiktiven Finanzkraft der Zentralkreise vor Finanzausgleich ist es nach Färber „... alleine vertretbar, ihren Umlagebedarf zu landesdurchschnittlichen Umlagesätzen anzusetzen" (Färber-Gutachten, S. 30). Die fiktive Finanzkraft der Zentralkreise vor Finanzausgleich ist also definiert als Produkt aus dem landesdurchschnittlichen Umlagesatz und den im Gesamtkreis vorhandenen Umlagegrundlagen.

Die Verwendung solcher "Umlagekraftmeßzahlen", die bei den Gemeindeverbänden an Stelle einer Steuerkraftmeßzahl treten, 
ist durchaus üblich, wenn es um die Verteilung von Schlüsselzuweisungen aus einem speziellen Topf für die Zentralkreise geht. Im rheinland-pfälzischen Finanzausgleich ist ein solches Vorgehen jedoch weder beabsichtigt noch möglich. Die Verwendung von Umlagekraftmeßzahlen ist diesem System fremd.

Über den Umfang der dem Gesamtkreis zufließenden Schlüsselzuweisungen entscheiden in finanzausgleichspolitisch sinnvoller Weise Finanzkraft und Finanzbedarf des Gesamtkreises. Die Zuteilung auf Zentralkreis und kreisangehörige Gemeinden erfolgt dann nach dem Schlüssel 69/31, ohne daß damit eine abschliessende Regelung beabsichtigt wäre. Diese ist vielmehr über die Kreisumlage und mit Blick auf die kreisspezifische Aufgabenteilung von den lokalen Gebietskörperschaften selbst vorzunehmen, und zwar mit Hilfe eines flexiblen, nicht festgeschriebenen Umlagesatzes.

Tabelle 5 illustriert die Ableitung von „Übernivellierungseffekten“ entsprechend der Vorgehensweise von Färber - unter Verwendung fiktiver Finanzkraftzahlen für die Zentralkreise. Diese resultieren aus dem durchschnittlichen Umlagesatz der beiden Landkreise A und B $(32,2 \%)$ multipliziert mit der Finanzkraft der Gemeinden nach Schlüsselzuweisungen. Schon daran kann man Kritik üben, denn in den Umlagegrundlagen sind die Schlüsselzuweisungen an die Gemeinden enthalten, und die fiktive Finanzkraft der Zentralkreise hängt infolgedessen von der Verteilung der Schlüsselzuweisungen $a b$, zu deren Beurteilung diese Kennzahlen dienen sollen.

Nach dem Färber-Verfahren ergibt sich in Spalte 5 der Tabelle rechnerisch eine Übernivellierung des Zentralkreises A, der hinter den Zentralkreis B zurückfällt. Genauer ausgeführt: Vor Schlüsselzuweisungen $B 2$ weist die Modellrechnung eine fiktive Finanzkraft in Höhe von 369 DM pro Einwohner für den Zentralkreis A 
Tabelle 5: „Übernivellierung“ bei den Zentralkreisen durch Schlüsselzuweisungen?

\begin{tabular}{|c|c|c|c|c|c|c|c|c|c|}
\hline \multirow[t]{2}{*}{$\begin{array}{c}\text { Gebietskörper- } \\
\text { schaften }\end{array}$} & \multicolumn{2}{|c|}{$\begin{array}{c}\text { Finanzkraft vor } \\
\text { SZW B2 [1] }\end{array}$} & \multirow{2}{*}{$\begin{array}{r}\begin{array}{r}\text { Finanz- } \\
\text { bedarf }\end{array} \\
\text { DM/E }\end{array}$} & \multirow{2}{*}{$\begin{array}{c}\text { SZW B2 } \\
\mathrm{DM} / \mathrm{E}\end{array}$} & \multicolumn{2}{|c|}{$\begin{array}{c}\text { Finanzkraft nach } \\
\text { SZW B2 }\end{array}$} & \multirow{2}{*}{$\begin{array}{r}\begin{array}{c}\text { Kreisum- } \\
\text { lage [2] }\end{array} \\
\text { DM/E }\end{array}$} & \multicolumn{2}{|c|}{$\begin{array}{c}\text { Finanzkraft nach } \\
\text { Kreisumlage }\end{array}$} \\
\hline & $\mathrm{DM} / \mathrm{E}$ & FK [3] & & & $\mathrm{DM} / \mathrm{E}$ & FK [3] & & DM/E & FK [3] \\
\hline Gesamtkreis A & 1.100 & $110,0 \%$ & 1.400 & 150 & 1.250 & $104,2 \%$ & $34,6 \%[4]$ & 1.250 & $104,2 \%$ \\
\hline Zentralkreis $\mathrm{A}$ & 369 & $108,0 \%$ & & 104 & 473 & $98,5 \%$ & 397 & 500 & $104,2 \%$ \\
\hline Gemeinden A & 1.100 & $110,0 \%$ & 1.400 & 47 & 1.147 & $108,0 \%$ & -397 & 750 & $104,2 \%$ \\
\hline Gemeinde 1 & 880 & $80,0 \%$ & 1.400 & 81 & 961 & $83,8 \%$ & -332 & 628 & $83,8 \%$ \\
\hline Gemeinde 2 & 1.100 & $100,0 \%$ & 1.400 & 47 & 1.147 & $100,0 \%$ & -397 & 750 & $100,0 \%$ \\
\hline Gemeinde 3 & 1.320 & $120,0 \%$ & 1.400 & 12 & 1.332 & $116,2 \%$ & -461 & 872 & $116,2 \%$ \\
\hline Gesamtkreis B & 900 & $90,0 \%$ & 1.400 & 250 & 1.150 & $95,8 \%$ & $29,4 \%[4]$ & 1.150 & $95,8 \%$ \\
\hline Zentralkreis B & 315 & $92,0 \%$ & & 173 & 487 & $101,5 \%$ & 288 & 460 & $95,8 \%$ \\
\hline Gemeinden B & 900 & $90,0 \%$ & 1.400 & 78 & 978 & $92,0 \%$ & -288 & 690 & $95,8 \%$ \\
\hline Gemeinde 1 & 720 & $80,0 \%$ & 1.400 & 105 & 825 & $84,4 \%$ & -243 & 583 & $84,4 \%$ \\
\hline Gemeinde 2 & 900 & $100,0 \%$ & 1.400 & 78 & 978 & $100,0 \%$ & -288 & 690 & $100,0 \%$ \\
\hline Gemeinde 3 & 1.080 & $120,0 \%$ & 1.400 & 50 & 1.130 & $115,6 \%$ & -332 & 797 & $115,6 \%$ \\
\hline
\end{tabular}

[1] Steuerkraft zuzüglich Schlüsselzuweisungen A. SZW = Schlüsselzuweisungen.

[2] Zentralkreis A übernimmt $40 \%$ der jeweiligen Gesamtkreisausgaben.

[3] Finanzkraft bezogen auf den Durchschnitt der jeweiligen Gebietskörperschaftsgruppe.

[4] Erforderlicher Kreisumlagesatz zur Finanzierung der Zentralkreisausgaben gemäß [2]. 
und $315 \mathrm{DM}$ pro Einwohner für den Zentralkreis $\mathrm{B}$ aus. Diese Zahlen bilden - etwas abgeschwächt durch die Einbeziehung der Schlüsselzuweisungen an die Gemeinden - die Finanzkraftreihenfolge der Gesamtkreise vor Schlüsselzuweisungen B2 ab. Der Zentralkreis A verfügt dann über $108 \%$, der Zentralkreis $B$ über $92 \%$ der durchschnittlichen (fiktiven) Finanzkraft dieser Gebietskörperschaftsgruppe.

Addiert man nun die tatsächlich an die Zentralkreise fließenden Zuweisungen und diese fiktiven Finanzkraftzahlen, so ergeben sich (ebenfalls fiktive) Finanzkraftzahlen nach Schlüsselzuweisungen B2. Sie belaufen sich im Modell auf 473 DM pro Einwohner für den Zentralkreis A sowie 487 DM pro Einwohner für den Zentralkreis B. Die Finanzkraftreihenfolge hat sich - gemessen an den fiktiven Werten - umgekehrt: Zentralkreis $A$ verfügt nur noch über $98,5 \%$, Zentralkreis $B$ hingegen über $101,5 \%$ der durchschnittlichen Finanzkraft der Körperschaftsgruppe.

Die Modellrechnung macht aber auch deutlich, daß die errechnete Übernivellierung entfällt, wenn man auf die sachlich nicht vertretbare Verwendung einer am Landesdurchschnitt der Kreisumlage orientierten fixen und damit ausgleichsunfähigen Finanzkraft vor Finanzausgleich verzichtet. Wird stattdessen eine im Finanzausgleich ermittelte, den Schlüsselzuweisungen B2 angepaßte Kreisumlage einsetzt, so stellt sich nämlich nach Abschluß des gesamten Finanzausgleichs die ursprüngliche Finanzkraftreihenfolge mit 104,2 \% für Zentralkreis A und 95,8 \% für Zentralkreis B ein (Spalte 6). Infolgedessen gilt: Wenn man die finanzwissenschaftlich begründete Deutung der Kreisumlage als ein aktives und flexibles Element des Finanzausgleichs akzeptiert, dann ist die Behauptung, das rheinland-pfälzische Finanzausgleichsgesetz bewirke durch $\S 10$ Abs. 3 und $\S 11$ Abs. 2 Übernivellierungen bei den Zentralkreisen, nicht aufrechtzuerhalten. 
Vor diesem Hintergrund stellt sich die Frage, ob das Färber-Verfahren zur Beurteilung der Distributionswirkungen des rheinlandpfälzischen Finanzausgleichs überhaupt geeignet erscheint. Dagegen sprechen folgende Überlegungen:

(1) Im rheinland-pfälzischen System basiert das tatsächliche Aufkommen der Kreisumlage in starkem Maße auf Faktoren, die erst durch den Finanzausgleich geschaffen werden. Dies betrifft sowohl die Umlagegrundlagen, in denen die Schlüsselzuweisungen an die Gemeinden enthalten sind, als auch die jeweiligen Umlagesätze, die nicht nur die Unterschiede in der Aufgabenverteilung, sondern auch die Unterschiede in den Schlüsselzuweisungen der Zentralkreise reflektieren. Der landesdurchschnittliche Umlagesatz, der den fiktiven Finanzkraftzahlen zugrundeliegt, ist mithin eine finanzausgleichsabhängige Größe, was seine Eignung als "Normierungsfaktor" erheblich beeinträchtigt.

(2) Da sich die Finanzkraft der Zentralkreise vor Finanzausgleich nicht finanzausgleichsunabhängig bestimmen läßt, ist der Versuch sinnlos, eine entsprechende Finanzkraftrangfolge zu ermitteln. Hinzu kommt, daß die Finanzkraftrangfolge nach Verteilung der Schlüsselzuweisungen nur unter der Voraussetzung einer (jedenfalls hinsichtlich einer Korrektur der Zuweisungseffekte) festgeschriebenen Kreisumlage mit der endgültigen Finanzkraftrangfolge übereinstimmt.

Somit drängt sich der Eindruck auf, daß hier ein Verfahren gewählt wurde, mit dessen Hilfe auf einer Stufe des Finanzausgleichs Übernivellierungseffekte konstruiert werden können, die nur deshalb problematisch erscheinen, weil man die nächste Stufe des Finanzausgleichs - die systemkonform eingesetzte Kreisumlage - nicht berücksichtigen will. 


\section{b. Probleme einer Gegensteuerung mittels der Kreisumlage}

Die Übernivellierungsthese erweist sich bei Einbeziehung der Kreisumlage in die Beurteilung des Ausgleichsverfahrens als unzutreffend. Man könnte allenfalls darauf verweisen, daß die Kreisumlage faktisch nicht so flexibel sei, wie es zur Herstellung einer aufgabengerechten Verteilung der Finanzkraft innerhalb der Gesamtkreise erforderlich wäre. Die Frage nach den Grenzen der Kreisumlage als Instrument des Finanzausgleichs muß daher gestellt und diskutiert werden.

Die Kreisumlage kann immer nur eine Umverteilung der dem Gesamtkreis zur Verfügung stehenden Finanzkraft bewirken. Es wurde gezeigt, daß der rheinland-pfälzische Finanzausgleich auf der Ebene der Gesamtkreise in geradezu idealer Weise funktioniert, denn er gewährleistet eine Gleichbehandlung zwischen Gesamtkreisen und kreisfreien Städten sowie eine erwünschte und begrenzte Nivellierung zwischen unterschiedlich finanzstarken Gesamtkreisen (vgl. Kapitel C.3. und C.4.).

Daraus ergibt sich eine erste wesentliche Schlußfolgerung: Die "Begünstigung" der Zentralkreise in finanzschwachen Gesamtkreisen bei der Verteilung der Schlüsselzuweisungen wird durch eine entsprechende "Benachteiligung" der Gemeinden auf der Gesamtkreisebene aufgewogen. Umgekehrt verfügen die Zentralkreise finanzstarker Gesamtkreise über relativ geringere Schlüsselzuweisungen, denen entsprechend höhere Schlüsselzuweisungen ihrer Gemeinden gegenüberstehen.

Wenn nun die Zentralkreise finanzstarker Gesamtkreise einen relativ höheren Kreisumlagesatz beschließen, um ihre Finanzausstattung ihrem aufgabenbedingten Finanzbedarf anzupassen, so kann darin auf keinen Fall eine Benachteiligung der kreisangehörigen Gemeinden als Gruppe gesehen werden. Diese geben viel- 
mehr über die Kreisumlage nur zurück, was sie - gemessen an ihrem Finanzbedarf - zuviel erhalten haben. Im Durchschnitt kann es also auch nicht zu einem übermäßigen Eingriff in die Finanzhoheit der kreisangehörigen Gemeinden kommen.

Damit ist allerdings noch nicht gesagt, daß auch die einzelnen Gemeinden von einer relativ höheren Kreisumlage nicht übermäßig belastet werden. Die Modellrechnungen belegen aber auch in dieser Hinsicht das Gegenteil. So zeigt Tabelle 5 (S. 71), daß innerhalb der Gruppe der kreisangehörigen Gemeinden trotz unterschiedlicher Kreisumlagesätze die Finanzkraftunterschiede durch den gesamten Finanzausgleich abgebaut werden. Man mag die Ausgleichseffekte auf der Gemeindeebene gemessen am Nivellierungsziel als zu gering einstufen und aus diesem Grund für einen höheren Gemeindeanteil an den Schlüsselzuweisungen plädieren (vgl. Abschnitt C.5.), aber das betrifft eine hier nicht zu diskutierende politische Entscheidung.

Unzutreffend ist jedoch die These von Färber, ein Verstoß gegen das Gebot der Gleichbehandlung sei deshalb anzunehmen, weil der Finanzausgleich in Rheinland-Pfalz dazu führe, daß die finanzschwachen Gemeinden eines finanzstarken Gesamtkreises schlechter behandelt würden als vergleichbare Gemeinden eines finanzstarken Gesamtkreises (vgl. Färber-Gutachten, S. 72). Der folgende Sachverhalt bildet den Hintergrund dieser Überlegung.

Der Verteilungsschlüssel 69/31 bewirkt, daß die Zentralkreise in den finanzstarken Gesamtkreisen relativ weniger Schlüsselzuweisungen B2 erhalten als die Zentralkreise in den finanzschwachen Gesamtkreisen. Sie müssen deshalb - bei gleichen Ausgabenanteilen der Zentralkreise - stärker als jene auf die Finanzierung über die Kreisumlage zurückgreifen. Das kann dazu führen, daß in verschiedenen Gesamtkreisen gelegene Gemeinden, welche vor Schlüsselzuweisungen B2 absolut - gemessen an den DM- 
pro-Einwohner-Werten - finanzkraftgleich waren, nach Finanzausgleich unterschiedlich ausgestattet sind.

Diese Mechanik betrifft aber nicht nur die finanzschwachen, sondern in gleicher Weise die finanzstarken Gemeinden unterschiedlicher Gesamtkreise. Immerhin kann man konzedieren, daß die finanzschwachen Gemeinden deshalb stärker betroffen sind als die finanzstarken, weil der Verteilungsschlüssel 69/31 gegenüber einem "gemeindefreundlicheren" Schlüssel die finanzstarken Gemeinden eines Gesamtkreises begünstigt (vgl. Kapitel C.5.).

Was die Bewertung des Sachverhaltes unter dem Maßstab der "Gleichbehandlung" angeht, so ist zu betonen, daß sich dieser Maßstab nur auf Vergleichbares anwenden läßt. Es stellt sich also die Frage, ob Gemeinden, welche verschiedenen Gesamtkreisen angehören, überhaupt vergleichbar sind. Zu bejahen wäre das grundsätzlich nur, wenn die Rahmenbedingungen, unter welchen diese Gemeinden operieren - insbesondere auch die Art der Aufgabenverteilung zwischen Zentralkreis und Gemeinden - identisch sein sollten. Davon kann man jedoch keinesfalls ausgehen.

Insbesondere verbietet sich eine Gegenüberstellung der absoluten DM-pro-Einwohner-Werte, weil dabei unberücksichtigt bleibt, daß die einander gegenübergestellten Gemeinden Gliedkörperschaften von Gesamtkreisen sind, deren Finanzkraft und finanzielle Binnenstruktur ( $u$. U. erheblich) differieren. Diese Unterschiede darf man bei einem Vergleich über die Kreisgrenzen hinweg nicht außer acht lassen. Jeder Zentralkreis erfüllt zusammen mit seinen kreisangehörigen Gemeinden die kommunalen Aufgaben. Eine zwangsläufige Folge dieser Verbindung zwischen den kreisangehörigen Gemeinden und ihrem Zentralkreis ist die Teilhabe und Beteiligung an den relativen Vor- und Nachteilen des jeweiligen Gesamtkreises, insbesondere auch soweit sie auf einer überbzw. unterdurchschnittlichen Finanzkraft beruhen. 
Da sich die Position einer Gemeinde primär in Bezug auf ihre lokale Gemeinschaft definiert, kann die Forderung nach Gleichbehandlung im Finanzausgleich nur bedeuten, daß Gemeinden, welche vor Schlüsselzuweisungen B2 einen gleich großen Anteil an der Finanzkraft ihres Gesamtkreises hatten, auch nach Finanzausgleich bzw. nach Kreisumlage insoweit annähernd gleich ausgestattet sein müssen. Der Vergleich muß daher auf die relative Finanzkraft abstellen, nicht auf die in absoluten DM-pro-Einwohner-Werten gemessene absolute Finanzkraft.

Tabelle 5 (S. 71) illustriert auch die Wirkungen des Ausgleichsverfahrens auf die relativen Finanzkraftpositionen. Betrachtet man beispielsweise die finanzschwachen Gemeinden A 1 und B 1, welche vor Finanzausgleich jeweils über $80 \%$ der kreisdurchschnittlichen Finanzkraft verfügen, so führt der Finanzausgleich nach Verteilung der Schlüsselzuweisungen B2 und der darauf abgestimmten Kreisumlage zu einer Erhöhung der relativen Finanzkraft von A 1 auf $83,8 \%$ und von B 1 auf $84,4 \%$ des Kreisdurchschnitts. Gemessen an der relativen Finanzkraft liegen die beiden für einen Vergleich relevanten Gemeinden also nur um 0,6 Prozentpunkte auseinander. Ihre Anteile sind immer noch fast gleich groß, so daß der Forderung nach Gleichbehandlung der Gemeinden im Finanzausgleich entsprochen wird.

Nur wenn man den Vergleich anhand der relativen Finanzkraft vor Schlüsselzuweisungen B2 durchführt, wird die gewachsene finanzielle Binnenordnung der beiden Kreise so geachtet, wie dies der Respekt vor einer autonomen Gebietskörperschaft im Finanzausgleich verlangt. Das ist nicht der Fall, wenn man den Finanzausgleich so beurteilt, als gäbe es die Kreise mit ihren unterschiedlichen finanziellen Strukturen nicht, sondern lediglich aus diesen Strukturen herausgelöste Gemeinden und Zentralkreise. Ob dies noch verfassungsmäßig ist, mag dahingestellt sein. Jedenfalls 
korrespondiert der Vergleich der relativen Finanzkraftzahlen eher mit dem Autonomiegedanken als die isolierte und daher irreführende Sicht der Gemeinden unabhängig von den Besonderheiten ihrer lokalen Gemeinschaft.

Um Mißverständnissen vorzubeugen, sei noch einmal betont, daß der rheinland-pfälzische Finanzausgleich die im Grundsatz zu erhaltende finanzielle Binnenstruktur der Landkreise respektiert und dennoch - den finanzausgleichspolitischen Zielen entsprechend die kreisinternen Finanzkraftunterschiede in gewissem Umfang abbaut. In der Tabelle 5 variieren die relativen Finanzkraftpositionen der Gemeinden vor Schlüsselzuweisungen B2 jeweils zwischen $80 \%$ und $120 \%$. Diese Spanne reduziert sich - bei proportionaler und damit verteilungsneutraler Kreisumlage - durch die Verteilung der Schlüsselzuweisungen B2 auf Werte zwischen $83,8 \%$ und $116,2 \%$ für den finanzstarken Gesamtkreis $A$ bzw. auf Werte zwischen $84,4 \%$ und $115,6 \%$ für den finanzschwachen Gesamtkreis B. Mithin ist das Finanzkraftgefälle nach Finanzausgleich sowohl im Gesamtkreis $A$ als auch im Gesamtkreis $B$ kleiner geworden. Der Nivellierungseffekt des Finanzausgleichs auf der Gemeindeebene fällt dabei in einem finanzschwachen Landkreis etwas stärker aus als in einem finanzstarken Landkreis.

Allerdings sind diese Unterschiede zum einen so gering, daß sie eine finanzpolitische Kritik kaum rechtfertigen können, zumal die relativ finanzschwachen Gemeinden des finanzstarken Gesamtkreises $\mathrm{A}$ immer noch eine vergleichsweise höhere absolute $\mathrm{Fi}$ nanzkraft aufweisen als diejenigen des Gesamtkreises B. Zum anderen gibt es auch keinen Anlaß zu solcher Kritik, denn die stärkere Ausgleichsintensität in finanzschwachen Landkreisen läßt sich durchaus plausibel mit dem Hinweis auf die dort stärkeren Anforderungen an die Solidarität der Kommunen rechtfertigen. 
Hinzu kommt, daß die hier in Rede stehenden Differenzen auch bei Verwendung eines anderen Schlüssels für die Aufteilung der Schlüsselzuweisungen B2 auf Zentralkreise und Gemeinden nicht verschwinden würden. Selbst wenn dieser Schlüssel der tatsächlichen Aufgabenteilung entspricht, bleibt es bei der etwas schwächeren Nivellierungsintensität im finanzstärkeren Gesamtkreis A. Tabelle 6 zeigt für den modellmäßig aufgabengerechten Schlüssel 40/60, daß die Finanzkraftspanne der Gemeinden nach Finanzausgleich im finanzstarken Landkreis $A$ zwischen $87,1 \%$ und $112,9 \%$ und im finanzschwachen Landkreis B zwischen $88,0 \%$ und $112,0 \%$ liegt.

Festzuhalten bleibt, daß eine proportionale, alle Umlagegrundlagen gleichmäßig belastende Kreisumlage weder die Gemeinden insgesamt, noch die finanzschwachen Gemeinden finanzstarker Gesamtkreise über Gebühr belastet. Eine völlig andere Frage ist es, ob unzumutbare Belastungen infolge der Anwendung von Splitting oder Progression zustande kommen. Diesbezügliche Überlegungen wären aber nur von Interesse, wenn der aufgabenorientierte Einsatz der Kreisumlage die Anwendung von Splitting oder Progression zwingend erforderlich machen würde. Davon kann jedoch - entgegen den Ausführungen im Färber-Gutachten (S. 60 ff.) - keine Rede sein.

Im übrigen widersprechen sich die dort vorgetragenen Thesen (1) von der Benachteiligung finanzsschwacher Gemeinden in finanzstarken Gesamtkreisen und (2) von der Unzulässigkeit einer prozentual stärkeren Belastung finanzstarker Gemeinden (S. 61). Eine proportionale Kreisumlage, die nach These 1 problematisch erscheint, wäre nach These 2 erwünscht und umgekehrt. Letztlich geht dieser Widerspruch auf eine unzulässige Vermischung der Frage nach der angemessenen Regulierung der Finanzkraft zwischen Zentralkreis und Gemeinden (fiskalische Funktion) mit der 
Tabelle 6: Benachteiligung finanzschwacher Gemeinden in finanzstarken Gesamtkreisen?

\begin{tabular}{|c|c|c|c|c|c|c|c|c|c|}
\hline \multirow{2}{*}{$\begin{array}{c}\begin{array}{c}\text { Gebietskörper- } \\
\text { schaften }\end{array} \\
\text { Schlüssel } 40 / 60\end{array}$} & \multicolumn{2}{|c|}{$\begin{array}{c}\text { Finanzkraft vor } \\
\text { SZW B2 [1] }\end{array}$} & \multirow{2}{*}{$\begin{array}{r}\begin{array}{r}\text { Finanz- } \\
\text { bedarf }\end{array} \\
\mathrm{DM} / \mathrm{E}\end{array}$} & \multirow{2}{*}{$\frac{\text { SZW B2 }}{\text { DM/E }}$} & \multicolumn{2}{|c|}{$\begin{array}{c}\text { Finanzkraft nach } \\
\text { SZW B2 }\end{array}$} & \multirow{2}{*}{$\begin{array}{r}\begin{array}{c}\text { Kreisum- } \\
\text { lage [2] }\end{array} \\
\mathrm{DM} / \mathrm{E}\end{array}$} & \multicolumn{2}{|c|}{$\begin{array}{c}\text { Finanzkraft nach } \\
\text { Kreisumlage }\end{array}$} \\
\hline & $\mathrm{DM} / \mathrm{E}$ & FK [3] & & & $\mathrm{DM} / \mathrm{E}$ & FK [3] & & $D M / E$ & FK [3] \\
\hline Gesamtkreis A & 1.100 & $110,0 \%$ & 1.400 & 150 & 1.250 & $104,2 \%$ & $37,0 \%[4]$ & 1.250 & $104,2 \%$ \\
\hline Zentralkreis $\mathrm{A}$ & 425 & $106,3 \%$ & & 60 & 485 & $101,0 \%$ & 440 & 500 & $104,2 \%$ \\
\hline Gemeinden A & 1.100 & $110,0 \%$ & 1.400 & 90 & 1.190 & $106,3 \%$ & -440 & 750 & $104,2 \%$ \\
\hline Gemeinde 1 & 880 & $80,0 \%$ & 1.400 & 156 & 1.036 & $87,1 \%$ & -383 & 653 & $87,1 \%$ \\
\hline Gemeinde 2 & 1.100 & $100,0 \%$ & 1.400 & 90 & 1.190 & $100,0 \%$ & -440 & 750 & $100,0 \%$ \\
\hline Gemeinde 3 & 1.320 & $120,0 \%$ & 1.400 & 24 & 1.344 & $112,9 \%$ & -497 & 847 & $112,9 \%$ \\
\hline Gesamtkreis B & 900 & $90,0 \%$ & 1.400 & 250 & 1.150 & $95,8 \%$ & $34,3 \%[4]$ & 1.150 & $95,8 \%$ \\
\hline Zentralkreis B & 375 & $93,8 \%$ & & 100 & 475 & $99,0 \%$ & 360 & 460 & $95,8 \%$ \\
\hline Gemeinden B & 900 & $90,0 \%$ & 1.400 & 150 & 1.050 & $93,8 \%$ & -360 & 690 & $95,8 \%$ \\
\hline Gemeinde 1 & 720 & $80,0 \%$ & 1.400 & 204 & 924 & $88,0 \%$ & -317 & 607 & $88,0 \%$ \\
\hline Gemeinde 2 & 900 & $100,0 \%$ & 1.400 & 150 & 1.050 & $100,0 \%$ & -360 & 690 & $100,0 \%$ \\
\hline Gemeinde 3 & 1.080 & $120,0 \%$ & 1.400 & 96 & 1.176 & $112,0 \%$ & -403 & 773 & $112,0 \%$ \\
\hline
\end{tabular}

[1] Steuerkraft zuzüglich Schlüsselzuweisungen $A$. SZW = Schlüsselzuweisungen.

[2] Zentralkreis A übernimmt $40 \%$ der jeweiligen Gesamtkreisausgaben.

[3] Finanzkraft bezogen auf den Durchschnitt der jeweiligen Gebietskörperschaftsgruppe.

[4] Erforderlicher Kreisumlagesatz zur Finanzierung der Zentralkreisausgaben gemäß [2]. 
Frage nach eventuell darüber hinausgehenden distributiven Zielen der Kreisumlage zurück.

\section{Die Problematik des Verteilungsschlüssels 69/31}

Im Abschnitt D.3. wurde gezeigt, daß eine Tendenz zur „Übernivellierung" bei den Zentralkreisen nur unter Voraussetzungen abzuleiten ist, die dem Problem nicht gerecht werden. Darüber hinaus lassen sich die Distributionswirkungen der Schlüsselzuweisungen noch im System mittels der Kreisumlage korrigieren. Dennoch könnte es sein, daß der Verteilungsschlüssel 69/31 einen sachgerechten Finanzausgleich zwar nicht verhindert, wohl aber über Gebühr erschwert.

\section{a. Mögliche Einwände gegenüber dem Verteilungsschlüssel $69 / 31$}

Der Verteilungsschlüssel 69/31 entspricht sicher nicht dem Verhältnis der Aufgabenteilung in einem durchschnittlichen Gesamtkreis. Daraus werden allerdings einseitige und daher irreführende Schlußfolgerungen gezogen.

(1) Der Haupteinwand richtet sich darauf, daß die vorgegebene Gewichtung nicht die durchschnittlichen Ausgabenbelastungen berücksichtigt, und korrespondierend dann auch nicht die entsprechenden Relationen der Finanzkraft zutreffend einschätzt, die die Gebietskörperschaftsgruppen im Verhältnis zueinander tatsächlich aufweisen. Die „fehlerhafte Gewichtung" führe auf der Ebene der Landkreise (Zentralkreise) zu Übernivellierungen. Steuerschwache Landkreise würden nach Finanzausgleich über mehr Mittel verfügen als steuerstarke Landkreise (vgl. Färber-Gutachten, S. 35 ff.). Wie in Abschnitt D.3. gezeigt, trifft diese „Übernivellierungsthese" nicht zu, weil 
sie den Finanzausgleich auf die Schlüsselzuweisungen verkürzt und nicht die tatsächlich "nach Finanzausgleich" eintretenden Wirkungen unter Einbeziehung der Kreisumlage zur Beurteilung heranzieht.

(2) Bei grundsätzlicher Akzeptanz der Korrekturfunktion der Kreisumlage könnte man immer noch der Auffassung sein, die durch den Verteilungsschlüssel 69/31 hervorgerufenen Wirkungen seien zu groß, um mit Hilfe der Kreisumlage ausbalanciert zu werden. Auch dieser Einwand kann nicht überzeugen, denn Abweichungen zwischen der durchschnittlichen Aufgabenteilung und dem Schlüssel 69/31 gleichen sich für den Gesamtkreis aus: Was der Zentralkreis zu wenig erhält, haben seine Gemeinden zuviel. Eine überdurchschnittliche Kreisumlage ist also noch kein Indiz für eine übermäßige Belastung der Gemeinden.

(3) Die Verwendung der Kreisumlage im Sinne des fiskalischen Finanzausgleichs geht auch nicht mit einer Ungleichbehandlung der kreisangehörigen Gemeinden einher. Zwar begrenzt der Schlüssel 69/31 gegenüber einer stärker aufgabenorientierten Lösung die Nivellierungseffekte des Finanzausgleichs auf Gemeindeebene, doch ergeben sich daraus keine willkürlichen Differenzen zwischen den Gemeinden, auch dann nicht, wenn sie unterschiedlich finanzstarken Gesamtkreisen angehören.

(4) Ein Rückgriff auf Splitting und/oder Progression bei der Kreisumlage ist nicht erforderlich, um Effekte zu korrigieren, die aus dem Verteilungsschlüssel 69/31 resultieren. Ob diese Möglichkeiten, die auf eine Übertragung distributiver Kompetenzen an die Zentralkreise hinauslaufen, per saldo finanzausgleichspolitisch problematische Wirkungen mit sich brin- 
gen, ist deshalb im vorliegenden Zusammenhang nicht relevant 1 .

\section{b. Zur Begründung des Verteilungsschlüssels 69/31}

Die gegen den „falschen" Schlüssel 69/31 vorgetragenen Einwände rechtfertigen keinesfalls die Ablehnung des rheinland-pfälzischen Systems. Aus finanzwissenschaftlicher Sicht stellt sich jedoch die Frage, ob dieser Schlüssel nicht auch positiv begründet werden kann. Anders ausgedrückt: Welche Eigenschaften muß ein Verteilungsschlüssel aufweisen, der den Bedürfnissen der Zentralkreise wie der kreisangehörigen Gemeinden gleichermassen Rechnung tragen soll? Folgende Kriterien können zur Beurteilung herangezogen werden:

(1) Der Verteilungsschlüssel darf eine aufgabenorientierte Verteilung der Finanzkraft zwischen Zentralkreisen und Gemeinden nicht verhindern.

(2) Die aufgabenorientierte Verteilung sollte wenn möglich schon auf der Ebene der Schlüsselzuweisungen zustande kommen, um den Korrekturbedarf bei der Kreisumlage zu minimieren.

(3) Der Verteilungsschlüssel sollte die Verwirklichung der Finanzausgleichsziele - insbesondere die Annäherung der Finanzkraftpositionen auf der kommunalen Ebene - nicht unnötig erschweren.

(4) Spannungen zwischen Zentralkreis und kreisangehörigen Gemeinden, die sich an der Höhe der Kreisumlage entzünden können, sollten möglichst vermieden werden.

1 Gleiches gilt übrigens für mögliche Kumulationswirkungen der Kreisumlage mit weiteren Umlagen, die bei den Gemeinden erhoben werden. Vgl. G. Färber, Schlüsselzuweisungen an die Landkreise im kommunalen Finanzausgleich von Rheinland Pfalz, Gutachten, Hannover 1994, S. 63 ff. 
Die genannten Kriterien dürften plausibel sein, stehen aber - wie die folgenden Überlegungen zeigen werden - nicht konfliktfrei nebeneinander.

Die geringsten Probleme bereitet das erste Kriterium, das auf das Verhältnis zwischen Zentralkreis und Gemeinden insgesamt bezogen ist. Eine aufgabenorientierte Verteilung der Finanzkraft innerhalb des Gesamtkreises wird durch einen vorgegebenen Schlüssel für die Zuweisungen nicht verhindert. Die Verteilung der Zuweisungen hat zwar Konsequenzen für die Festsetzung der Kreisumlage, doch ist ein sachgerechtes, an der Aufgabenverteilung orientiertes Zusammenspiel dieser Instrumente des Finanzausgleichs stets realisierbar.

Das zweite Kriterium stellt auf die Minimierung des Korrekturbedarfs ab. Hier ist zunächst zu prüfen, inwieweit - bei bestmöglicher Gestaltung - eine aufgabenorientierte Mittelverteilung über die Schlüsselzuweisungen herbeigeführt werden kann. Naheliegend erscheint dabei die Verwendung eines Schlüssels, der sich an der durchschnittlichen Aufgabenverteilung orientiert. Der Kreisumlage würde dann immer noch die Aufgabe zufallen, den nach Schlüsselzuweisungen verbleibenden Finanzbedarf der Zentralkreise unter Berücksichtigung der spezifischen Aufgabenteilung innerhalb des jeweiligen Gesamtkreises zu decken.

Ganz so einfach liegen die Dinge jedoch nicht. Zugunsten einer gemessen an ihrem Aufgabenanteil überdurchschnittlichen Dotierung der Zentralkreise läßt sich anführen, daß diesen vor Finanzausgleich deutlich weniger Finanzierungsmöglichkeiten als den Gemeinden zur Verfügung stehen, weil eigene Einnahmen in nennenswertem Umfang nicht vorhanden sind. Die Finanzkraft der Zentralkreise konstituiert sich erst im Finanzausgleich. Da die Differenz zwischen tatsächlicher Finanzkraft und Finanzbedarf vor Finanzausgleich größer ist als bei den Gemeinden, scheint ein 
überproportionaler Anteil an den Schlüsselzuweisungen durchaus vertretbar zu sein.

Allerdings muß man sehen, daß dann die geschilderten „Übernivellierungseffekte" an Bedeutung gewinnen, denen bei der Festlegung der Kreisumlagesätze Rechnung zu tragen ist. Hinzu kommt die Abschwächung der Nivellierungseffekte zwischen den kreisangehörigen Gemeinden, die mit einem höheren Anteil der Zentralkreise an den Schlüsselzuweisungen einhergeht. Letztlich kommt man an einer Abwägung zwischen den verschiedenen gegenläufigen Effekten nicht vorbei. Dabei sind folgende Aspekte zu beachten:

(1) Ein relativ hoher Anteil der Zentralkreise an den Schlüsselzuweisungen ist mit ihrer unzureichenden Finanzausstattung vor Finanzausgleich begründbar. Er steht einer aufgabenorientierten Verteilung der im Gesamtkreis vorhandenen Finanzkraft nicht entgegen.

(2) Je höher der Anteil der Zentralkreise an den Schlüsselzuweisungen, desto geringer die durchschnittlich erforderliche Kreisumlage. Aus finanzpsychologischen Gründen ist dies ein Vorteil, weil sich die Gemeinden bei einem direkten Zugriff auf ihre Finanzkraft stärker belastet fühlen als durch vorenthaltene Finanzzuweisungen. Die Spannungen zwischen Zentralkreis und Gemeinden werden von dieser Seite her gemindert.

Nicht nachvollziehbar ist daher auch die Aussage von Färber, der in der Vergangenheit beobachtbare Anstieg der Kreisum-

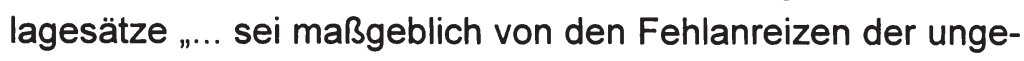
rechtfertigten Steuerkraftanrechnung im kommunalen Finanzausgleich verursacht" (Färber-Gutachten, S. 75). Das Gegenteil - ein im Durchschnitt dämpfender Effekt - wäre zu erwarten gewesen. 
(3) Während ein „zentralkreisfreundlicher" Schlüssel im Hinblick auf die aufgabenorientierte Finanzkraftverteilung und den Abbau der Spannungen im Gesamtkreis vorteilhaft erscheint, läuft er dem Kriterium der Minimierung des nachträglichen Korrekturbedarfs über die Kreisumlage tendenziell zuwider. Zwar reduziert sich der durchschnittliche Umlagesatz, aber die Streuung der Umlagesätze nimmt zu, denn die Zentralkreise finanzstarker Gesamtkreise benötigen bei gleichem Aufgabenanteil überdurchschnittliche Umlagesätze, während die Zentralkreise finanzschwacher Gesamtkreise mit unterdurchschnittlichen Umlagesätzen auskommen. Tendenziell vermindert dieser Effekt auch den unter (2) angeführten finanzpsychologischen Vorteil für die überdurchschnittlich finanzstarken Gesamtkreise.

(4) Ein negativer Zusammenhang besteht schließlich zwischen den Ausgleichszielen auf der kommunalen Ebene und einem hohen Zentralkreisanteil an den Schlüsselzuweisungen, denn die Annäherung der relativen Finanzkraftpositionen zwischen den Gemeinden wird dadurch abgeschwächt. Inwieweit der Zentralkreis in seiner Umlagepolitik (Splitting, Progression) und in seiner Ausgabenpolitik darauf Rücksicht nehmen kann und soll, ist eine offene Frage. Die wünschenswerte Nivellierungsintensität läßt sich jedenfalls nicht bzw. nur in groben Grenzen bestimmen, so daß der „richtige" Verteilungsschlüssel auch mit Hilfe dieses Kriteriums nicht festgelegt werden kann.

Aufgrund dieser Überlegungen gelangt man zu dem Ergebnis, daß der Schlüssel 69/31 aus finanzwissenschaftlicher Sicht weder eindeutig begründet, noch klar verworfen werden kann. Dies mag unbefriedigend sein, reflektiert aber letztlich nur die Tatsache, daß politische Entscheidungsträger einen Spielraum haben müssen, 
wenn verschiedene, teils miteinander nur eingeschränkt kompatible Ziele gegeneinander abzuwägen sind. Mit der gebotenen $\mathrm{Zu}$ rückhaltung kann man allenfalls für eine Überprüfung des Verteilungsschlüssels vor dem Hintergrund der aufgezeigten Wirkungen plädieren, wobei eine den durchschnittlichen Ausgabenanteilen näherkommende Gewichtung in Erwägung zu ziehen wäre.

\section{Das Problem der „Grenzbelastung“ im Finanzausgleich}

Ein Problem (nicht nur) des rheinland-pfälzischen Finanzausgleichs ist die Grenzbelastung der kommunalen Gebietskörperschaften, die sich im Falle eines Anstiegs der kommunalen Steuerkraft aufgrund sinkender Zuweisungsansprüche und steigender Umlageverpflichtungen ergibt. Im Hinblick auf die allokativen Eigenschaften kommunaler Finanzausgleichssysteme sei „... der negative Grenzertrag der Ansiedlung zusätzlicher Gewerbesteuerzahler für die Kreisfinanzen als außerordentlich kritisch anzusehen" (Färber-Gutachten, S. 73). Das Interesse der betroffenen Gebietskörperschaften an der Ansiedlung von Unternehmen und der Pflege der eigenen Wirtschafts- und Steuerkraft kann verloren gehen, wenn ein Anstieg der Steuerkraft der kreisangehörigen Gemeinden per saldo mit Einnahmeverlusten für den Kreishaushalt einhergeht.

Die allokativ begründete Kritik am rheinland-pfälzischen Finanzausgleich läßt sich wiederum anhand einer Modellrechnung nachvollziehen und überprüfen. Die relevanten Daten finden sich in Tabelle 7. Der obere Teil der Tabelle enthält die Ausgangsdaten, der untere Teil zeigt die Wirkungen einer Erhöhung der Steuerkraft der Gemeinde A 1. Folgende Aussagen können getroffen werden:

(1) Der Anstieg der Steuerkraft (um 90 DM pro Einwohner) in der Gemeinde A 1 erhöht die Finanzkraft des Gesamtkreises (um 
Tabelle 7: Das Problem der Grenzbelastung bei wachsender Steuerkraft

\begin{tabular}{|c|c|c|c|c|c|c|c|c|c|}
\hline \multirow[t]{2}{*}{$\begin{array}{c}\text { Gebietskörper- } \\
\text { schaften }\end{array}$} & \multicolumn{2}{|c|}{$\begin{array}{c}\text { Finanzkraft vor } \\
\text { SZW B2 [1] }\end{array}$} & \multirow{2}{*}{$\begin{array}{r}\begin{array}{c}\text { Finanz- } \\
\text { bedarf }\end{array} \\
\text { DM/E }\end{array}$} & \multirow{2}{*}{$\frac{\text { SZW B2 }}{\text { DM/E }}$} & \multicolumn{2}{|c|}{$\begin{array}{c}\text { Finanzkraft nach } \\
\text { SZW B2 }\end{array}$} & \multirow{2}{*}{$\begin{array}{r}\begin{array}{c}\text { Kreisum- } \\
\text { lage [2] }\end{array} \\
\text { DM/E }\end{array}$} & \multicolumn{2}{|c|}{$\begin{array}{c}\text { Finanzkraft nach } \\
\text { Kreisumlage }\end{array}$} \\
\hline & $\mathrm{DM} / \mathrm{E}$ & FK [3] & & & $D M / E$ & FK [3] & & $\mathrm{DM} / \mathrm{E}$ & FK [3] \\
\hline Gesamtkreis A & 1.000 & $100,0 \%$ & 1.400 & 200 & 1.200 & $100,0 \%$ & $32,2 \%[4]$ & 1.200 & $100,0 \%$ \\
\hline Zentralkreis A & 342 & $100,0 \%$ & & 138 & 480 & $100,0 \%$ & 342 & 480 & $100,0 \%$ \\
\hline Gemeinden A & 1.000 & $100,0 \%$ & 1.400 & 62 & 1.062 & $100,0 \%$ & -342 & 720 & $100,0 \%$ \\
\hline Gemeinde 1 & 800 & $80,0 \%$ & 1.400 & 93 & 893 & $84,1 \%$ & -288 & 605 & $84,1 \%$ \\
\hline Gemeinde 2 & 1.000 & $100,0 \%$ & 1.400 & 62 & 1.062 & $100,0 \%$ & -342 & 720 & $100,0 \%$ \\
\hline Gemeinde 3 & 1.200 & $120,0 \%$ & 1.400 & 31 & 1.231 & $115,9 \%$ & -396 & 835 & $115,9 \%$ \\
\hline Gesamtkreis A & 1.030 & $101,5 \%$ & 1.400 & 185 & 1.215 & $100,6 \%$ & $32,2 \%[4]$ & 1.215 & $100,6 \%$ \\
\hline Zentralkreis A & 350 & $101,2 \%$ & & 128 & 478 & $99,8 \%$ & 350 & 478 & $99,8 \%$ \\
\hline Gemeinden A & 1.030 & $101,5 \%$ & 1.400 & 57 & 1.087 & $101,2 \%$ & -350 & 737 & $101,2 \%$ \\
\hline Gemeinde 1 & 890 & $86,4 \%$ & 1.400 & 79 & 969 & $89,1 \%$ & -312 & 657 & $89,1 \%$ \\
\hline Gemeinde 2 & 1.000 & $97,1 \%$ & 1.400 & 62 & 1.062 & $97,7 \%$ & -342 & 720 & $97,7 \%$ \\
\hline Gemeinde 3 & 1.200 & $116,5 \%$ & 1.400 & 31 & 1.231 & $113,2 \%$ & -396 & 835 & $113,2 \%$ \\
\hline
\end{tabular}

[1] Steuerkraft zuzüglich Schlüsselzuweisungen $A . S Z W=$ Schlüsselzuweisungen.

[2] Zentralkreis A übernimmt $40 \%$ der jeweiligen Gesamtkreisausgaben.

[3] Finanzkraft bezogen auf den Durchschnitt der jeweiligen Gebietskörperschaftsgruppe.

[4] Erforderlicher Kreisumlagesatz zur Finanzierung der Zentralkreisausgaben gemäß [2]. 
30 DM pro Einwohner). Die relative Finanzkraft des Gesamtkreises $\mathrm{A}$ vor Finanzausgleich nimmt gegenüber anderen $\mathrm{Ge}-$ samtkreisen zu.

(2) Der Gesamtkreis A verliert dadurch Finanzzuweisungen im Umfang der Hälfte des Finanzkraftzuwachses. Bei gegebener Schlüsselmasse würde allerdings der Grundbetrag bzw. der "Finanzbedarf" für alle Landkreise steigen, was den Zuweisungsanspruch des Gesamtkreises A wieder (geringfügig) erhöhen würde; ein Effekt, der in der Modellrechnung unberücksichtigt bleibt. Grundsätzlich gilt aber, daß die höhere Steuerkraft im Gesamtkreis $A$ auch den anderen am Finanzausgleich beteiligten Gesamtkreisen (und kreisfreien Städten) zugute kommt.

(3) Innerhalb des Gesamtkreises A verteilt sich der Verlust an Schlüsselzuweisungen zu $69 \%$ auf den Zentralkreis und zu $31 \%$ auf die Gemeinden, d. h. im vorliegenden Fall auf die Gemeinde A 1. Dem Verlust des Zentralkreises steht - bei konstantem Kreisumlagesatz - ein Umlagegewinn gegenüber, der sich aus dem Wachstum der Umlagegrundlagen im Gesamtkreis ergibt. Per saldo tritt jedoch keine volle Kompensation ein, sondern der Zentralkreis verliert an Finanzkraft nach Finanzausgleich. Dagegen profitiert die Gemeinde A 1 auch nach Finanzausgleich von der gewachsenen Steuerkraft.

(4) Zentralkreis A kann den Einnahmeverlust nur durch eine Erhöhung der Kreisumlage ausgleichen. Er reduziert damit den Vorteil der Gemeinde A 1, muß aber auch die übrigen Gemeinden stärker belasten. Bei proportionaler Kreisumlage gilt also, daß ein Anstieg der Steuerkraft in einer Gemeinde entweder für den Zentralkreis oder für die übrigen kreisangehörigen Gemeinden negative finanzielle Konsequenzen hat. Vorteilhaft ist er nur für die Gemeinde selbst (und in geringem 
Maße auch für die anderen Gesamtkreise sowie kreisfreien Städte). Vermeiden lassen sich diese Wirkungen nur, wenn der Zentralkreis auf Splitting oder Progression zurückgreift, um die Belastung auf die Gemeinde zu konzentrieren, die den Verlust "verursacht" hat ${ }^{1}$.

Insgesamt sind die Grenzbelastungseffekte des Ausgleichsverfahrens als problematisch einzustufen. Sie beruhen insofern auf dem speziellen System der Verteilung der Schlüsselzuweisungen, als dieses den Zentralkreisen einen gemessen an ihrer Aufgabenquote relativ hohen Anteil zukommen läßt. Vor diesem Hintergrund ist zwar kein fundamentaler Systemwechsel angezeigt, wohl aber eine Überprüfung des Verteilungsschlüssels 69/31 in Richtung auf eine "gemeindefreundlichere" Lösung.

Im Färber-Gutachten (S. 74 ff.) wird aus dem Befund einer negativen Grenzeinnahmekraft der Zentralkreise bei wachsender Steuerkraft der kreisangehörigen Gemeinden gefolgert, dieser Effekt könnte auch zu einer allgemeinen Erhöhung der Kreisumlagesätze beitragen. Finanzstarke Kreise, die relativ wenig Zuweisungen erhalten und sich über höhere Kreisumlagesätze refinanzieren müssen, würden damit eine Sogwirkung auf die Umlagesätze auch bei vor Finanzausgleich finanzschwächeren Landkreisen auslösen. Die systemimmanente Tendenz zur Expansion der Umlagesätze störe das Verhältnis zwischen Zentralkreis und Gemeinden und bedrohe daher die kommunale Selbstverwaltung von Gemeinden und Gemeindeverbänden gleichermaßen.

Diese These von einer systemimmanenten Tendenz zur Erhöhung der Kreisumlagesätze hat spekulativen Charakter. Einer Ex-

1 Gegen einen solchen Einsatz der distributiven Instrumente läßt sich finanzausgleichspolitisch im übrigen wenig einwenden, denn er dient der durchaus nachvollziehbaren Neutralisierung unerwünschter Konsequenzen einer wachsenden kommunalen Steuerkraft auf andere Gemeinden im Gesamtkreis. 
pansion der Kreisumlagen sind schon dadurch Grenzen gesetzt, daß die Kreistagsdelegierten häufig auch Gemeinderepräsentanten sind. Auch der Verweis auf die empirische Entwicklung besagt wenig, denn ein Anstieg der Kreisumlagesätze kann aus ganz verschiedenen Gründen eingetreten sein, insbesondere auch aufgrund einer stärker "zentralen" Aufgabenerfüllung in den Landkreisen. Es sei an dieser Stelle noch einmal hervorgehoben, daß der Verteilungsschlüssel 69/31 am wenigsten zu einem im Durchschnitt wachsenden Umlagesatz beigetragen haben kann, denn er bewirkt eine vergleichsweise hohe Dotierung der Zentralkreise mit Schlüsselzuweisungen und reduziert damit den durchschnittlichen Umlagebedarf der Zentralkreise.

Im übrigen könnte der Gefahr einer Aushöhlung der Selbstverwaltung auf Gemeindeebene und einer Erhöhung politischer Spannungen zwischen Zentralkreis und Gemeinden durch wachsende Kreisumlagesätze mit Hilfe eines relativ einfachen Regelmechanismus entgegengewirkt werden. Eine Erhöhung der Kreisumlagesätze impliziert für die kreisangehörigen Gemeinden bei gegebenen Ausgaben entweder eine Erhöhung der Realsteuerhebesätze oder eine zusätzliche Verschuldung. Man kann die Auffassung vertreten, daß es den kreisangehörigen Gemeinden nicht zugemutet werden soll, ihren Finanzbedarf in stärkerem Umfang als die Zentralkreise selbst durch Kredite zu finanzieren.

So gesehen dürfte der Zentralkreis die Kreisumlage nur erhöhen, wenn sein Verschuldungsgrad (Schuldenstand zu Netto-Ausgaben) wenigstens dem durchschnittlichen Verschuldungsgrad seiner Gemeinden entspricht. Die Anwendung dieser Regel würde einer Überlastung der Umlage und damit einer Expansion der Kreisausgaben zu Lasten der Gemeinden entgegenwirken. Der Einbau einer solchen Begrenzung für die Kreisumlage würde das System des kommunalen Finanzausgleichs sinnvoll ergänzen. 
Wolfgang Scherf - 978-3-631-75194-7

Downloaded from PubFactory at 01/11/2019 07:16:26AM

via free access 


\section{E. Die Ergebnisse der Untersuchung im Überblick}

Abschließend sollen die wichtigsten Ergebnisse der Untersuchung noch einmal thesenartig zusammengefaßt werden:

(1) Eine Besonderheit des kommunalen Finanzausgleichs in Rheinland-Pfalz ist die konsequente Verfolgung des „Einwohner $=$ Einwohner"-Prinzips und der damit verbundene Verzicht auf eine Zerlegung der Schlüsselmasse auf die verschiedenen Gebietskörperschaftsgruppen. Die Einbeziehung aller Gemeinden und Gemeindeverbände in ein einheitliches Verteilungssystem erfordert eine Berücksichtigung der funktionellen Gliederung im Kreisbereich.

Zwischen Gesamtkreisen und kreisfreien Städten ist ein sinnvoller Vergleich der Wirkungen von Finanzausgleichssystemen möglich, da diese Ebenen übereinstimmende Funktionen ausüben. Innerhalb eines Gesamtkreises werden die öffentlichen Aufgaben jedoch teilweise von den kreisangehörigen Gemeinden und teilweise von den Zentralkreisen erfüllt. Bei der Beurteilung des Finanzausgleichs muß man beachten, daß Zentralkreise untereinander nur eingeschränkt vergleichbar sind, da der Zentralisierungsgrad der Aufgabenerfüllung zwischen den Gesamtkreisen variiert.

(2) Das rheinland-pfälzische System führt nur dann zu finanzausgleichspolitisch vertretbaren Ergebnissen, wenn die Schlüsselzuweisungen im kreisangehörigen Bereich als erste Stufe des Ausgleichsverfahrens mit der Kreisumlage als zweiter Stufe sinnvoll und systemgerecht verknüpft werden. Die Kreisumlage hat immer eine Verschiebung der Finanzkraft zwischen den Gemeinden und ihrem Zentralkreis zur Folge. Es gibt keinen nachvollziehbaren Grund dafür, die erhaltenen Schlüsselzuweisungen nicht neben der spezifischen kreisin- 
ternen Aufgaben- und Ausgabenteilung bei der Festsetzung der Kreisumlage zu berücksichtigen. Im Gegenteil: Eine aufgabenorientierte Regulierung der Finanzkraft ist andernfalls, und zwar unabhängig vom Verteilungsschlüssel für die Schlüsselzuweisungen, überhaupt nicht möglich.

(3) Bei ordnungsgemäßem Einsatz der Kreisumlage hat das Ausgleichsverfahren einige Vorteile. Seine wesentlichen Eigenschaften sind:

(a) die Gleichbehandlung von Gesamtkreisen und kreisfreien Städten,

(b) eine den Zielen des horizontalen Finanzausgleichs entsprechende Annäherung der Finanzkraftpositionen bei den Gesamtkreisen,

(c) eine bezogen auf die Aufgabenteilung gleichmäßige Partizipation von Zentralkreis und Gemeinden an der jeweiligen Kreisfinanzkraft

(d) und eine vom Verteilungsschlüssel bestimmte Annäherung der Finanzkraftpositionen zwischen den kreisangehörigen Gemeinden.

Das heutige System ist dem alten Drei-Säulen-Modell im übrigen auch nicht etwa deshalb unterlegen, weil der Versuch, die Ausgleichsaufgabe in einem Schritt zu bewältigen, mathematisch unlösbar wäre. Ein Vergleich beider Verfahren belegt ihre prinzipielle Äquivalenz, sofern von gleichen Zielen und entsprechend gestalteten Ausgleichsinstrumenten ausgegangen wird.

(4) Die im Färber-Gutachten und dem sich darauf stützenden Beschluß des Oberverwaltungsgerichts Koblenz geäußerte Kritik am rheinland-pfälzischen Finanzausgleich ist in den zentralen 
Punkten irreführend oder unzutreffend. Die Ursache dafür liegt in der Verkürzung der Überlegungen auf die Schlüsselzuweisungen an die Zentralkreise. Für eine Beurteilung aus finanzwissenschaftlicher Sicht unabdingbare Elemente des Ausgleichsverfahrens werden einfach ausgeblendet oder durch problematische Annahmen ihrer Funktion beraubt. Dies betrifft auch und gerade die These von der Übernivellierung bei den Zentralkreisen.

(5) Das Verbot einer Übernivellierung kann in Bezug auf die Zentralkreise schon deshalb nicht sinnvoll angewandt werden, weil sich die Finanzkraft der Zentralkreise erst im Finanzausgleich konstituiert. Eine Festschreibung des Kreisumlagesatzes zum Zwecke der Ableitung fiktiver Finanzkraftzahlen für die Zentralkreise ist unvertretbar, weil der durchschnittliche (und erst recht der kreisspezifische) Umlagesatz selbst nicht finanzausgleichsunabhängig bestimmt werden kann. Hinzu kommt, daß die Finanzkraftrangfolge nach Schlüsselzuweisungen nur unter der Voraussetzung einer festgeschriebenen Kreisumlage mit der endgültigen Finanzkraftrangfolge übereinstimmt, nicht aber unter der Voraussetzung eines systemkonform flexiblen Einsatzes der Kreisumlage. Bei variabler Kreisumlage gibt es im kommunalen Finanzausgleich keine "Übernivellierungseffekte" durch Schlüsselzuweisungen.

(6) Einem korrigierenden Einsatz der Kreisumlage stehen auch keine unüberwindlichen Hindernisse oder Nebenwirkungen entgegen. Man muß in diesem Zusammenhang berücksichtigen, daß finanzstarke Zentralkreise, die wenig Schlüsselzuweisungen erhalten und daher einen überdurchschnittlichen Umlagesatz beschließen, damit nur auf eine überdurchschnittliche Finanzkraft ihrer Gemeinden zurückgreifen. Da ein solcher Rückgriff ohne Verwendung von Splitting und Progres- 
sion erfolgen kann, gibt es auch keinen Anlaß, eine übermässige Belastung der finanzstarken Gemeinden im Gesamtkreis zu befürchten. Im Gegenteil: Bei proportionaler Kreisumlage kommt es zu einer möglicherweise unerwünschten, aber nicht gravierenden Abschwächung der Nivellierungseffekte auf Gemeindeebene.

(7) Der Verteilungsschlüssel 69/31 steht einem sachgerechten Finanzausgleich keineswegs entgegen. $\mathrm{Er}$ hat positive wie negative Eigenschaften, die bei einer politischen (Neu-) Festsetzung abzuwägen sind. Der relativ hohe Anteil der Zentralkreise an den Schlüsselzuweisungen korrespondiert zunächst einmal mit ihrer unzureichenden Finanzausstattung vor $\mathrm{Fi}$ nanzausgleich. Darüber hinaus reduziert er den im Durchschnitt erforderlichen Umlagesatz. Dies ist ein finanzpsychologischer Vorteil und entlastet das Verhältnis zwischen Zentralkreisen und ihren Gemeinden. Andererseits impliziert ein solcher Schlüssel eine größere Streuung der Umlagesätze, eine Abschwächung der Nivellierungseffekte zwischen den kreisangehörigen Gemeinden und negative Grenzbelastungen der Zentralkreise bei wachsender Steuerkraft. Dies mag per saldo für eine stärker an den durchschnittlichen Aufgabenrelationen orientierte "gemeindefreundlichere" Lösung sprechen, doch sollte die Wahl des Verteilungsschlüssels angesichts seiner teils gegenläufigen Effekte der finanzpolitischen Entscheidung überlassen bleiben.

Insgesamt kann man dem kommunalen Finanzausgleich in Rheinland-Pfalz attestieren, daß er aus finanzwissenschaftlicher Sicht vertretbare Ausgleichseffekte mit sich bringt. Die Regelungen sind allerdings ebensowenig perfekt im Sinne eines theoretisch „optimalen" Systems wie die in anderen Bundesländern praktizierten Verfahren. Die Besonderheiten des rheinland-pfälzischen Modells 
- das „Einwohner = Einwohner"-Prinzip und der Verzicht auf eine Zerlegung der Schlüsselmasse - erfordern im kreisangehörigen Bereich eine Zurechnung der Finanzkraft- und Bedarfsmeßzahlen auf Zentralkreis und Gemeinden sowie einen aufgabenorientierten Einsatz der Kreisumlage. Der Verteilungsschlüssel 69/31 ist dabei nicht die einzig mögliche Lösung, doch am Prinzip der schlüsselmäßigen Dotierung beider Ebenen der Gesamtkreise im Zuweisungsverfahren kommt man nicht vorbei. Alternative Möglichkeiten - etwa eine Rückkehr zum Drei-Säulen-Modell - sind nur mit relativen Vor- und Nachteilen, nicht aber mit überzeugenden Verbesserungen verbunden. Es gibt also aus finanzwissenschaftlicher Sicht keinen zwingenden Grund, das bestehende System des kommunalen Finanzausgleichs in wesentlichen Elementen zu verändern oder gar aufzugeben. 


\section{FINANZWISSENSCHAFTLICHE SCHRIFTEN}

Band 1 Werner Steden: Finanzpolitik und Einkommensverteilung. Ein Wachstums- und Konjunkturmodell der Bundesrepublik Deutschland. 1979.

Band 2 Rainer Hagemann: Kommunale Finanzplanung im föderativen Staat. 1976.

Band 3 Klaus Scherer: Maßstäbe zur Beurteilung von konjunkturellen Wirkungen des öffentlichen Haushalts. 1977.

Band 4 Brita Steinbach: "Formula Flexibility" - Kritische Analyse und Vergleich mit diskretionärer Konjunkturpolitik. 1977.

Band 5 Hans-Georg Petersen: Personelle Einkommensbesteuerung und Inflation. Eine theoretisch-empirische Analyse der Lohn- und veranlagten Einkommensteuer in der Bundesrepublik Deutschland. 1977.

Band 6 Friedemann Tetsch: Raumwirkungen des Finanzsystems der Bundesrepublik Deutschland. Eine Untersuchung der Auswirkungen der Finanzreform von 1969 auf die Einnahmenposition der untergeordneten Gebietskörperschaften und ihrer regionalpolitischen Zieladäquanz. 1978.

Band 7 Wilhelm Pfähler: Normative Theorie der fiskalischen Besteuerung. Ein methodologischer und theoretischer Beitrag zur Integration der normativen Besteuerungstheorie in der Wohlfahrtstheorie. 1978.

Band 8 Wolfgang Wiegard: Optimale Schattenpreise und Produktionsprogramme für öffentliche Unternehmen. Second-Best Modelle im finanzwirtschaftlichen Staatsbereich. 1978.

Band 9 Hans P. Fischer: Die Finanzierung des Umweltschutzes im Rahmen einer rationalen Umweltpolitik. 1978.

Band 10 Rainer Paulenz: Der Einsatz finanzpolitischer Instrumente in der Forschungs- und Entwicklungspolitik. 1978.

Band 11 Hans-Joachim Hauser: Verteilungswirkungen der Staatsverschuldung. Eine kreislauftheoretische Inzidenzbetrachtung. 1979.

Band 12 Gunnar Schwarting: Kommunale Investitionen. Theoretische und empirische Untersuchungen der Bestimmungsgründe kommunaler Investitionstätigkeit in NordrheinWestfalen 1965-1972. 1979.

Band 13 Hans-Joachim Conrad: Stadt-Umland-Wanderung und Finanzwirtschaft der Kernstädte. Amerikanische Erfahrungen, grundsätzliche Zusammenhänge und eine Fallstudie für das Ballungsgebiet Frankfurt am Main. 1980.

Band 14 Cay Folkers: Vermögensverteilung und staatliche Aktivität. Zur Theorie distributiver Prozesse im Interventionsstaat. 1981.

Band 15 Helmut Fischer: US-amerikanische Exportförderung durch die DISC-Gesetzgebung. 1981.

Band 16 Günter Ott: Einkommensumverteilungen in der gesetzlichen Krankenversicherung. Eine quantitative Analyse. 1981.

Band 17 Johann Hermann von Oehsen: Optimale Besteuerung. (Optimal Taxation). 1982.

Band 18 Richard Kössler: Sozialversicherungsprinzip und Staatszuschüsse in der gesetzlichen Rentenversicherung. 1982.

Band 19 Hinrich Steffen: Zum Handlungs- und Entscheidungsspielraum der kommunalen Investitionspolitik in der Bundesrepublik Deutschland. 1983.

Band 20 Manfred Scheuer: Wirkungen einer Auslandsverschuldung des Staates bei flexiblen Wechselkursen. 1983. 
Band 21 Christian Schiller: Staatsausgaben und crowding-out-Effekte. Zur Effizienz einer Finanzpolitik keynesianischer Provenienz. 1983.

Band 22 Hannelore Weck: Schattenwirtschaft: Eine Möglichkeit zur Einschränkung der öffentlichen Verwaltung? Eine ökonomische Analyse. 1983.

Band 23 Wolfgang Schmitt: Steuern als Mittel der Einkommenspolitik. Eine Ergänzung der Stabilitätspolitik? 1984.

Band 24 Wolfgang Laux: Erhöhung staatswirtschaftlicher Effizienz durch budgetäre Selbstbeschränkung? Zur Idee einer verfassungsmäßig verankerten Ausgabengrenze. 1984.

Band 25 Brita Steinbach-van der Veen: Steuerinzidenz. Methodologische Grundlagen und empirisch-statistische Probleme von Länderstudien. 1985.

Band 26 Albert Peters: Ökonomische Kriterien für eine Aufgabenverteilung in der Marktwirtschaft. Eine deskriptive und normative Betrachtung für den Allokationsbereich. 1985.

Band 27 Achim Zeidler: Möglichkeiten zur Fortsetzung der Gemeindefinanzreform. Eine theoretische und empirische Analyse. 1985.

Band 28 Peter Bartsch: Zur Theorie der längerfristigen Wirkungen 'expansiver' Fiskalpolitik. Eine dynamische Analyse unter besonderer Berücksichtigung der staatlichen Budgetbeschränkung und ausgewählter Möglichkeiten der öffentlichen Defizitfinanzierung. 1986.

Band 29 Konrad Beiwinkel: Wehrgerechtigkeit als finanzpolitisches Verteilungsproblem. Möglichkeiten einer Kompensation von Wehrungerechtigkeit durch monetäre Transfers. 1986.

Band 30 Wolfgang Kitterer: Effizienz- und Verteilungswirkungen des Steuersystems. 1986.

Band 31 Heinz Dieter Hessler: Theorie und Politik der Personalsteuern. Eine Kritik ihrer Einkommens- und Vermögensbegriffe mit Blick auf die Leistungsfähigkeitstheorie. 1994.

Band 32 Wolfgang Scherf: Die beschäftigungspolitische und fiskalische Problematik der Arbeitgeberbeiträge zur Rentenversicherung. Eine Auseinandersetzung mit der Kritik an der lohnbezogenen Beitragsbemessung. 1987.

Band 33 Andreas Mästle: Die Steuerunion. Probleme der Harmonisierung spezifischer Gütersteuern. 1987.

Band 34 Günter Ott: Internationale Verteilungswirkungen im Finanzausgleich der Europäischen Gemeinschaften. 1987.

Band 35 Heinz Haller: Zur Frage der zweckmäßigen Gestalt gemeindlicher Steuern. Ein Diskussionsbeitrag zur Gemeindesteuerreform. 1987.

Band 36 Thomas Kuhn: Schlüsselzuweisungen und fiskalische Ungleichheit. Eine theoretische Analyse der Verteilung von Schlüsselzuweisungen an Kommunen. 1988.

Band 37 Walter Hahn: Steuerpolitische Willensbildungsprozesse in der Europäischen Gemeinschaft. Das Beispiel der Umsatzssteuer-Harmonisierung. 1988.

Band 38 Ulrike Hardt: Kommunale Finanzkraft. Die Problematik einer objektiven Bestimmung kommunaler Einnahmemöglichkeiten in der gemeindlichen Haushaltsplanung und im kommunalen Finanzausgleich. 1988.

Band 39 Jochen Michaelis: Optimale Finanzpolitik im Modell überlappender Generationen. 1989.

Band 40 Bernd Raffelhüschen: Anreizwirkungen der sozialen Alterssicherung. Eine dynamische Simulationsanalyse. 1989

Band 41 Berend Diekmann: Die Anleihe- und Darlehenstransaktionen der Europäischen Gemeinschaften. 1990.

Band 42 Helmut Kaiser: Konsumnachfrage, Arbeitsangebot und optimale Haushaltsbesteuerung. Theoretische Ergebnisse und mikroökonometrische Simulation für die Bundesrepublik Deutschland. 1990. 
Band 43 Rüdiger von Kleist: Das Gramm-Rudman-Hollings-Gesetz. Ein gescheiterter Versuch der Haushaltskonsolidierung. 1991.

Band 44 Rolf Hagedorn: Steuerhinterziehung und Finanzpolitik. Ein theoretischer Beitrag unter besonderer Berücksichtigung der Hinterziehung von Zinserträgen. 1991.

Band 45 Cornelia S. Behrens: Intertemporale Verteilungswirkungen in der gesetzlichen Krankenversicherung der Bundesrepublik Deutschland. 1991.

Band 46 Peter Saile: Ein ökonomischer Ansatz der Theorie der intermediären Finanzgewalten Die Kirchen als Parafisci. 1992.

Band 47 Peter Gottfried: Die verdeckten Effizienzwirkungen der Umsatzsteuer. Eine empirische allgemeine Gleichgewichtsanalyse. 1992.

Band 48 Andreas Burger: Umweltorientierte Beschäftigungsprogramme. Eine Effizienzanalyse am Beispiel des "Sondervermögens Arbeit und Umwelt". 1992.

Band 49 Jeanette Malchow: Die Zuordnung verteilungspolitischer Kompetenzen in der Europäischen Gemeinschaft. Eine Untersuchung aufgrund einer Fortentwicklung der ökonomischen Theorie des Föderalismus. 1992.

Band 50 Barbara Seidel: Die Einbindung der Bundesrepublik Deutschland in die Europäischen Gemeinschaften als Problem des Finanzausgleichs. 1992.

Band 51 Ralph Wiechers: Markt und Macht im Rundfunk. Zur Stellung der öffentlich-rechtlichen Rundfunkanstalten im dualen Rundfunksystem der Bundesrepublik Deutschland. 1992.

Band 52 Klaus Eckhardt: Probleme einer Umweltpolitik mit Abgaben. 1993.

Band 53 Oliver Schwarzkopf: Die Problematik unterschiedlicher Körperschaftsteuersysteme innerhalb der EG. 1993.

Band 54 Thorsten Giersch: Bergson-Wohlfahrtsfunktion und normative Ökonomie. 1993.

Band 55 Li-Fang Chou: Selbstbeteiligung bei Arzneimitteln aus ordnungspolitischer Sicht. Das Beispiel der Bundesrepublik Deutschland. 1993.

Band 56 Harald Schlee: Einkommensteuerliche Behandlung von Transferzahlungen. Zur Neuordnung der Familienbesteuerung sowie der Besteuerung von Versicherungsleistungen und Sozialtransfers. 1994.

Band 57 Alexander Spermann: Kommunales Krisenmanagement. Reaktionen baden-württembergischer Stadtkreise auf steigende Sozialhilfekosten und Einnahmenausfälle (198092). 1993.

Band 58 Otto Roloff / Sibylle Brander / Ingo Barens / Claudia Wesselbaum: Direktinvestitionen und internationale Steuerkonkurrenz. 1994.

Band 59 Claudia Wesselbaum-Neugebauer: Internationale Steuerbelastungsvergleiche. 1994.

Band 60 Stephanie Miera: Kommunales Finanzsystem und Bevölkerungsentwicklung. Eine Analyse des kommunalen Finanzsystems vor dem Hintergrund der sich abzeichnenden Bevölkerungsentwicklung am Beispiel Niedersachsens unter besonderer Berücksichtigung des Landkreises Wolfenbüttel und seiner Gemeinden. 1994.

Band 61 Wolfgang Scherf: Die Bedeutung des kaldorianischen Verteilungsmechanismus für die gesamtwirtschaftlichen Wirkungen der staatlichen Neuverschuldung. 1994.

Band 62 Rainer Volk: Vergleich der Vergünstigungseffekte der verschiedenen investitionsfördernden Maßnahmen. 1994.

Band 63 Hans-Georg Napp: Kommunale Finanzautonomie und ihre Bedeutung für eine effiziente lokale Finanzwirtschaft. 1994. 2., unveränderte Auflage 1994.

Band 64 Bernd Rahmann / Uwe Steinborn / Günter Vornholz: Empirische Analyse der Autonomie lokaler Finanzwirtschaften in der Europäischen Gemeinschaft. 1994. 
Band 65 Carsten Kühl: Strategien zur Finanzierung der Altlastensanierung. 1994.

Band 66 Stephan Boll: Intergenerationale Umverteilungswirkungen der Fiskalpolitik in der Bundesrepublik Deutschland. Ein Ansatz mit Hilfe des Generational Accounting. 1994.

Band 67 Karl Justus Bernhard Neumärker: Finanzverfassung und Staatsgewalt in der Demokratie. Ein Beitrag zur konstitutionellen Finanztheorie. 1995.

Band 68 Christian Haslbeck: Zentrale versus dezentrale Internalisierung externer Effekte bei unvollständiger Information. 1995.

Band 69 Regina Müller: Horizontale oder vertikale Transfers zur Durchsetzung eines horizontalen Finanzausgleichs. 1995.

Band 70 Christian Hockenjos: Öffentliche Sporttörderung in der Bundesrepublik Deutschland. Darstellung und finanztheoretische Analyse. 1995.

Band 71 Manfred Rosenstock: Die Kontrolle und Harmonisierung nationaler Beihilfen durch die Kommission der Europäischen Gemeinschaften. 1995.

Band 72 Christian Rüsch: Wohnungsbau- und Wohneigentumspolitik im Rahmen der Einkommensteuer. Eine Analyse unter steuersystematischen, verteilungspolitischen und fiskalischen Aspekten. 1996.

Band 73 Stephan Winters: Die kollektive Vorsorge für den Pflegefall im Alter. Eine Untersuchung am Beispiel der gesetzlichen Pflegeversicherung in den Niederlanden. 1996.

Band 74 Knut Blind: Allokationsineffizienzen auf Sicherheitsmärkten: Ursachen und Lösungsmöglichkeiten. Fallstudie: Informationssicherheit in Kommunikationssystemen. 1996.

Band 75 Barbara Petrick-Rump: Ökonomische Wirkungen von Steueramnestien. Untersuchung konkreter Erfahrungen ausgewählter Länder mit dem Einsatz von Steueramnestien anhand eines effizienten Steueramnestieprogramms. 1996.

Band 76 Georg Hirte: Effizienzwirkungen von Finanzausgleichsregelungen. Eine Empirische Allgemeine Gleichgewichtsanalyse für die Bundesrepublik Deutschland. 1996.

Band 77 Ulrike Kirchhoff: Die rheinland-pfälzischen Gemeinden im System des Finanzausgleichs. 1996.

Band 78 Kerstin Keil: Der soziale Mietwohnungsbau: Mängel und Alternativen. 1996.

Band 79 Bernhard Manzke: Kinderlastenausgleich versus verstärkte Einwanderung. Alternative Ansätze zur langfristigen Sicherung der Gesetzlichen Rentenversicherung. 1997.

Band 80 Hariolf M. Wenzler: Institutionenökonomik und öffentliche Finanzkontrolle. Eine Analyse am Beispiel der Europäischen Union. 1997.

Band 81 Joachim Nagel: Supply-Side Policy in den USA. Eine theoretische und empirische Analyse der angebotsorientierten Wirtschaftspolitik Reagans unter besonderer Berücksichtigung steuerlicher Aspekte. 1997.

Band 82 Heinz Lampert: Krise und Reform des Sozialstaates. 1997.

Band 83 Monika Hanswillemenke / Bernd Rahmann: Zwischen Reformen und Verantwortung für Vollbeschäftigung. Die Finanz- und Haushaltspolitik der sozial-liberalen Koalition von 1969 bis 1982. 1997.

Band 84 Berthold Fürst: Die Maastrichter Budgetkriterien im Konflikt mit der Verschuldungsautonomie der deutschen Gebietskörperschaften. 1997.

Band 85 Burkhard Pahnke: Einkommensorientierte Förderung des sozialen Mietwohnungsbaues. Bestandsaufnahme und Kritik. 1998.

Band 86 Judith Safford: Staatsverschuldung im Vereinigten Königreich. Die öffentliche Verschuldung unter der Konservativen Regierung von 1979-1994. Ursachen und Auswirkungen. 1998. 
Band 87 Ralf Oberheide: Die Bekämpfung der Steuerumgehung. 1998.

Band 88 Achim Truger: Die neue Finanzwissenschaft zwischen Realitätsferne und Irrelevanz der Annahmen. Eine methodologische Analyse potentieller Verteidigungsstrategien der neuen Finanzwissenschaft gegen den Vorwurf der Realitätsferne ihres entscheidungstheoretischen Fundamentes. 1998.

Band 89 Karin Bickel: Familienbezogene Elemente im System der gesetzlichen Rentenversicherung. Unter besonderer Berücksichtigung von Ein-Eltern-Familien. 1998.

Band 90 Wolfgang Scherf: Schlüsselzuweisungen und Kreisumlage. Die Problematik der Finanzierung der Landkreise am Beispiel des kommunalen Finanzausgleichs von RheinlandPfalz. 1998. 
Frank Ziegele

\section{Hochschule und Finanzautonomie}

\section{Grundlagen und Anwendung einer politisch-ökonomischen Theorie der Hochschule}

Frankfurt/M., Berlin, Bern, New York, Paris, Wien, 1997. 306 S., 32 Abb.

Kollektive Entscheidungen, Wirtschaftspolitik und öffentliche Finanzen.

Herausgegeben von Cay Folkers. Bd. 5

ISBN 3-631-32348-4 · br. DM 98.-*

Die Ausweitung der Finanzautonomie der Hochschulen ist ein wesentliches Element der aktuellen Reformpolitik in Deutschland. Im Rahmen einer politisch-ökonomischen Analyse werden die Effizienzeffekte unterschiedlicher Formen der Finanzautonomie ermittelt. Zu diesem Zweck wird unter Verwendung von mikroökonomischen und Public-choice-Ansätzen eine Theorie des Angebots von Forschung und Lehre entwickelt. Die Modellanalyse ermöglicht es, die gängigen Plausibilitätsargumente zur Finanzautonomie durch theoretisch fundierte Aussagen zu ersetzen. Sowohl die Bedingungen, unter denen die Einführung von Finanzautonomie ökonomische Vorteile enwarten läßt, als auch die Gefahren der Autonomie werden aufgezeigt. Eine empirische Überprüfung der Modellergebnisse erfolgt anhand der Wirkungen des Modellversuchs zur Finanzautonomie an der Ruhr-Universität Bochum.

Aus dem Inhalt: Grundlagen einer ökonomischen Theorie der Hochschule . Die Finanzautonomie der deutschen Hochschulen und ihre Reform . Politisch-ökonomische Modelle des Verhaltens der Anbieter von Forschung und Lehre - Effizienzwirkungen unterschiedlicher Formen der Finanzautonomie - Ergebnisse des Modellversuchs zur Finanzautonomie an der Ruhr-Universität Bochum.

Frankfurt/M - Berlin - Bern - New York - Paris - Wien

Auslieferung: Verlag Peter Lang AG

Jupiterstr. 15, CH-3000 Bern 15

Telefax (004131) 9402131

*inklusive Mehrwertsteuer

Preisänderungen vorbehalten 
Wolfgang Scherf - 978-3-631-75194-7

Downloaded from PubFactory at 01/11/2019 07:16:26AM

via free access 